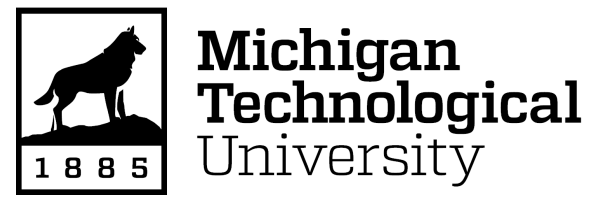

Michigan Technological University Digital Commons @ Michigan Tech

Dissertations, Master's Theses and Master's Reports

2017

\title{
A Study of High Temperature Heat Pipes and the Impact of Magnetic Field on the Flow of Liquid Metal
}

Udit Sharma

Michigan Technological University, udits@mtu.edu

Copyright 2017 Udit Sharma

\section{Recommended Citation}

Sharma, Udit, "A Study of High Temperature Heat Pipes and the Impact of Magnetic Field on the Flow of Liquid Metal", Open Access Master's Thesis, Michigan Technological University, 2017.

https://doi.org/10.37099/mtu.dc.etdr/381

Follow this and additional works at: https://digitalcommons.mtu.edu/etdr

Part of the Electro-Mechanical Systems Commons, Energy Systems Commons, Heat Transfer, Combustion Commons, and the Nuclear Engineering Commons 
A STUDY OF HIGH TEMPERATURE HEAT PIPES AND THE IMPACT OF MAGNETIC FIELD ON THE FLOW OF LIQUID METAL

By

Udit Sharma

\begin{abstract}
A THESIS
Submitted in partial fulfillment of the requirements for the degree of MASTER OF SCIENCE

In Mechanical Engineering
\end{abstract}

MICHIGAN TECHNOLOGICAL UNIVERSITY

2017

(C) 2017 Udit Sharma 
This thesis has been approved in partial fulfillment of the requirements for the Degree of MASTER OF SCIENCE in Mechanical Engineering.

Department of Mechanical Engineering - Engineering Mechanics

Thesis Advisor: Dr. Jeffrey S. Allen

Committee Member: $\quad$ Dr. Chang Kyoung (CK) Choi

Committee Member: $\quad$ Dr. Ezequiel Medici

Department Chair: $\quad$ William W. Predebon 
To my parents,

B. K. Sharma \& Archana Sharma,

to my brother

Rachit Sharma

and my grandfather

R. P. Sharma 


\section{TABLE OF CONTENT}

LIST OF FIGURES..................................................................... VII



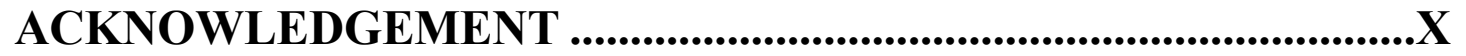

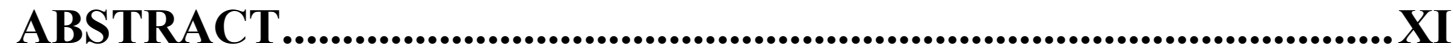

CHAPTER 1. INTRODUCTION................................................... 1

1.1 Operational Principle and Fundamental Conditions ......................4

$1.2 \quad$ Types of Heat Pipe ...............................................................................6

CHAPTER 2. COMPONENTS AND CHARACTERISTICS ........... 10

$2.1 \quad$ Working Fluids ......................................................................................10

2.2 Operational Temperature Range .......................................................13

$2.3 \quad$ Temperature Drop........................................................................15

$2.4 \quad$ Types of Wick Structure ………………................................................16

CHAPTER 3. OPERATIONAL LIMITS .............................................. 18

3.1 Capillarity .............................................................................................19

3.2 Pressure Drop \& Recovery ..............................................................21

3.2.1 Pressure Gradient in Liquid Phase .......................................21

3.2.2 Pressure Difference in Vapor Phase ......................................22

3.3 Temperature Difference........................................................................26

3.4 Heat Transport Limitations.................................................................31

3.4.1 Continuum Flow Limit............................................................33 
3.4.2 Frozen Startup Limit ………………………………….......33

3.4.3 Capillary Limit .......................................................................

3.4.4 Viscous/ Vapor Pressure Limit.....................................................35

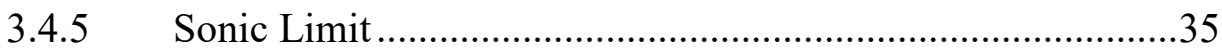

3.4.6 Entrainment Limit ..................................................................

3.4.7 Boiling Limitation ...................................................................

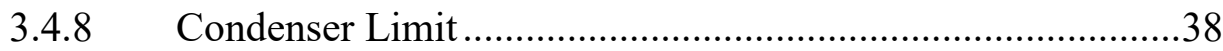

CHAPTER 4. HIGH TEMPERATURE HEAT PIPES..................... 40

4.1 Working Fluid .........................................................................................40

4.2 Structural Material................................................................................41

4.3 Distinguishing Properties and Applications....................................42

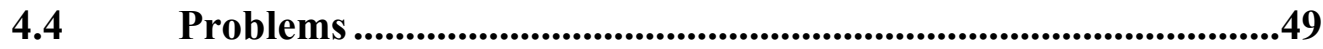

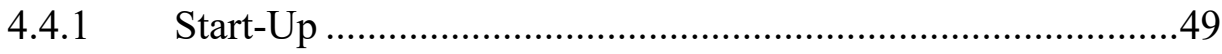

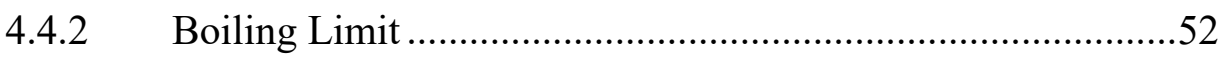



CHAPTER 5. MAGNETOHYDRODYNAMIC EFFECT ................. 57

5.1 What is MHD ..................................................................................60

$5.2 \quad$ History .........................................................................................60

5.3 Physics of MHD Phenomena................................................................61

CHAPTER 6. MATHEMATICAL MODEL ...................................65

6.1 Our Approach ..................................................................................65

6.2 Magnetic Reynold's number.............................................................69

6.3 Relationship between Magnetic Field and Magnetic Field Intensity $\quad \mathbf{7 0}$

6.4 N-S Equation Analysis........................................................................70 
6.5 Impact on Capillary Limit ..................................................................71

6.5.1 Impact of Magnetic Field ......................................................

6.5.2 Impact of Heat Flux................................................................. 74

6.5.3 Impact of Temperature ……………………...........................76

CHAPTER 7. SPATIALLY VARYING MAGNETIC FIELD......... 78

CHAPTER 8. RESULTS AND DISCUSSION ................................ 83

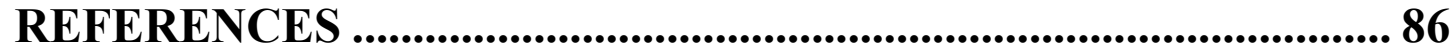

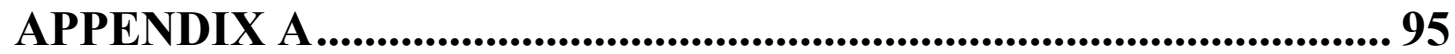

Permissions for reference......................................................................................95 


\section{LIST OF FIGURES}

Figure 1.1 Comparison of Heat Pipe and Thermosyphon [2] ............. 2

Figure 1.2 Sections of Heat Pipe [2] ........................................................ 3

Figure 1.3 Schematic of a Conventional Heat Pipe [1] ........................ 5

Figure 1.4 Resistor Model of Heat Pipe [1] .......................................... 6

Figure 1.5 Two Phase Thermo-Syphon [1] .................................................. 8

Figure 1.6 Vapor Chamber [1] ...................................................................... 9

Figure 1.7 Gas Loaded Heat Pipe [1]................................................... 9

Figure 2.1 Figure of Merit of Some Fluids [6] ....................................... 13

Figure 2.2 Temperature Drop Axially in Heat Pipe [7] ..................... 15

Figure 2.3 Types of Homogeneous Wick [1] ..................................... 17

Figure 2.4 Types of Composite Wick Structure [1]............................... 17

Figure 3.1 Density Variation at Liquid-Vapor Interface [4] .............. 18

Figure 3.2 Force Imbalance at the Interface [4] .................................... 19

Figure 3.3 Vapor Pressure Change along Heat Pipe (Adiabatic Section

Omitted) $[2]$.......................................................................................................... 23

Figure 3.4 Pressure Recovery more than Vapor Phase [2] ............... 25

Figure 3.5 Pressure Recovery less than Vapor Phase [2] ................... 25

Figure 3.6 Net Pressure Recovery [2] ................................................. 25

Figure 3.7 Temperature Drop along Heat Pipe [12] ........................... 27

Figure 3.8 Temperature Drop Sites inside Heat Pipe [13].................. 28

Figure 3.9 Operating Limits of a Heat Pipe [6] .................................... 32

Figure 3.10 Transition from Viscous to Sonic Limit [1] ..................... 37

Figure 4.1 Merit Number of Certain Fluids [18] .................................. 41 
Figure 4.2 Space Nuclear Power Reactor Model [30] .......................... 44

Figure 4.3 Cross-section of Heat Pipe Cooled Leading Edge [33] .... 45

Figure 4.4 Indirect Heating of Stirling Engine Using Heat Pipe as Heat

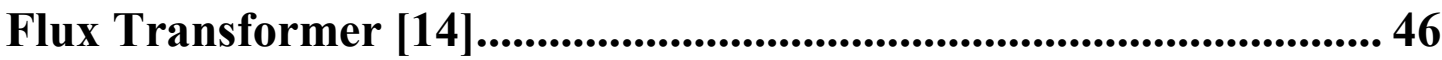

Figure 4.5 Cross Sectional View of Nuclear Core [36]....................... 47

Figure 4.6 Axial Cut of Nuclear Core [36] ........................................... 48

Figure 4.7 A Model Showing Drill with and without Heat Pipe [37] 49

Figure 4.8 Sodium Heat Pipe Various Heat Input ................................. 51

Figure 4.9 Comparison of Sodium Heat Pipe Startup Time with Different Wick Structures [19] .................................................................... 52

Figure 4.10 Temperature and Pressure Variation in Radial Direction [44] 53

Figure 4.11 Incipient of Boiling Corresponding to Sonic Limit [44] 54 Figure 4.12 Electrochemistry of Micro Cell Erosion [19].................... 56 Figure 5.1 Schematic of a Nuclear Fusion Reactor [1] ...................... 58 Figure 5.2 Liquid Metal Heat Pipe in Nuclear Reactor [1] ................ 59 Figure 5.3 Effect of Magnetic Field on Heat Transfer Ability [1] .... 60 Figure 6.1 Impact of Magnetic Field on Capillary Limit .................... 73

Figure 6.2 Effect of Temperature on Viscosity ...................................... 73

Figure 6.3 Impact of Heat Flux ...................................................... 75

Figure 6.4 Impact of Temperature...................................................... 76

Figure 7.1 Variation of Local Hartmann Number Spatially .............. 81 Figure 7.2 Comparison of Uniform and Non-Uniform Magnetic for the Impact on Capillary Limit ............................................................................ 82 


\section{LIST OF TABLES}

Table 1.1 Modes of Condensate Return [2] .......................................... 3

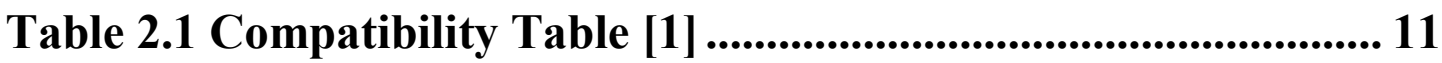

Table 2.2 Temperature Distribution Table [1] ...................................... 14

Table 3.1 Superheating Required for Nucleation [2] ........................... 29

Table 3.2 Various Thermal Resistance for a Water Heat Pipe [14] 31

Table 4.1 High Temperature Heat Pipe Materials [6] .......................... 42 


\section{ACKNOWLEDGEMENT}

This work is not an individual effort; it is the combination of motivation and guidance of the entire person involved. I would like to thank my advisor Dr. Jeffrey $S$. Allen for his continuous support and guidance throughout the work. I have been motivated by my friends and colleagues to maintain the level of dedication throughout the task.

I would also like to thank all the authors and the publishers who has given me the permission to use their material in my work. Appendix covers all the permission grant for the work.

Last but not the least I would like to thanks all the faculty member and the person involved in providing me the proper way of going through the work and obtain the result timely. 


\section{ABSTRACT}

A study of high temperature heat pipe was conducted to understand its characteristics. A review of working fluid, temperature, wick structure, problems, operational limit and applications was done. Alkali metal were concluded as the most viable candidate for the working fluid.

The impact of three parameters namely magnetic field, heat flux and temperature was analyzed on the performance of HTHP (High Temperature Heat Pipe). The presence of magnetic field had the most considerable impact on reducing the pumping limit of the heat pipe while the temperature had almost negligible effect. Magnetic field results in the pressure drop and adversely affect the fluid inside the heat pipe. The adverse impact was characterized due to the conducting nature of the working fluid.

Analyzing the Magnetohydrodynamic (MHD) equation showed that the reason for the pressure drop inside heat pipe was Lorentz force. The flow was found to be dependent on three dimensionless number namely Capillary number, Hartmann number and aspect ratio of heat pipe.

Thereafter a mathematical model was developed to inquire if the presence of non-uniform magnetic field can increase the capillary limit over the uniform magnetic field. It was found that an exponential varying field along the axial direction of the heat pipe improves the performance

of the device. The results corresponding to uniform and non-uniform field were compared and concluded in our study. 


\section{Chapter 1. Introduction}

There have been a number of ways of transferring the heat, but heat pipe is considered one of the most efficient and effective mode. The heat can be transferred over distances with no additional power input requirement and equivalently small cross-sectional area. Even the heat flux transfer through heat pipe is considerably higher than most of the conventional mode of heat transfer. The process of heat transfer is nearly isothermal and its design is comparably cheap and simple, which makes it a remarkable, probably the best mode of heat transfer. This device as an added advantage can also act as heat flux transformer. [1]

The concept of heat pipe related device dates back to mid-nineteenth century, when the first heat pipe known as Perkins tube was invented. This was a gravity assisted heat pipe, also known as thermosyphon. The working principle of thermosyphon is that the fluid at the bottom of the tube is heated, the fluid after vaporization moves to the upper part of the tube where it is condensed and the condensate returns to the bottom through the assist of gravity. [2] [3]. A comparison of heat pipe and thermosyphon is shown in Figure 1.1

A heat pipe is different from thermosyphon in the context that heat pipe has a wick and utilizes capillary force to drive the flow. The wick helps in carrying the flow continuously without the assistance of gravity. The evaporator in thermosyphon is situated at the bottom but inside a heat pipe it can have any orientation. Heat pipe is sometimes referred to a 
device, which is capable of transferring heat either through the action of osmosis or magnetic force. Alternative modes of condensate return are shown in Table 1.1.



Figure 1.1 Comparison of Heat Pipe and Thermosyphon [2]

The heat pipe has three sections:

- Heat addition section or evaporator

- Heat rejection section or condenser

- Isothermal section or adiabatic section 
Table 1.1 Modes of Condensate Return [2]

\begin{tabular}{|l|l|}
\hline Gravity & Themal syphon \\
\hline Capillary Force & Standard Heat Pipe \\
\hline Centripetal Force & Rotating Heat Pipe \\
\hline Magnetic Force & Magnetic fluid Heat Pipe \\
\hline Osmotic Forces & Osmotic Heat Pipe \\
\hline Bubble Pump & Inverse Thermal Syphon \\
\hline
\end{tabular}

The working fluid in the heat pipe is heated in the evaporator and due to high temperature and pressure, the vaporized fluid move towards the condenser where it is condensed, and this condensate returns to the evaporator by capillary action in the wick. Fluid remains in saturated condition unless working temperature is between critical point and triple point. [4] Sections of the heat pipe are shown in Figure $\mathbf{1 . 2}$

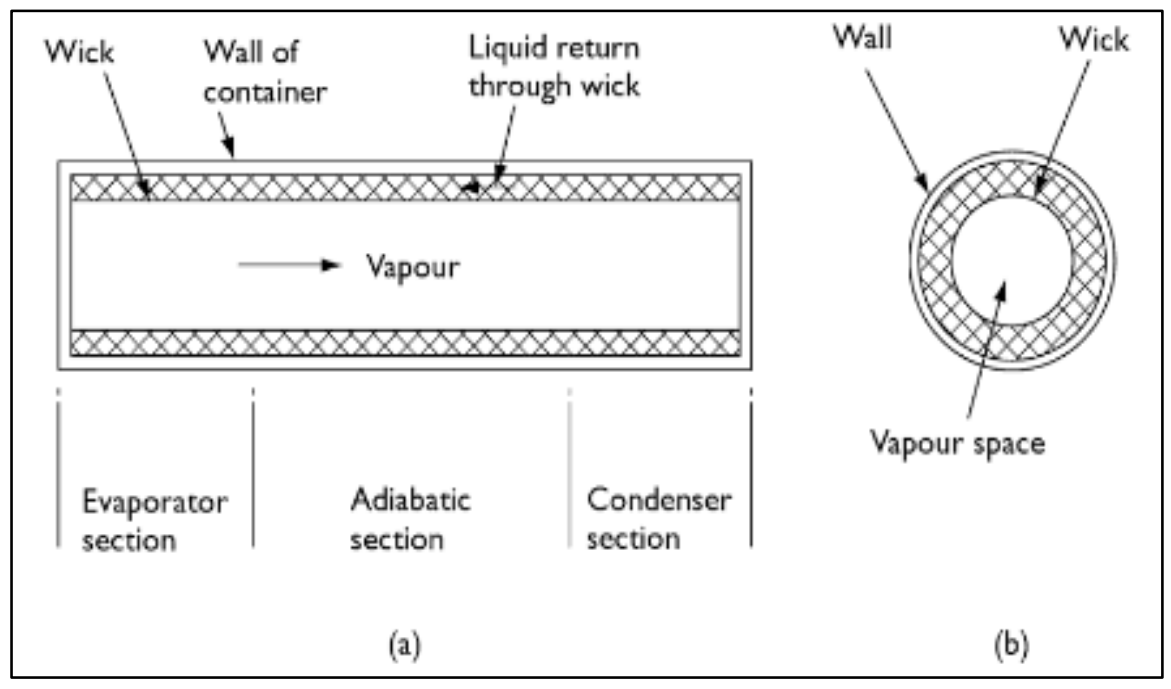

Figure 1.2 Sections of Heat Pipe [2] 
The performance of a heat pipe is defined in terms of 'equivalent thermal conductivity'. A heat pipe using water as working fluid and operating at $150^{\circ} \mathrm{C}$ will have a thermal conductivity approximately 500 times greater than that of a copper bar of equivalent cross-section. This is because heat is absorbed and rejected during evaporation and condensation isothermally as latent heat. The major characteristics of a heat pipe are:

- High thermal conductivity

- Can act as thermal flux transformer

- The operation is almost isothermal

- Can attain variable thermal impedance

\subsection{Operational Principle and Fundamental Conditions}

The basic operational principle of heat pipe has already been discussed, but to have a better understanding of how this device works see Figure 1.3. The major components include a solid container, a wick structure and a working fluid.

The heat is applied to the pipe through the wall at the evaporator where the fluid is vaporized and due to this vapor pressure, the flow of the fluid takes place towards the condenser section. At the condenser end cap the heat is rejected, the vapor is condensed, and the condensate is pumped back to the evaporator section due to the capillary pressure created by the menisci of the wick structure The capillary pressure works against viscous pressure drop required between condenser and evaporator liquid-vapor interface and any gravitational or body force acting on the fluid as in equation 1 


$$
\Delta P_{c}>\Delta P_{l v}+\Delta P_{b g}
$$

$\Delta \mathrm{P}_{\mathrm{c}}$ is capillary pressure, $\Delta \mathrm{P}_{\mathrm{lv}}$ liquid-vapor interface viscous pressure drop and $\Delta \mathrm{P}_{\mathrm{bg}}$ gravitational or body force pressure drop.

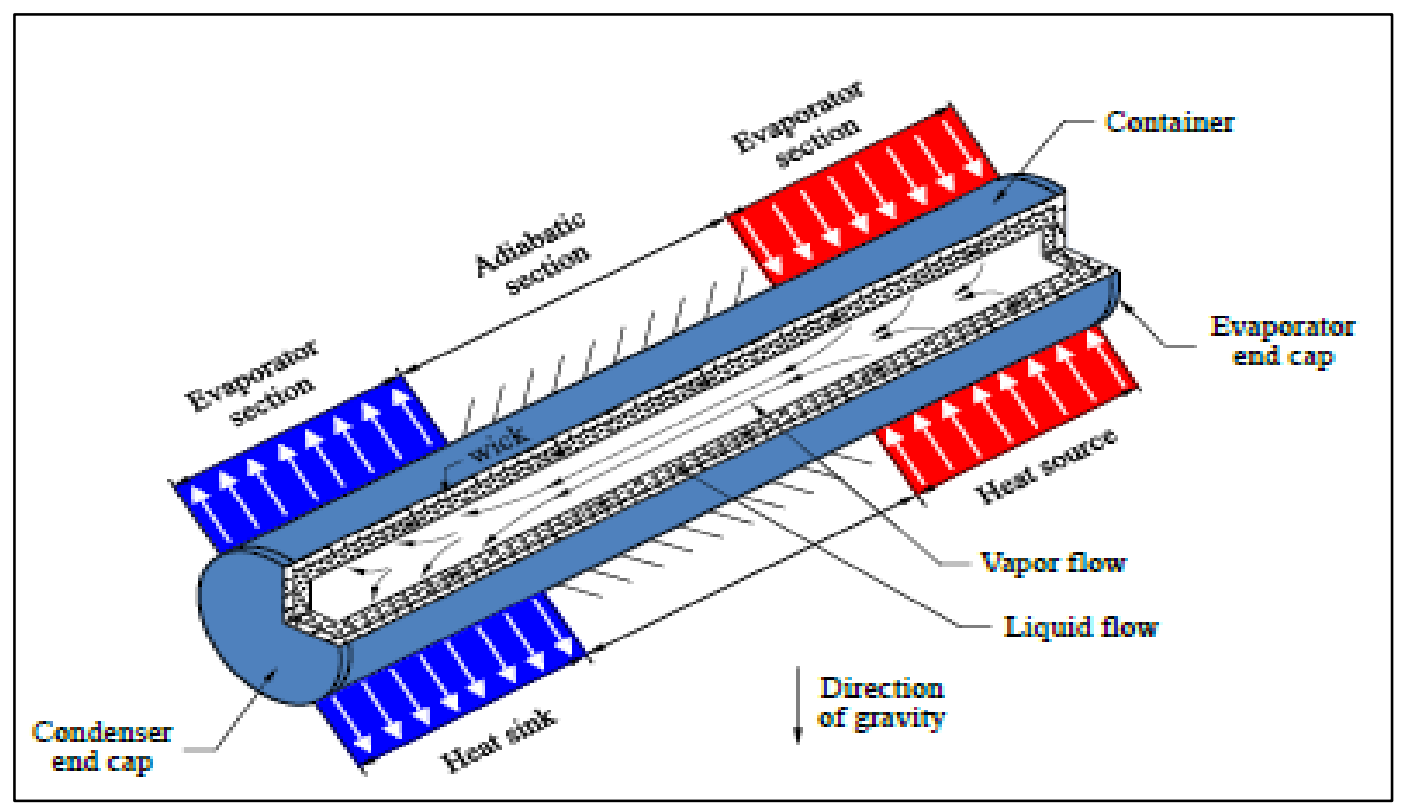

Figure 1.3 Schematic of a Conventional Heat Pipe [1]

If equation 1 is not satisfied, then heat pipe will dry-out and operation will cease for this reason the condenser end-cap is curved while evaporator end-cap is flat to have a driving pressure gradient throughout the flow of the fluid. The resistive diagram of the heat pipe is shown in Figure 1.4

- R1- outside source-evaporator contact resistance

- R2- evaporator wall resistance

- R3- evaporator wick resistance 
- R4- evaporator liquid-vapor interface resistance

- R5- vapor channel resistance

- R6- condenser liquid-vapor interface resistance

- R7- condenser wick resistance

- R8- condenser wall resistance

- R9- outside sink-condenser contact resistance

- Rs- Wall and wick resistance

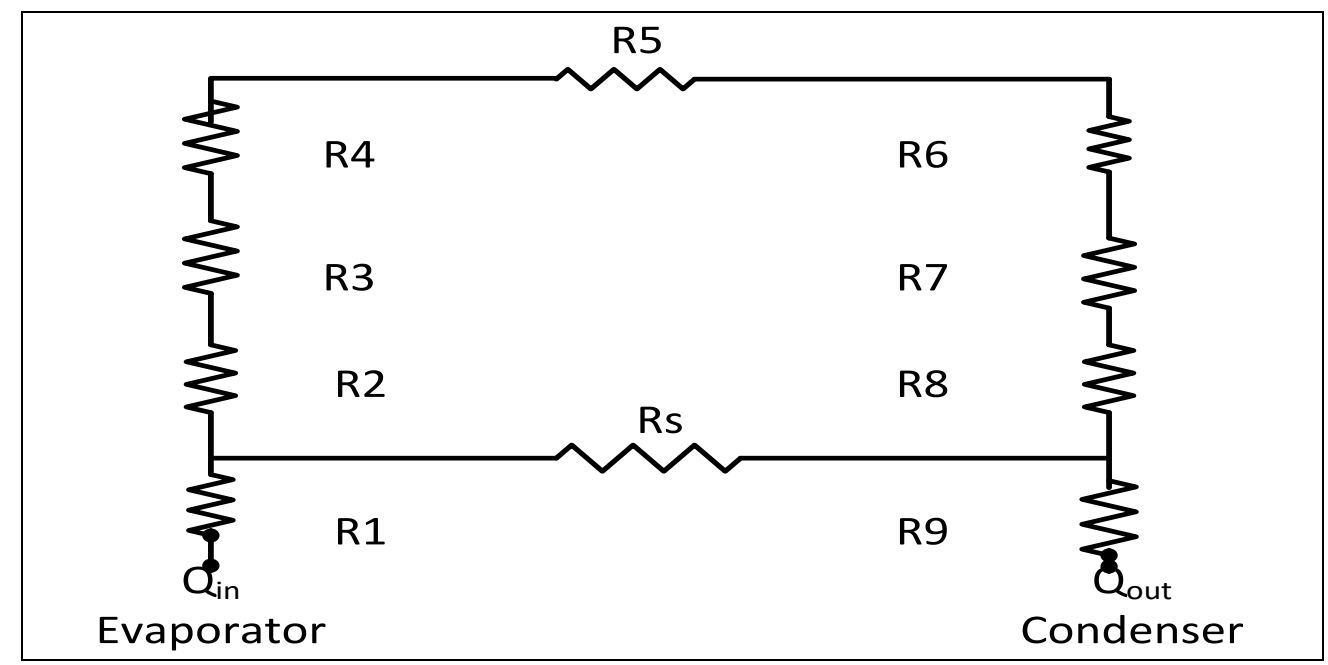

Figure 1.4 Resistor Model of Heat Pipe [1]

\subsection{Types of Heat Pipe}

Most heat pipes use capillary force to drive the flow; sometimes, gravitational, osmotic forces etc. are also used for driving the flow. Most of the heat pipes have circular cross-section but other geometries have been 
constructed depending upon the application. [1] [5] Several types of heat pipes are:

- Two Phase Closed Thermo-syphon: These are the gravity assisted heat pipe. This may or may not have wick structure. See Figure 1.5.

- Capillary Driven Heat Pipe: These heat pipes have the wick structure present in it and the fluid flow is maintained using difference in capillary pressure between the condenser and evaporator.

- Annular Heat Pipes: These are similar to the capillary driven heat pipe, the only difference being in their geometry. Conventional heat pipes have circular cross-section while annular heat pipe has the annular cross-section because of which the wick grooves can be put at the outside and inside of the inner and outer pipe respectively. This is used for increasing the overall area of heat input and rejection, thereby increasing the thermal response and capability of heat transfer.

- Vapor Chamber: These are the capillary driven heat pipes that have additional wick grooves added between the condenser and evaporator, if evaporator is located above the condenser. This aids in driving the condensate flow and prevent the dry out. Vapor chamber is shown in Figure 1.6.

- Other Types of Heat pipe:

- Rotating heat pipe

- Gas-Loaded heat pipe (Figure 1.7)

$\circ$ Loop heat pipe 
- Pulsating heat pipe

○ Monogroove heat pipe

○ Non-Conventional heat pipe

- Leading edge heat pipe

- Heat pipe vane turbine cooling



Figure 1.5 Two Phase Thermo-Syphon [1] 


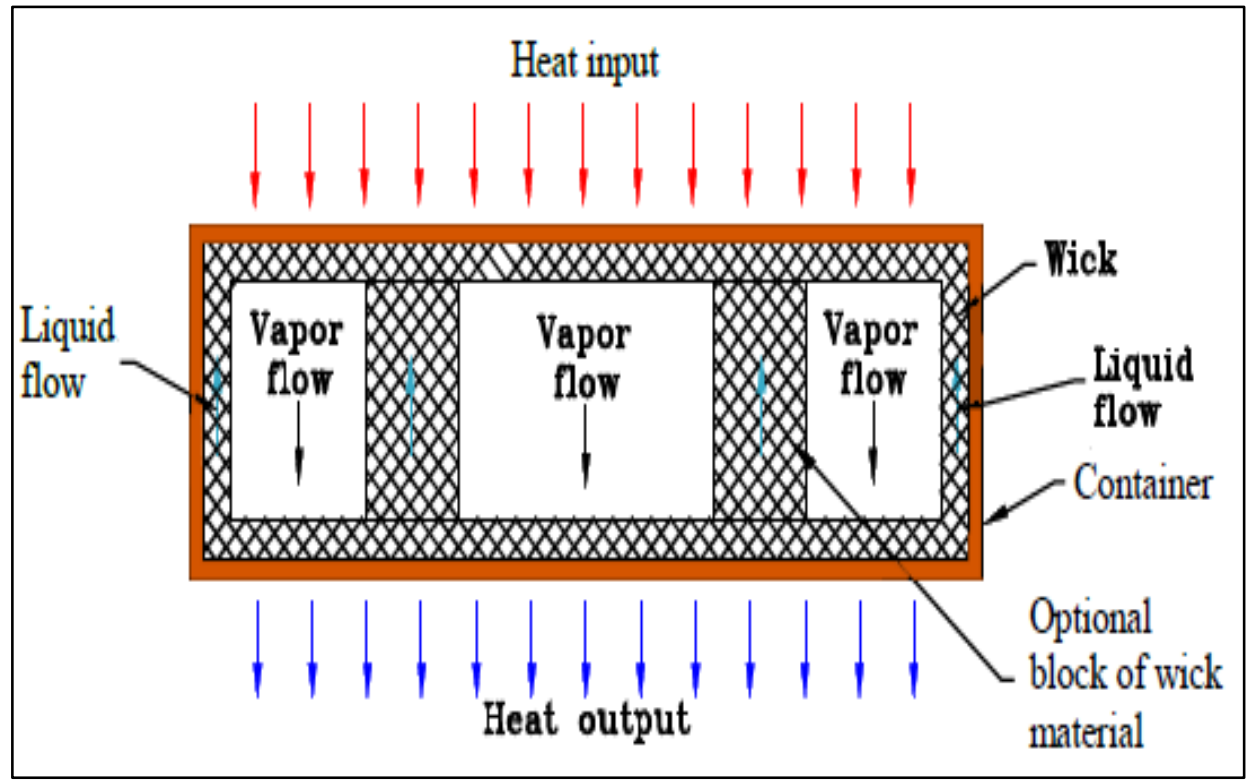

Figure 1.6 Vapor Chamber [1]

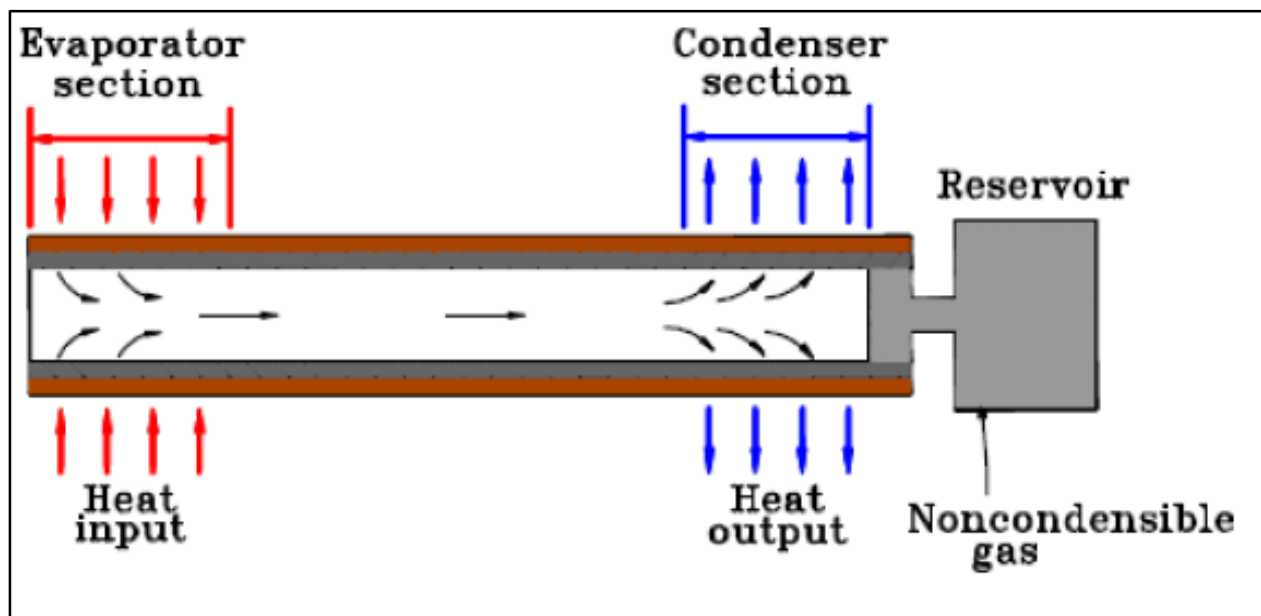

Figure 1.7 Gas Loaded Heat Pipe [1] 


\section{Chapter 2. Components and Characteristics}

The major components of the heat pipes are container wall, working fluid and wick structure. The working fluid is chosen based on the temperate conditions, for example water cannot be used as working fluid for heat pipe used for fusion blankets in nuclear reactors. Similarly, the container material should be compatible with the fluid in order to avoid any damage or rust. Aluminum cannot be used as wall material if Lithium is being used as working fluid for high temperature applications. Wick structure is important in determining the rate of heat transfer through heat pipes. The combination of all the components determines the heat transfer ability and the type of application of the heat pipe. A heat pipe has variety of applications from being used in the laptop or computers to the space shuttle. The heat pipes have different working fluid for different temperature and applications.

\subsection{Working Fluids}

The working fluids are chosen considering the temperature range of operation of the heat pipe. The basic rule to choose the fluid is that its saturation pressure be more than $0.1 \mathrm{~atm}$ and less than $20 \mathrm{~atm}$. If the saturation pressure is low then vapor pressure limit will be attained and for high saturation pressure the resistance of the heat pipe will be high. The container wall must be chosen such that it does not react or decompose due to the fluid. The compatibility table of working fluid and container material is shown in Table 2.1 . 
Table 2.1 Compatibility Table [1]

\begin{tabular}{|c|c|c|}
\hline Working Fluid & Compatible Material & $\begin{array}{c}\text { Incompatible } \\
\text { Material }\end{array}$ \\
\hline Water & $\begin{array}{l}\text { Stainless Steel, Copper, } \\
\text { Silica, Nickel, Titanium }\end{array}$ & Aluminum, Inconel \\
\hline Ammonia & $\begin{array}{c}\text { Aluminum, Stainless Steel, } \\
\text { Iron, Nickel }\end{array}$ & \\
\hline Methanol & $\begin{array}{c}\text { Stainless Steel, Iron, Nickel, } \\
\text { Copper, Brass, Silica }\end{array}$ & Aluminum \\
\hline Acetone & $\begin{array}{c}\text { Aluminum, Stainless Steel, } \\
\text { Copper, Brass, Silica }\end{array}$ & \\
\hline Lithium & $\begin{array}{l}\text { Tungsten, Tantalum, } \\
\text { Molybdenum, Niobium }\end{array}$ & $\begin{array}{c}\text { Stainless Steel, } \\
\text { Inconel, Nickel, } \\
\text { Titanium }\end{array}$ \\
\hline Sodium & $\begin{array}{l}\text { Stainless Steel, Nickel, } \\
\text { Inconel, Niobium }\end{array}$ & Titanium \\
\hline Mercury & Stainless Steel & $\begin{array}{c}\text { Nickel, Tantalum, } \\
\text { Molybdenum, } \\
\text { Niobium, Inconel }\end{array}$ \\
\hline Silver & Tungsten, Tantalum & Rhenium \\
\hline
\end{tabular}

There are certain properties, which are desired from a working fluid:

- Good thermal stability

- High surface tension

- High latent heat and thermal conductivity 
- Compatible with wall material

- Low viscosity

It is necessary that a working fluid should generate sufficient capillary pressure to work against gravity and viscous drag. Using the additive can increase the conductivity or wettability but it will have negative impact during the phase change process. Vapor pressure should also be high, as low vapor pressure will tend to produce high thermal gradient and high vapor velocity.

The basic criteria in most of the cases to choose a working fluid is dependent upon figure of merit also known as merit number (M). It is defined as in equation (2)

$$
M=\frac{\sigma \rho_{L} h_{f g}}{\mu_{L}}
$$

Greater the merit number higher the heat transport ability. The Figure 2.1 shows the merit number of certain fluids. 


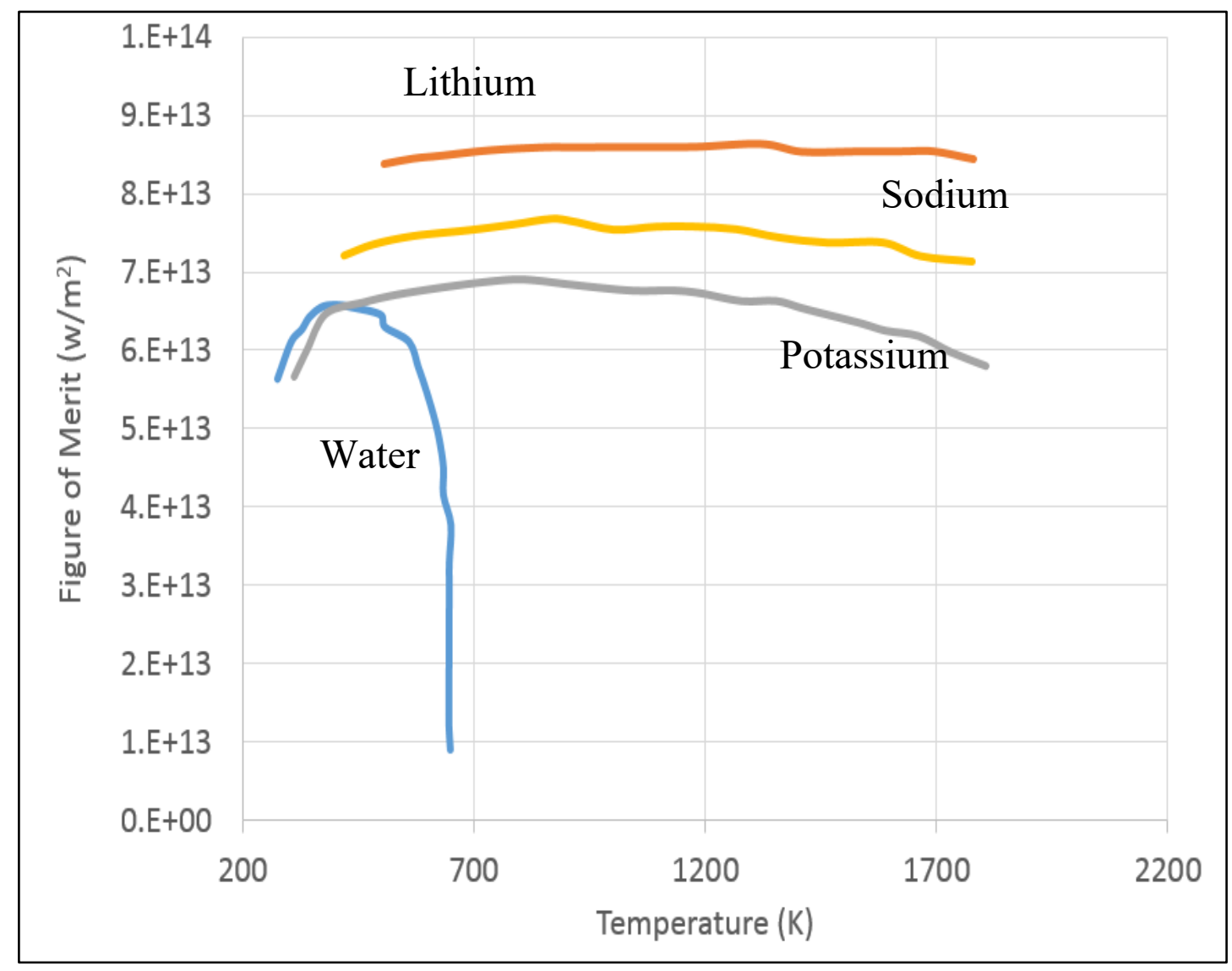

Figure 2.1 Figure of Merit of Some Fluids [6]

2.2Operational Temperature Range

Heat pipes can operate at wide variety of temperature ranging from freezing point of oxygen to the boiling point of lithium as shown in Table 2.2 .

- Cryogenic temperature range: Heat pipes operating between 4 and $200 \mathrm{~K}$ comes in this division, working fluid includes oxygen, argon etc. 
- Low temperature range: Heat pipes operating between 200 and 550 $\mathrm{K}$ are considered low temperature heat pipe. Water, ammonia and acetone are the most common fluid for this range

- Medium temperature range: These operate in the range of 550 to $750 \mathrm{~K}$ and use mercury as the working fluid.

- High temperature range: All heat pipes working beyond $750 \mathrm{~K}$ comes under this category. Depending upon the need and temperate conditions, sodium, lithium, potassium etc. can be used as the working fluid.

Table 2.2 Temperature Distribution Table [1]

\begin{tabular}{|c|c|c|}
\hline Working Fluid & Useful Range, K & Temperature Range \\
\hline Helium & $2-4$ & Cryogenic \\
\hline Hydrogen & $14-31$ & Cryogenic \\
\hline Oxygen & $73-119$ & Cryogenic \\
\hline Ethane & $150-240$ & Cryogenic, Low \\
\hline Ammonia & $213-373$ & Low \\
\hline Acetone & $273-393$ & Low \\
\hline Water & $303-550$ & Low \\
\hline Mercury & $523-923$ & Medium \\
\hline Sodium & $873-1473$ & High \\
\hline Lithium & $1273-2073$ & High \\
\hline
\end{tabular}




\subsection{Temperature Drop}

Heat pipes are considered isothermal but; there is some temperature difference accompanied with the flow. This drop occurs due to the flow of heat through wall thickness, wick structure and liquid-vapor interface. The maximum temperature is achieved at the evaporator end cap while minimum at condenser end cap.

The vapor inside the heat pipe is saturated and the temperature is the function of vapor pressure. By knowing the pressure drop the temperature drop across the heat pipe can be calibrated. The temperature drop is within the range of few degrees, which has been assured by measuring the pressure drop of about $1 \%$ in most of the cases.

In certain exceptional cases of high temperature heat pipe and during startup this temperature difference can be high. The expected temperature drop along the axial direction of the heat pipe is shown in Figure 2.2.

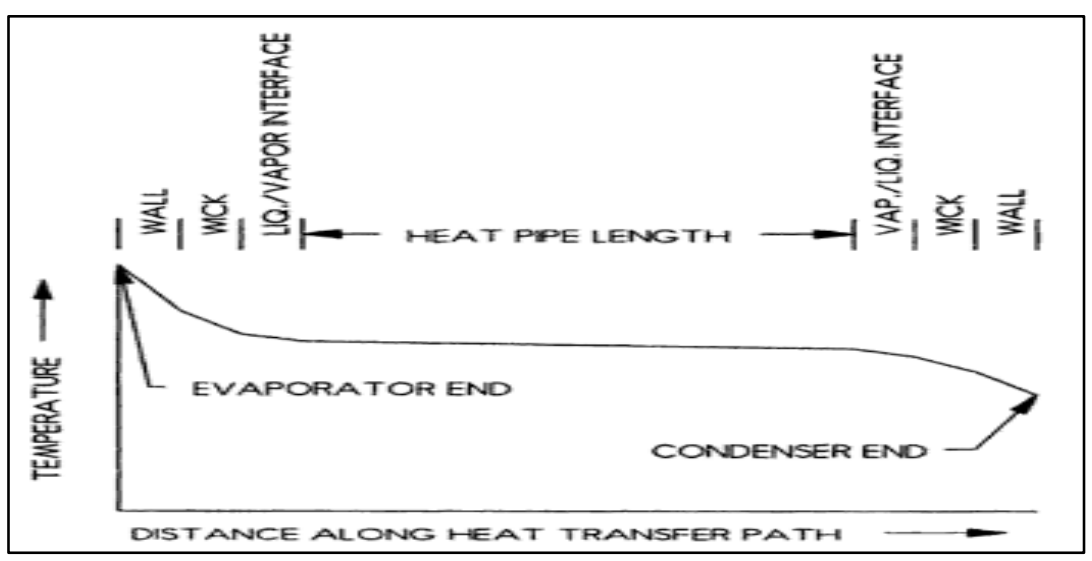

Figure 2.2 Temperature Drop Axially in Heat Pipe [7] 


\subsection{Types of Wick Structure}

The task of the wick structure is to transport the condensate back to the evaporator through the action of capillary force. The permeability of the wick should be as high as possible to avoid the capillary resistance to the flow. The major characteristics of wick are:

- Minimum capillary radius

- High permeability

- High effective thermal conductivity

High permeability and thermal conductivity are balanced against capillary radius. There are two types of wick structure

- Homogeneous: These are constructed of a single type of material. The cloth fabric can act as the wick material. The major three types of homogeneous wick used in the study are screen, arterial and annular. (Figure 2.3)

- Composite: These wicks are difficult to prepare and are mainly used in customary applications. It has different types of pores in a single heat pipe so that high capillary pressure and less resistance to the flow of the liquid return is obtained at once. (Figure 2.4)

A research for space shuttle experiment was carried out on different types of wick structure to reveal which type will be suitable for what type of application. The results indicated that homogeneous and arterial wick are insensitive to gravity effects means those wicks worked almost similar in ground as well as flight but the annular gap wick was not found consistent. [8] 
Homogeneous wick was found to have minimum thermal resistance, annular gap started more quickly while arterial had maximum performance margin. Nevertheless, considering the major benefit of having the better performance margin, arterial can be said to have an advantage over the others and is best suited for the space shuttle experiment. [8]

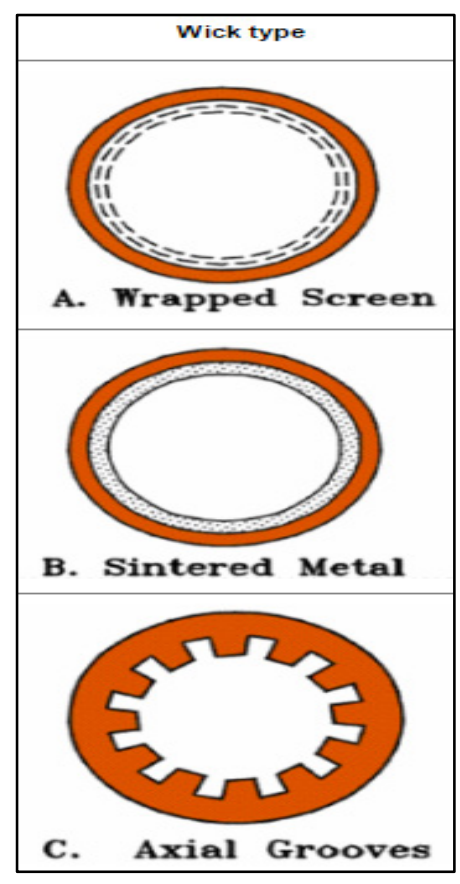

Figure 2.3 Types of Homogeneous Wick [1]

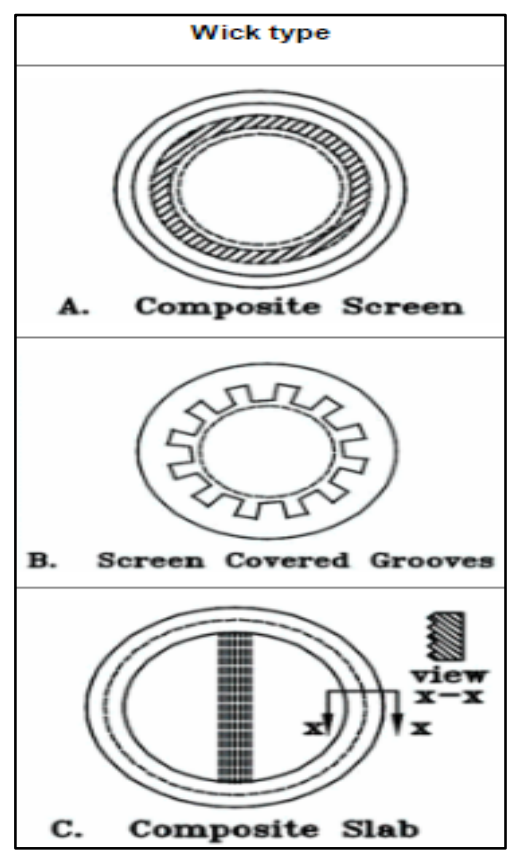

Figure 2.4 Types of Composite Wick Structure [1] 


\section{Chapter 3. Operational Limits}

Heat pipe involves phase changing phenomena, the liquid-vapor interface is demarcated but in reality, this process occurs gradually through a small window [9]. This can be clearly understood from Figure 3.1. Due to the decrease in the density a net perpendicular and parallel force, to the surface at the interface starts to exist which is known as the surface tension. This surface tension is the primary reason for the capillary driven actions. This imbalance force is shown in Figure 3.2.

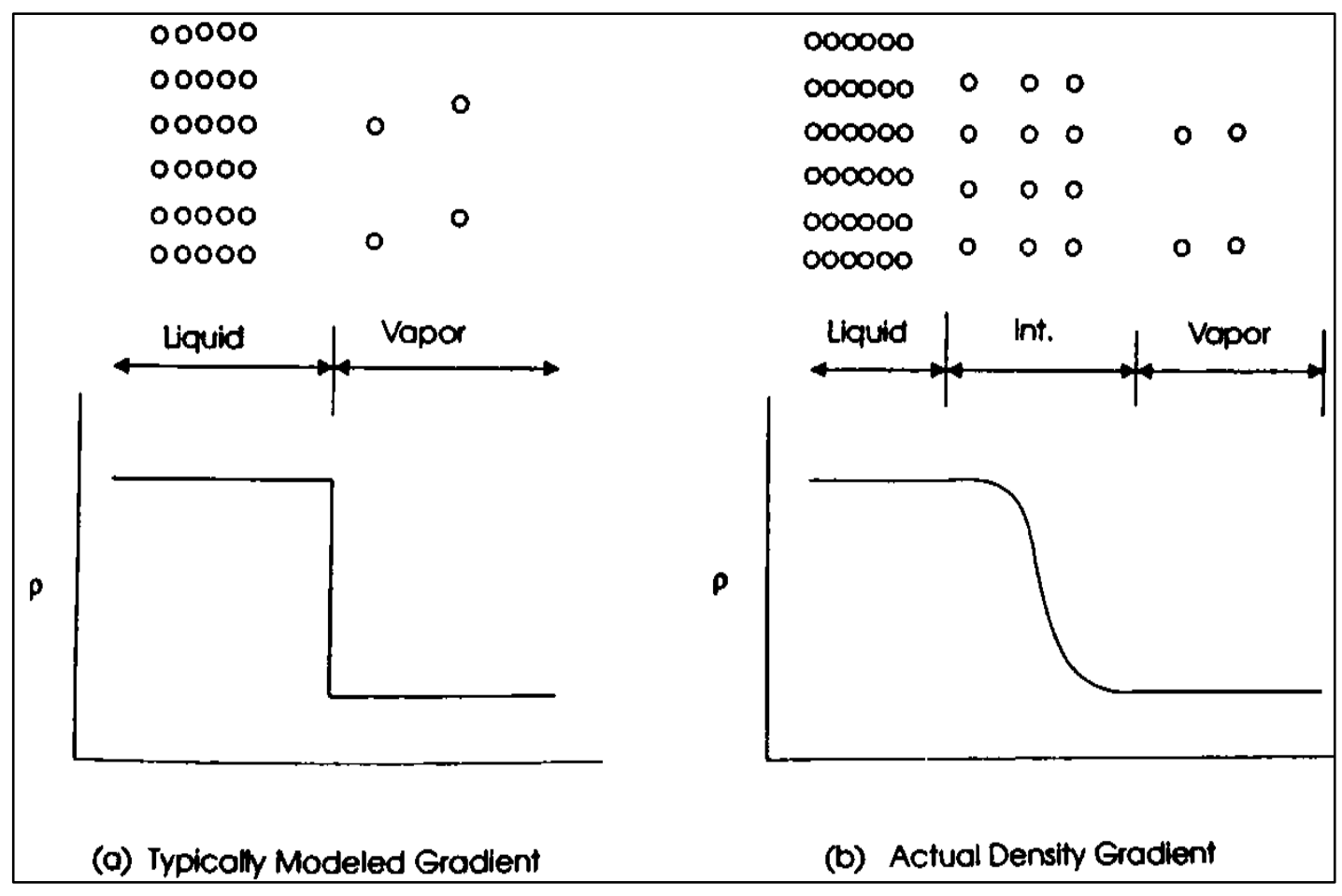

Figure 3.1 Density Variation at Liquid-Vapor Interface [4] 


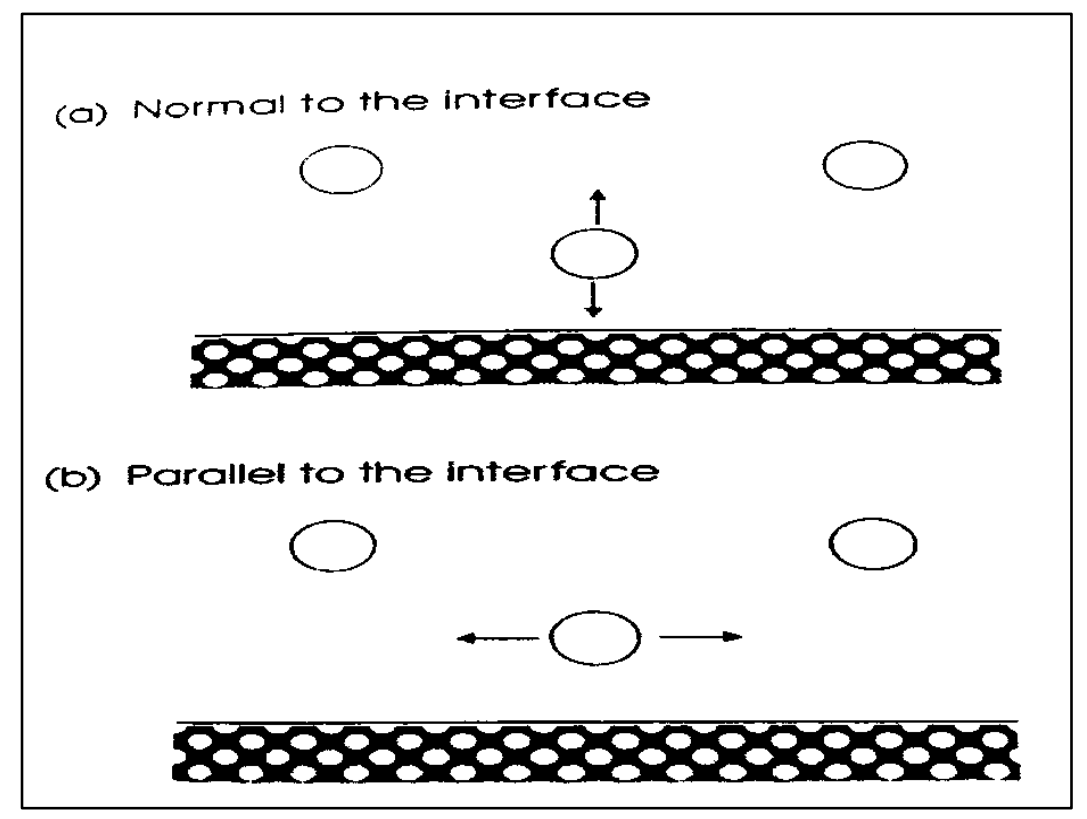

Figure 3.2 Force Imbalance at the Interface [4]

\subsection{Capillarity}

The resultant force or pressure created because of capillary action can be giving by equation (2).

$$
\Delta P=\sigma\left(\frac{1}{r_{1}}+\frac{1}{r_{2}}\right)
$$

This is the equation for the liquid-vapor interface, in which the orientation of liquid and vapor radii is perpendicular to each other. This equation is obtained after applying the first law of thermodynamics, which thereby gives the Helmholtz free energy function. Further analysis of the free energy function reveals the above equation (4).

$$
d F=-S d T+\mu d N+\Sigma \delta W
$$


In general, case of capillary rise phenomena is seen when a small diameter tube (straw) is inserted in water and the water tends to go up. Under such situation, the capillary pressure acting at the interface of the tube will be equal to the net force over its circumference and the final equation for capillary pressure difference can be summed up as (5)

$$
\Delta P_{c}=2 \sigma * \frac{\cos \theta}{r}
$$

It can be observed in equation (5) that the capillary action is dependent upon $\theta$, which is known as the angle of contact. The dip and rise of the menisci is dependent on this angle. When $\theta$ is more than $90^{\circ}$ the meniscus is expected to dip like in case of mercury, while if $\theta$ is acute the capillary rise phenomena is observed like in water. This contact angle defines the wetting characteristic of the fluid. The fluid tends to wet the surface when $\theta$ is acute while acts as non-wetting substance in case of obtuse angle of contact.

The equilibrium equation for drop is given by (6) [9]

$$
\sigma_{s v}=\sigma_{s l}+\sigma_{l v} \cos \theta
$$

Helmholtz free energy function is given by equation (7) which needs to be minimum to properly predict the flow characteristic of fluid

$$
d F=\sigma_{l v} d A_{l v}+\sigma_{s l} d A_{s l}+\sigma_{s v} d A_{s v}
$$

An increment in solid-liquid interface area will result in the decrement of solid-vapor interface area and vice versa, equation (8) can be quoted

$$
d A_{s v}=-d A_{s l}
$$


When the free surface energy is minimized then it yields young's equation (6). In order to operate the heat pipe effectively free energy function should be zero or less, which is defined as equation (9)

$$
d F=4 \pi L \sigma_{l v} \cos \theta d r_{l}\left(1-\frac{r_{l}}{r_{v}}\right)
$$

So one of the following condition needs to be satisfied

- The radius in liquid space should decrease making $\mathrm{dr}_{1}$ negative and then $\left(1-\frac{r_{l}}{r_{v}}\right)$ needs to be positive, or

- The radius of vapor space in vapor channel must always be greater than that in liquid channel.

\subsection{Pressure Drop \& Recovery}

The flow in the liquid phase is laminar and the extension of HagenPoiseuille equation can be used in the study of pressure gradient. The mass change per unit length is considered constant and the length of the heat pipe is defined by 'effective length' (10)

$$
l_{e f f}=l_{a}+\frac{l_{e}+l_{c}}{2}
$$

where subscripts a, c, e, and eff signifies adiabatic, condenser, evaporator and effective resp.

\subsubsection{Pressure Gradient in Liquid Phase}

Different equation are used for different types of wick to define the pressure gradient. For homogeneous wicks, the Darcy equation and its 
extension in the form of Kozeny equation can be applied which are given by $(11) \&(12)$

$$
\begin{gathered}
\Delta P_{1}=\frac{\mu_{l} l_{e f f} \dot{m}}{\rho_{l} K A} \\
\Delta P_{1}=\frac{150 \mu_{l}\left(1-\epsilon^{3}\right) l_{e f f} v}{D^{2} \epsilon^{3}}
\end{gathered}
$$

The above equations are applicable to laminar flow only, where

$\mathrm{K}$ is Permeability, $\mathrm{v}$ is superficial velocity, $\varepsilon$ is porosity $\varepsilon=\frac{\text { Volume of voids }}{\text { Volume of body }}$

for non-homogeneous wicks,(58) is valid for groove wicks while (14) for composite wicks.

$$
\begin{gathered}
\Delta P_{1}=\frac{8 \mu_{l} l \dot{Q}}{\rho_{l} N L \pi\left(\frac{1}{2} d_{e}\right)^{4}} \\
\Delta P_{1}=\frac{6 \mu_{l} l \dot{Q}}{\rho_{l} \omega^{3} L \pi r_{v}}
\end{gathered}
$$

\subsubsection{Pressure Difference in Vapor Phase}

The pressure drop in the vapor phase will occur at three different sections; evaporator, adiabatic and condenser. The pressure drop at the evaporator will increase the axial velocity of the flow towards condenser 
section. The task of the evaporator pressure drop is to accelerate the flow. In the same way, the pressure drop in the condenser will be equivalent to that of the evaporator but with negative value. In the condenser section, the vapor will come to rest and the kinetic head will be converted to the pressure head. It can then be considered as the region of pressure recovery as shown in Figure 3.3. In reality, the pressure recovery is not $100 \%$ and an experiment was performed on sodium heat pipe to reveal that the recovery was about $60 \%$. [10] The inertial term in evaporator and condenser section is given by (15)

$$
\Delta P^{\prime}{ }_{v}=\rho v^{2}
$$

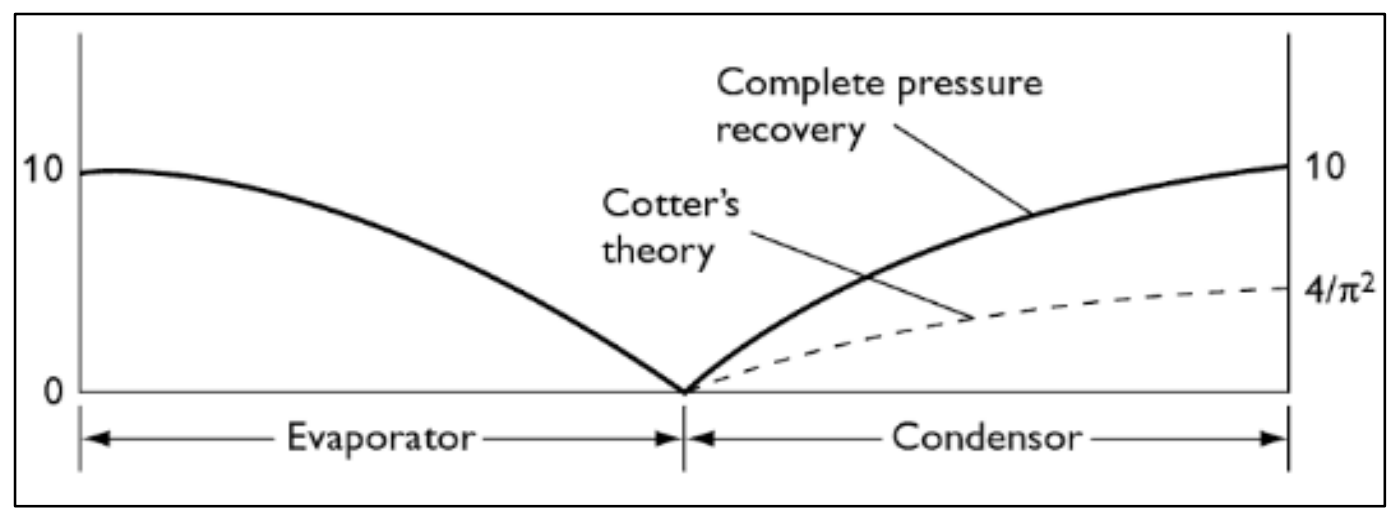

Figure 3.3 Vapor Pressure Change along Heat Pipe (Adiabatic Section Omitted) [2]

Inertial effect is independent of the length of section, but there is another term associated with the pressure drop, which is the viscous pressure drop. This viscous pressure drop will be defined by (16) for the evaporator. 


$$
\Delta P^{\prime \prime}{ }_{v}=\frac{8 \mu_{v} l_{e} \dot{m}}{\rho_{v} 2 \pi\left(r_{v}\right)^{4}}
$$

This pressure drop will be similar in the condenser, while in the adiabatic section it will depend the flow is either laminar or turbulent.

Entire pressure drop with pressure recovery will be given by (17).

$$
\Delta P_{v}=\frac{8 \mu_{v} \dot{m}}{\rho_{v} \pi\left(r_{v}\right)^{4}}\left(\frac{l_{e}+l_{c}}{2}+l_{a}\right)
$$

The Figure 3.4, Figure 3.5 \& Figure 3.6 shows the entire concept of the pressure drop in the liquid and vapor phase at once along the length of heat pipe, for better analysis viscous component is not taken into account.

At high vapor velocity choked flow may occur similar to nozzle. [11] The pressure recovery will take place unless a value of supersonic/choked flow is attained. 


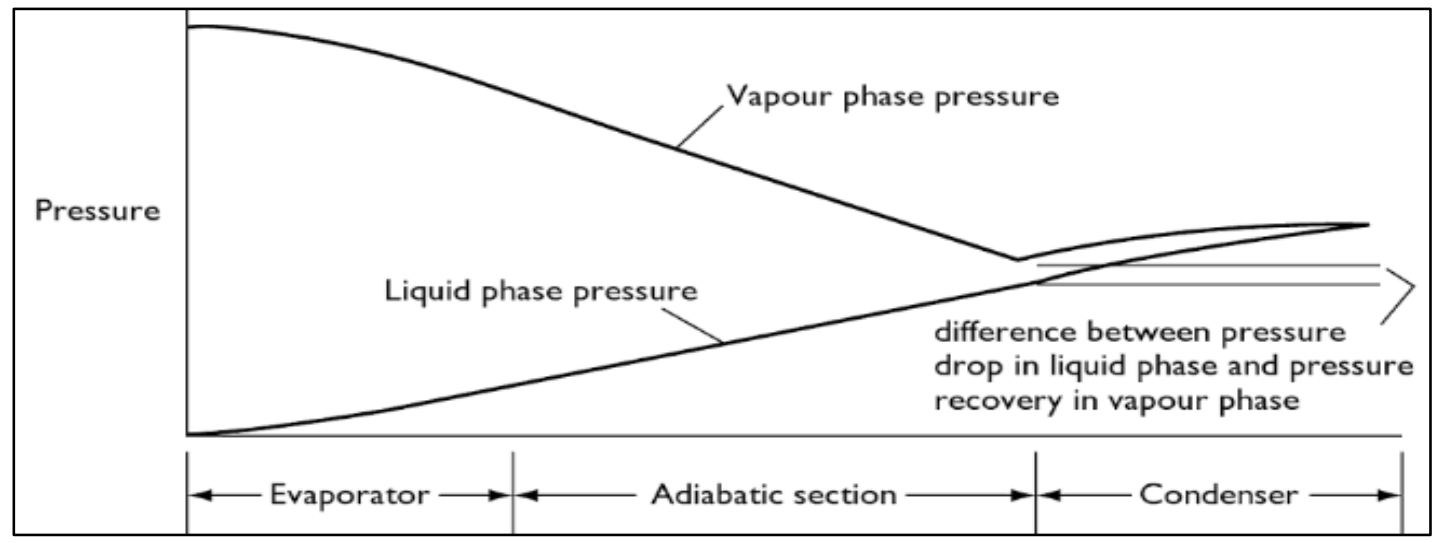

Figure 3.4 Pressure Recovery more than Vapor Phase [2]

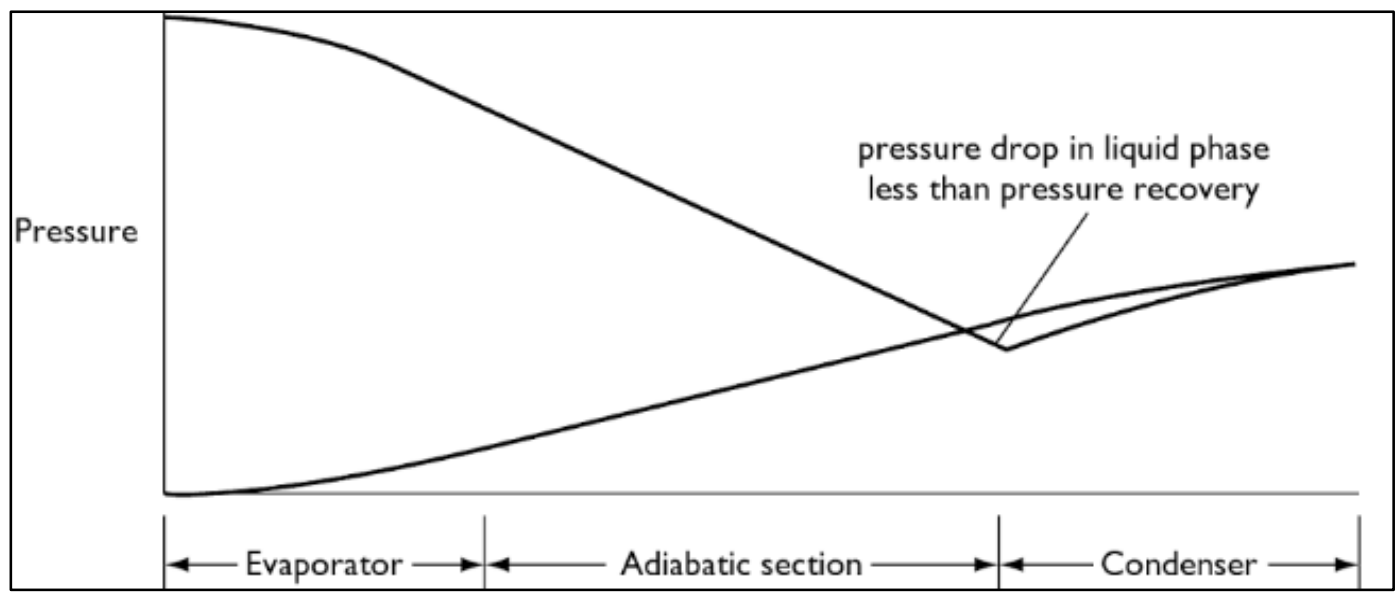

Figure 3.5 Pressure Recovery less than Vapor Phase [2]

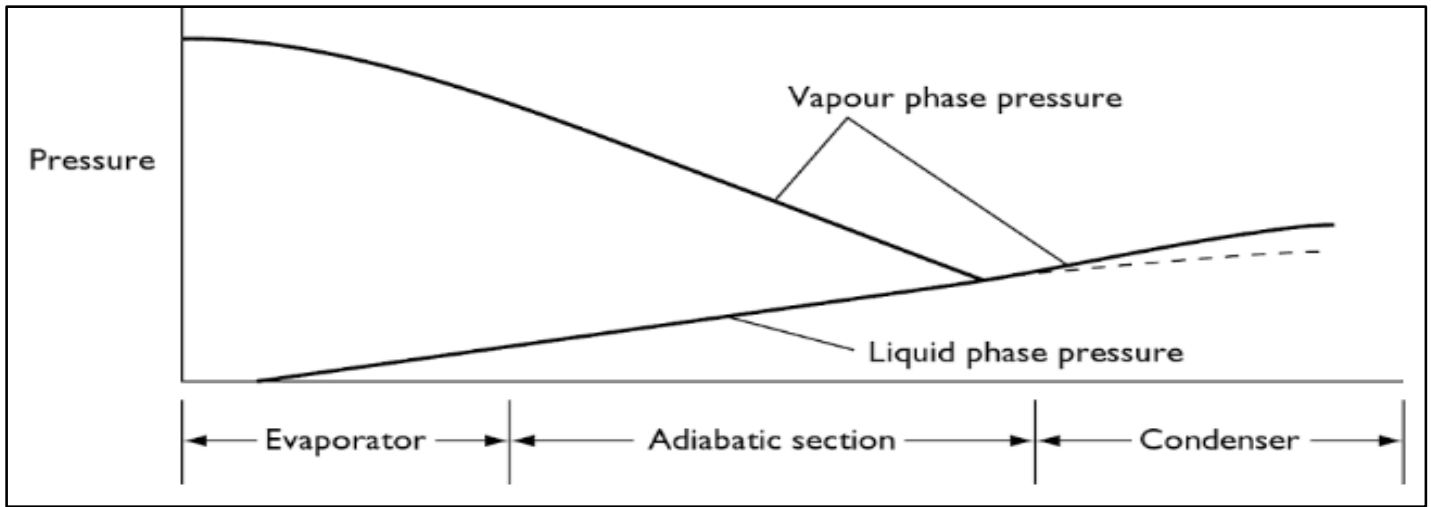

Figure 3.6 Net Pressure Recovery [2] 
The relations that can be used the find choked flow are (15), (18) \& (19)

$$
\begin{gathered}
\frac{P_{o}}{P_{2}}-1=\gamma M^{2} \\
\frac{\rho_{o}}{\rho_{2}}=\frac{P_{o} T_{2}}{P_{2} T_{o}}=\frac{1+\gamma M^{2}}{1+\left(\frac{\gamma-1}{\gamma M^{2}}\right)}
\end{gathered}
$$

$\mathrm{M}=$ Mach number

$\gamma=$ Specific heat ratio

\subsection{Temperature Difference}

Maximum temperature in the heat pipe is achieved at the evaporator end cap while minimum at the condenser. There is small temperature drop between evaporator and condenser. Temperature drop occurs because of the thermal resistance and the resistance of wall and wick.

In the previous section, pressure drop in the heat pipe was discussed and the vapor inside the heat pipe is saturated all the time. The temperature drop is considered as the function of the pressure drop so temperature variation will have similar characteristics as that of the pressure variation. Isothermal operation of the heat pipe is an indicator that the effective thermal resistance of the heat pipe is low.

The temperature drop occurs through the regions:

- Boiling through plane surfaces

- Boiling through wicked surface 
- Liquid-vapor interface temperature drop

All the above conditions may occur in both the evaporator and the condenser. The estimated temperature profile is shown in Figure 3.7 and the corresponding temperature drop model is shown in Figure 3.8.

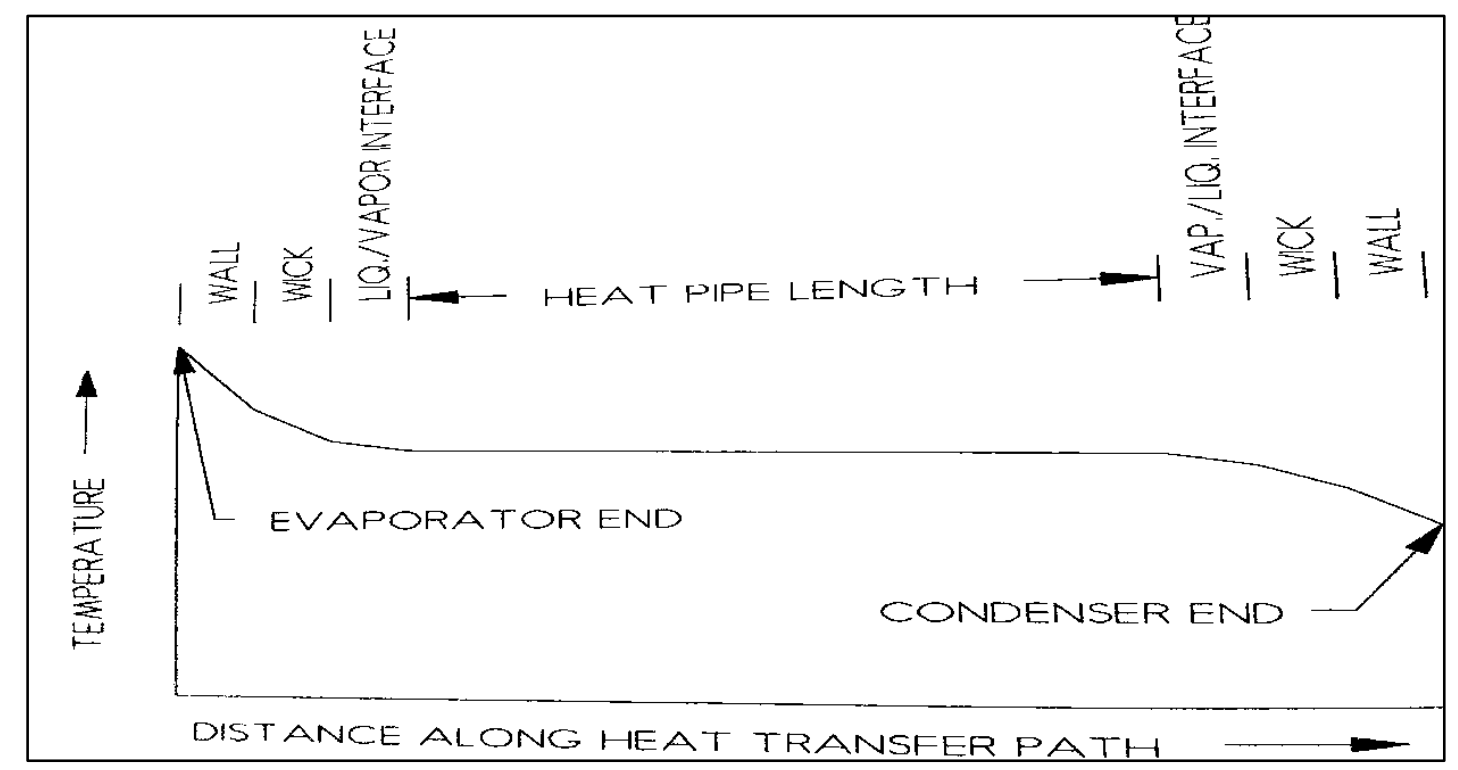

Figure 3.7 Temperature Drop along Heat Pipe [12] 




Figure 3.8 Temperature Drop Sites inside Heat Pipe [13]

During the startup of the heat pipe, the temperature difference can be as high as $100^{\circ} \mathrm{C}$ for liquid metal heat pipes, because the working fluid is initially in solid state. The superheating at the evaporator is needed to initiate the flow and nucleation is shown in Table 3.1.

Among all the phenomena involved heat transfer, the most complicated one is through the wick. The boiling inside the wick not only involves the boiling through the plane surfaces rather it adds up certain sites for nucleation which modifies the vapor and liquid flow from the surface. 
Table 3.1 Superheating Required for Nucleation [2]

\begin{tabular}{|c|c|c|}
\hline Fluid & $\begin{array}{c}\text { Boiling Point } \\
(\mathbf{K})\end{array}$ & $\Delta \mathbf{T}\left({ }^{\mathbf{0}} \mathbf{C}\right)$ \\
\hline Ammonia & 239.7 & 2 \\
\hline Water & 373 & 1.9 \\
\hline Potassium & 1047 & 8.9 \\
\hline Sodium & 1156 & 26.4 \\
\hline Lithium & 1613 & 44.6 \\
\hline
\end{tabular}

General equations that can be used to solve for finding nucleate boiling, boiling through wick etc. are summarized in equation (20)equation (28)

$$
Q_{1}=h_{e} A_{e} \Delta T_{1}
$$

$$
Q_{9}=h_{c} A_{c} \Delta T_{9}
$$

$$
q_{2}=\frac{k \Delta T_{2}}{t}
$$

$$
q_{8}=\frac{k \Delta T_{8}}{t}
$$




$$
\begin{gathered}
R_{3}=\frac{d}{k_{w} A_{e}} \\
R_{7}=\frac{d}{k_{w} A_{c}} \\
q_{4}=\frac{L^{2} P_{v} \Delta T_{4}}{(2 \pi R T)^{1 / 2} R T^{2}} \\
q_{6}=\frac{L^{2} P_{v} \Delta T_{6}}{(2 \pi R T)^{1 / 2} R T^{2}} \\
\Delta T_{5}=\frac{R T^{2} \Delta P_{v}}{L P_{v}}
\end{gathered}
$$

$A_{e} \& A_{c}$ are the evaporator and condenser wall areas

$h_{e} \& h_{c}$ are the heat transfer coefficients of evaporator and condenser outer surfaces

$$
\mathrm{k}=\text { thermal conductivity of the heat pipe wall, } \mathrm{t}=\text { thickness of the }
$$
wall, $d=$ wick thickness, $k_{w}=$ effective wick thermal conductivity

$$
\mathrm{R}=\text { gas constant for vapor, } \mathrm{L}=\text { latent heat, } \mathrm{P}_{\mathrm{v}}=\text { vapor pressure }
$$


$\mathrm{T}=$ absolute temperature of the vapor Entire temperature drops are corresponding to Figure 3.8 .

Table 3.2 Various Thermal Resistance for a Water Heat Pipe [14]

\begin{tabular}{|c|c|}
\hline Resistance & ${ }^{\circ} \mathrm{C} / \mathrm{W}$ \\
\hline $\mathrm{R}_{1}$ & $10^{3}-10$ \\
\hline $\mathrm{R}_{2}$ & $10^{-1}$ \\
\hline $\mathrm{R}_{3}$ & 10 \\
\hline $\mathrm{R}_{4}$ & $10^{-5}$ \\
\hline $\mathrm{R}_{5}$ & $10^{-8}$ \\
\hline $\mathrm{R}_{6}$ & $10^{-5}$ \\
\hline $\mathrm{R}_{7}$ & 10 \\
\hline $\mathrm{R}_{8}$ & $10^{-1}$ \\
\hline $\mathrm{R}_{9}$ & $10^{3}-10$ \\
\hline
\end{tabular}

\subsection{Heat Transport Limitations}

The ability of heat pipe to transport heat is not infinite, it is constrained by a number of factors. The lowest limit among all the possible limitations gives the operating limit of the heat pipe shown in Figure 3.9 




Figure 3.9 Operating Limits of a Heat Pipe [6]

There are eight limitations associated with a heat pipe:

- Continuum flow limit

- Frozen startup limit

- Viscous limit (Vapor pressure limit)

- Sonic limit

- Entrainment limit

- Capillary limit

- Condenser limit

- Boiling limit 


\subsubsection{Continuum Flow Limit}

This limit is reached in small heat pipes in which the vapor flows in the free molecular state and the continuum state of vapor is not reached. Due to non-continuum nature of the heat pipe, large temperature gradients exist along the heat pipe and the device can no longer be considered as an isothermally operating instrument. Transition temperature below which this limit exists is given by equation (29)

$$
T_{t r}=\frac{P_{s a t}}{\rho R_{g}} e^{\left(-\frac{h_{f g}}{R_{g}}\left(\frac{1}{T_{t r}}-\frac{1}{T_{s a t}}\right)\right)}
$$

\subsubsection{Frozen Startup Limit}

Working fluid in the high temperature heat pipes are liquid metals, which at ambient temperature and pressure are in the solidified state in the wick. When the heat is supplied at the evaporator end of the heat pipe, the frozen fluid at the evaporator side starts to vaporize but the temperature at the other end is not enough to liquefy the fluid at the condenser end cap. The vapor flow to the condenser section and are stuck there due to unmelted/ frozen fluid. In the same the heat near the evaporator sections liquefies the fluid nearby that region in the wick, which result inundates the evaporator. This result in the delay or sometimes the stoppage of the operation. The condition needed to avoid this is shown in equation (30) [15]

$$
\frac{\varepsilon \rho_{l} A^{\prime}{ }_{w} h_{f g}}{C\left(T_{m e l}-T_{\infty}\right)} \geq 1
$$


$\varepsilon=$ Porosity of wick structure, $\rho_{1}=$ liquid density, $A^{\prime}{ }_{w}=$ Cross-

section of working fluid in the wick, $\mathrm{C}=$ Heat capacity per unit length, $\mathrm{h}_{\mathrm{fg}}$ $=$ Latent heat of vaporization.

\subsubsection{Capillary Limit}

This limit is accompanied due to the inability of the wick structure to provide sufficient pressure for the liquid to flow from the condenser to the evaporator. This happens when the pressure loss inside the heat pipe are more than the maximum capillary pressure. If the pressure drop is less than the capillary pressure then the radii of the menisci will be selfadjusting unless a situation of maximum attainable radius is achieved. This can be summarized from equation (31)

$$
\left(\Delta P_{c}\right)_{\max } \geq\left(\Delta P_{\text {drop }}\right)_{\text {total }}
$$

If the above equation is not satisfied, then the liquid will not flow back to the evaporator and a dry out will occur. This condition occurs when the liquid-vapor interface fails to meet the net force against the frictional losses and the heat transfer from evaporator to condenser shuts off. The maximum heat transfer for the capillary limit is given by equation (32) [16]

$$
\dot{Q}_{c}=\frac{\sigma_{l} \rho_{l} l_{v}}{\mu_{l}} \frac{K A_{w}}{l_{e f f}}\left(\frac{2}{r_{e f f}}-\frac{\rho_{l} g l_{t} \cos \varphi}{\sigma_{l}}\right)
$$


$\mathrm{K}=$ Permeability, $1_{\mathrm{t}}=$ Total length of heat pipe, $\mathrm{r}_{\mathrm{eff}}=$ Wick capillary evaporator radius

\subsubsection{Viscous/ Vapor Pressure Limit}

This limit is reached when the vapor pressure at the condenser end cap and the available vapor in the evaporator is low, the viscous force in that case becomes dominant. The pressure gradient is not enough to carry the vapor from evaporator to condenser end and the heat transfer in this case is limited. This type of limit is either seen when the heat pipes are long or in liquid metal heat pipes where the viscous forces are dominant. The maximum heat transfer limit of this is given by equation (33)

$$
Q_{v}=\frac{A_{v} r^{2}{ }_{v} l_{v} \rho_{v} P_{v}}{16 \mu_{v} l_{\text {eff }}}\left(1-\frac{P^{2}{ }_{v, c}}{P^{2}{ }_{v}}\right)
$$

Pressure gradient should be more than one-tenth of the vapor pressure to avoid this.

\subsubsection{Sonic Limit}

This type of limitation is seen in the heat pipe working at low temperature because of associated low vapor densities or inside the liquid metal heat pipes. Unlike the viscous limit, this constraint is because of inertial effects. This limitation can be related to the choked flow of the convergent-divergent nozzle. Unlike the nozzle flow, the mass flow (heat input and rejection rate) in heat pipe is varying while the area remains constant.

The condenser temperature can be decreased to a certain extent, beyond a certain heat rejection rate the evaporator temperature will remain 
constant which is the sonic limit. Sonic limit does not result in the dry out at the evaporator but it increases the evaporator temperature and temperature gradient and reduces the effectiveness of heat pipe.

Maximum heat transfer through sonic limit is given by equation (34).

$$
Q_{s}=A_{v} \cdot 474 l_{v}\left(\rho_{v} P_{v}\right)^{.5}
$$

A relationship can be set between viscous and sonic limit, and comparing the equation of both limits we can say that at low value of vapor density and pressure viscous force are dominant but as the product of this goes on increasing inertial effects starts to come into view. A transitional understanding is shown in Figure 3.10.

\subsubsection{Entrainment Limit}

The liquid and vapor inside the heat pipe flows in opposite direction, and in the case of vapor shear, force is more than the surface tension force of the liquid, the liquid tends to enter the evaporator. This results in lack of fluid inside the wick and the liquid is carried back to the condenser along with the vapor flow. This situation is mainly seen to occur because of excess liquid flow inside the wick structure. [17]

The maximum heat transfer ability of this type of limitation is shown in equation (35)

$$
Q_{e}=A_{v} \cdot l_{v}\left(\frac{\rho_{v} \sigma_{l}}{2 r_{c, a v g}}\right)^{.5}
$$




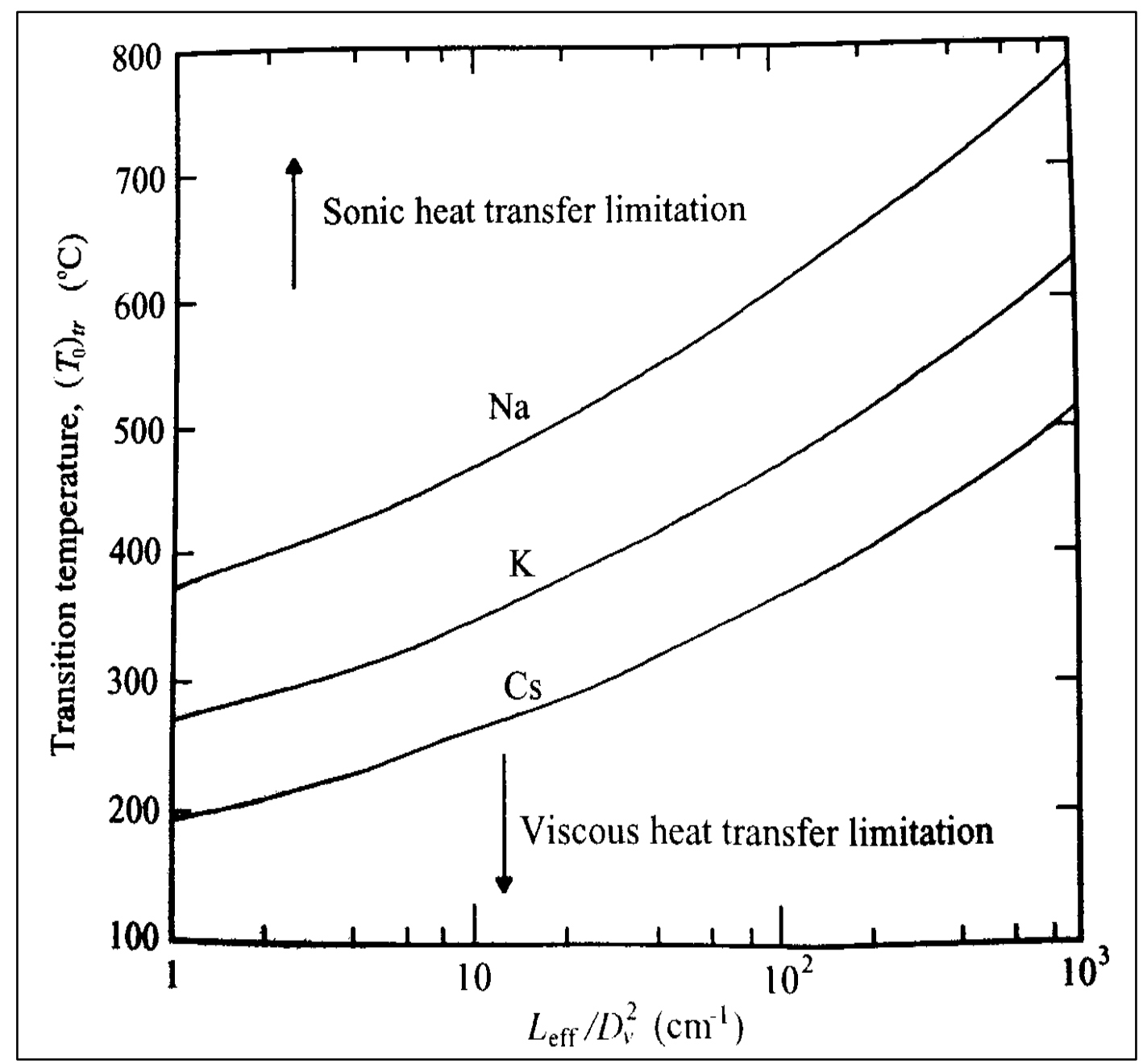

Figure 3.10 Transition from Viscous to Sonic Limit [1]

\subsubsection{Boiling Limitation}

Unlike other type of limitations, boiling limitation is caused due to excess radial heat flux while other phenomena studied deals with the axial heat transfer. When the heat flux is too high, or say that the wall temperature is high enough to boil/ create the nucleation site in the wick structure then the vapor bubble gets captured inside the wick and vapor blanket is formed. As a result, evaporator dry out or complete heat pipe 
dry out may take place. The process of boiling is accounted for two processes:

- Bubble formation

- Growth and collapse of bubble

Boiling limit is often referred to as the heat flux limit of the heat pipe. Bubble formation is triggered due to the temperature difference between pipe wall, fluid, and the number of nucleation sites in the wick structure.

Boiling limit is given by the following equation (36) [18]

$$
Q_{b . \max }=\frac{2 \pi l_{e f f} \lambda_{e f f} T_{v}}{h_{f g} \rho_{v}\left(\ln \frac{r_{i}}{r_{v}}\right)}\left(\frac{2 \sigma}{r_{b}}-\Delta P_{c}\right)
$$

$\lambda_{\text {eff }}=$ Effective thermal conductivity

$\mathrm{r}_{\mathrm{i}} / \mathrm{r}_{\mathrm{v}}=$ ratio of heat pipe radius to vapor cavity radius

\subsubsection{Condenser Limit}

The heat transfer limit through condenser is limited due to the following reasons:

- Operating temperature that the wall can handle

- Surface area constraints

- Lower heat transfer coefficient between condenser and sink.

This limit is often observed in high temperature heat pipes where radiation is the major source of heat transfer. This can be understood through equations (37) and (38). 


$$
Q_{c}=\iint \in \sigma\left(T^{4}-T_{\infty}{ }^{4}\right) d S_{c}
$$

$$
Q_{c}=S_{c} h\left(T_{c}-T_{\infty}\right)
$$

where $S_{c}$ is the surface area of the condenser.

It can be concluded that though heat pipe theoretically is a effective device and its operation seems simple. There are some design constraints and the next chapter gives a broader outlook about the understanding of a high temperature heat pipe. 


\section{Chapter 4. High Temperature Heat Pipes}

This chapter will introduce about high temperature heat pipes and their applications.

\subsection{Working Fluid}

Alkali metals are typically used as working fluids in high temperature application because they have high stability, high latent heat of vaporization and good thermal conductivity. [19] An investigation was also carried out by using lithium as the working fluid to cool the wings of the aircraft when they re-enter the atmosphere. [20]

It has already been discussed that the heat transport capability and the criteria to choose a working fluid is dependent upon the figure of merit. The merit number of alkali metal is flat comparable to water as shown in Figure 4.1. Up to $420 \mathrm{~K}$, the merit number for water is almost similar to that of potassium but thereafter it drops suddenly. It is because of the decrement in surface tension dominates the viscosity of water and merit number falls abruptly. From the figure we can conclude that potassium acts as a better working fluid than cesium and rubidium. Factors other than temperature and merit number that need to be given consideration while selecting a working fluid are availability, cost and the type of operation. Potassium, sodium and lithium are used as working fluid between the temperatures ranges of $700 \mathrm{~K}-1600 \mathrm{~K}$. 


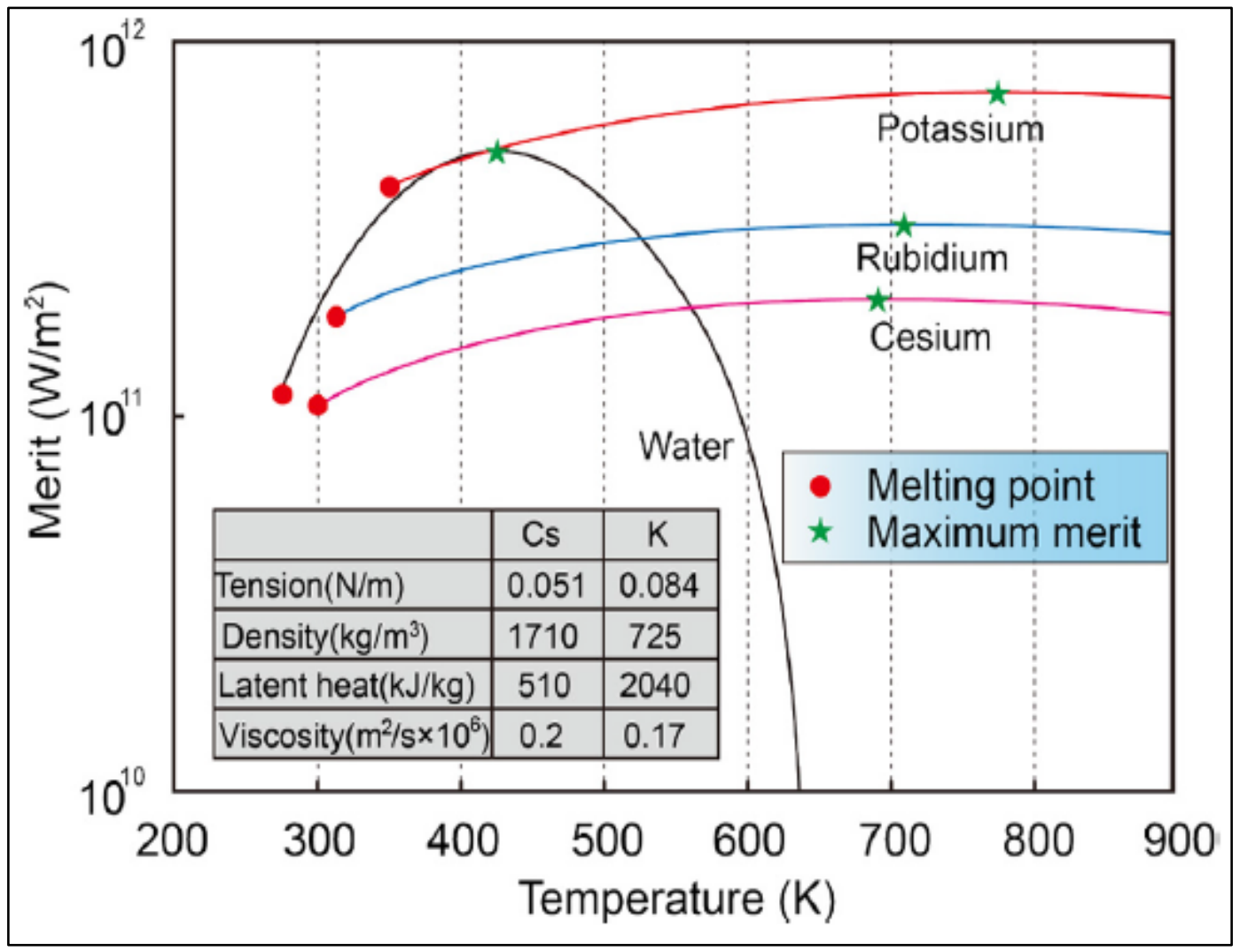

Figure 4.1 Merit Number of Certain Fluids [18]

\subsection{Structural Material}

The structural material needed for the manufacturing of heat pipe wall is dependent on temperature and pressure, type of working fluid, exposure to any irradiation. Working at high temperature can result in DBTT (Ductile to Brittle Transition Temperature) which can cause the leakage inside the alkali metal heat pipes. Table 4.1 gives an idea about the type of material used for high temperature heat pipes and their compatibility with the working fluid. 
Table 4.1 High Temperature Heat Pipe Materials [6]

\begin{tabular}{|c|c|c|c|}
\hline Material & Temp. (K) & Compatibility & $\begin{array}{c}\text { Melting Point } \\
\text { (K) }\end{array}$ \\
\hline Titanium & $775-875$ & $\mathrm{~K}$ & 1941 \\
\hline Steel Alloys & $875-900$ & $\mathrm{Na}, \mathrm{K}, \mathrm{Hg}$ & $<1700$ \\
\hline Super Alloys & $900-1150$ & $\mathrm{Na}, \mathrm{K}$ & $<1670$ \\
\hline $\begin{array}{c}\text { Molybdenum } \\
\text { Alloys }\end{array}$ & Up to 1800 & $\mathrm{Li}, \mathrm{Na}$ & $\leq 3023$ \\
\hline Tungsten Alloys & Up to 2200 & $\mathrm{Li}$ & 3695 \\
\hline Carbon & Up to 3000 & Metal liner & 3923 \\
\hline
\end{tabular}

Structural material is not limited to the usage of metals only, ceramics have been successfully tested and are proposed to use in the environment of abrasion and corrosion. Ceramics though cannot be used for direct heat transfer to sink. $\mathrm{SSiC}, \mathrm{Al}_{2} \mathrm{O}_{3}, \mathrm{Si}_{3} \mathrm{~N}_{4}$ are viable candidates for the use of ceramic as structural or shell material. [21]

\subsection{Distinguishing Properties and Applications}

Distinctive characteristics of high temperature heat pipes are:

- Sodium heat pipes has been found to operate for over 15 years continuously [22]

- Lithium heat pipe produced by one of the leading companies has the ability to transport $126 \mathrm{~kW} / \mathrm{cm}^{2}$ of heat flux [23]

- High power transfer capability of over $25 \mathrm{~kW}$ [24] 
- Enables the uniformity in crystal growth

- Maximum heat flux till 1973 achieved by a heat pipe was 1250 $\mathrm{MW} / \mathrm{m}^{2}$ at about $1600^{\circ} \mathrm{C}[25]$

- Many results and experiments in Germany and Russia reveal the heat flux of over $2.5 \mathrm{MW} / \mathrm{m}^{2}$ [26] [27]

Some of the varied applications of high temperature heat pipe are:

- Space Reactor Power System: The liquid metal heat pipes have been used for the heat removal from the radiator panel, using various working fluids. The reactors operate continuously for long time i.e. several years and generate heat corresponding to $1400-1700 \mathrm{~K}$ temperature, which can be removed efficiently using the heat pipes. Apart from the continuous heat removal at high rates, heat pipe gives an advantage of passive heat transport, long-term redundancy to failure, continued operation after shutdown and removal of heat from the core, low working fluid inventory, isothermal operation and lightweight. A study was conducted over this by Las Alamos National Laboratory, in which they used the heat pipes directly coupled into the nuclear core. [28] There have been other works relating to the use of alkali metal heat pipes for space power reactor. One of them is Mo-Li heat pipe that used annular screen wick and accomplished to transport $1 \mathrm{~kW} / \mathrm{cm}^{2}$ of heat flux at $1400-1700 \mathrm{~K}$. [29] A better understanding of a space nuclear power reactor can be made through figure 4.2, which clearly signifies the installation of the heat pipes in the reactor. A perforated metal divider is provided in the radiator segment between the inlet and exit channels and the sensible heat of the flowing coolant is removed into space using the combination of C-C fins attached to heat pipes. [30]

- Thermionic Reactor Program: Research has also been carried out to use heat pipes for heating thermionic emitter, cooling collector 
and for the radiation of heat in space applications. Successful



Figure 4.2 Space Nuclear Power Reactor Model [30]

implementation of these devices has been quoted with the use of $\mathrm{Nb}$ $\mathrm{Zr}$ heat pipe using Lithium as the working fluid. The devices have an operational life of about $4300 \mathrm{hrs}$. Without the sign of failure working at $1400 \mathrm{~K}$. [31] [32]

- Hypersonic Vehicle Leading Cooling: During the flight starting and the reentry to the atmosphere, aerospace undergoes a huge amount of heat flux generation especially at the nose i.e. at leading edge and at the wings. The temperature reaches to such a high value that it may not be considered under the safe operational limit. It is necessary to quickly dissipate the heat from the tip of the wing and for that purpose nose cap heat pipe has been proposed. The heat pipe with some other cooling mechanism can be employed to cool down the edges and wings. A sample of the heat pipe arrangement can be seen in Figure 4.3.

Considering the aerodynamics, the leading edges of the aerospace vehicles are sharp, heat flux corresponding to $5 \mathrm{MW} / \mathrm{m}^{2}$ can occur. The heat pipes are designed to match the shape of the 
leading edge and its nose acts as the evaporator. The fluid after evaporation transfer to downwind section where the fluid is condensed and pumps backs to nose through wick. The usage of heat pipes for this provides two advantages, firstly the temperature gradient along the edge is decreased and secondly, thermal stressed are exponentially reduced. Heat pipes with the combination of transpiration cooling has been tested and it has revealed some phenomenal results. [33] [34] [35]



Figure 4.3 Cross-section of Heat Pipe Cooled Leading Edge [33]

- Heat Flux Transformers: Heat pipes can also act as heat flux transformers if the area of evaporator and condenser is designed differently. The ratio of the heat flux of evaporator and condenser can be given by equation (39)

$$
\frac{q_{e}}{q_{c}}=\frac{\Delta P_{e}}{\Delta P_{c}}
$$

It can be concluded that even if the pressure difference in evaporator and condenser is small, the ratio can be high. This 
methodology is being applied to Stirling engine cycle where heat pipe acts as flux transformer between burner and engine heater head. A heat pipe using sodium as working fluid and operating at $1000 \mathrm{~K}$ is shown in Figure 4.4.

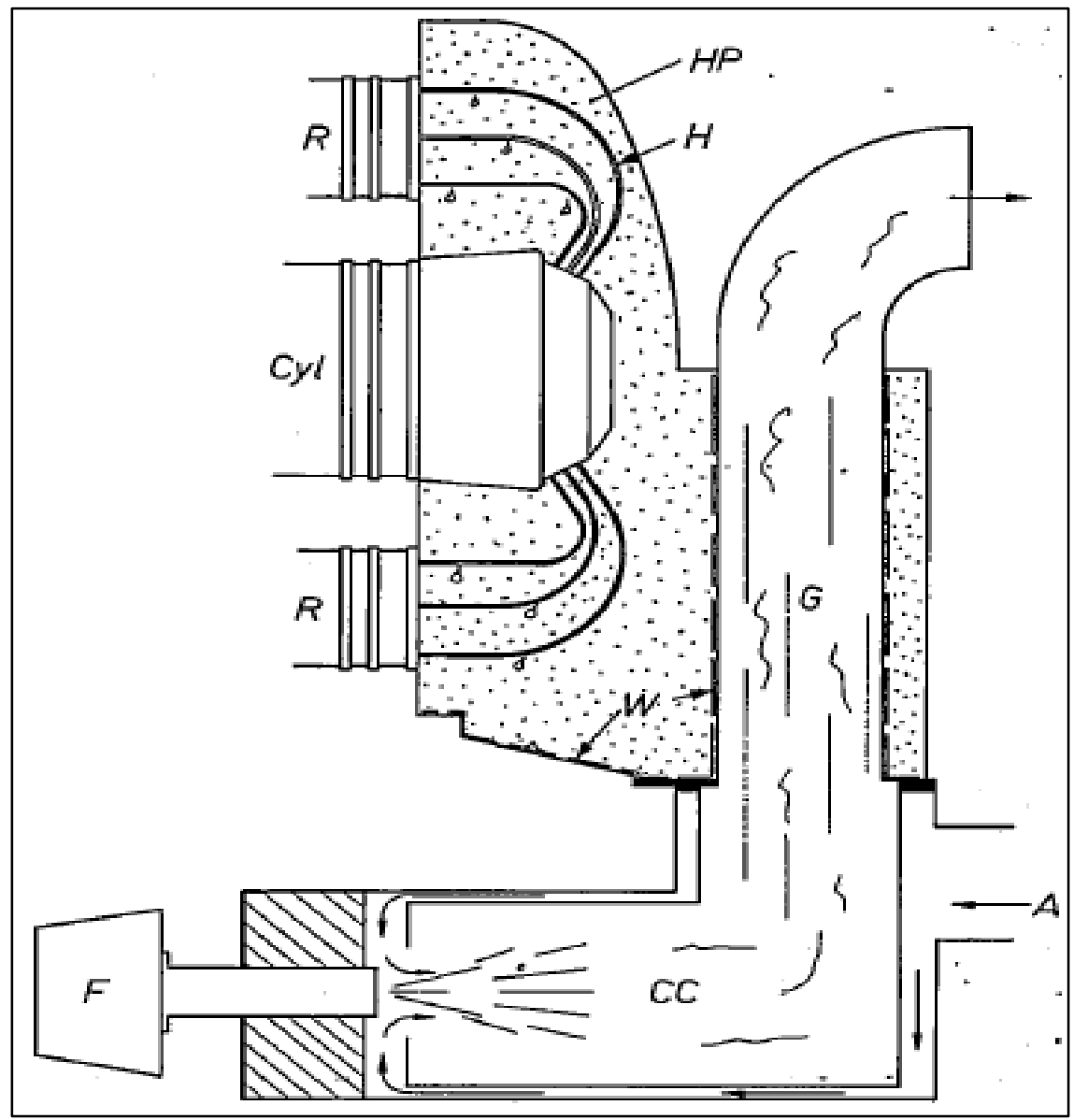

Figure 4.4 Indirect Heating of Stirling Engine Using Heat Pipe as Heat Flux Transformer [14]

- Nuclear Reactor: A model similar to space power application has been proposed to embed heat pipe inside the nuclear reactor to remove heat efficiently. An Encapsulated Nuclear Heat Source (ENHS) having solid core has been studied from which the heat is removed using alkali metal heat pipe. The heat pipe can work continuously for 20 years without refueling and the delivery 
temperature will also be high. This heat pipe uses sodium as the working fluid operating at about $1300 \mathrm{~K}$ at maximum limit. Since the working fluid is an alkali metal so the corrosive environment is avoided even at $550^{\circ} \mathrm{C}$ temperature. The heat pipe extends from the solid core to the area of low temperature where the coolant flows and the working fluid is condensed. The core has fuel rods which are embedded to heat pipes, the arrangement is such that for every 3 fuel rod 2 heat pipes operate. A solid core is formed by using metallic structure between the fuel rod and heat pipes. The crosssectional and axial view of the design is shown in Figure $4.5 \&$ Figure 4.6

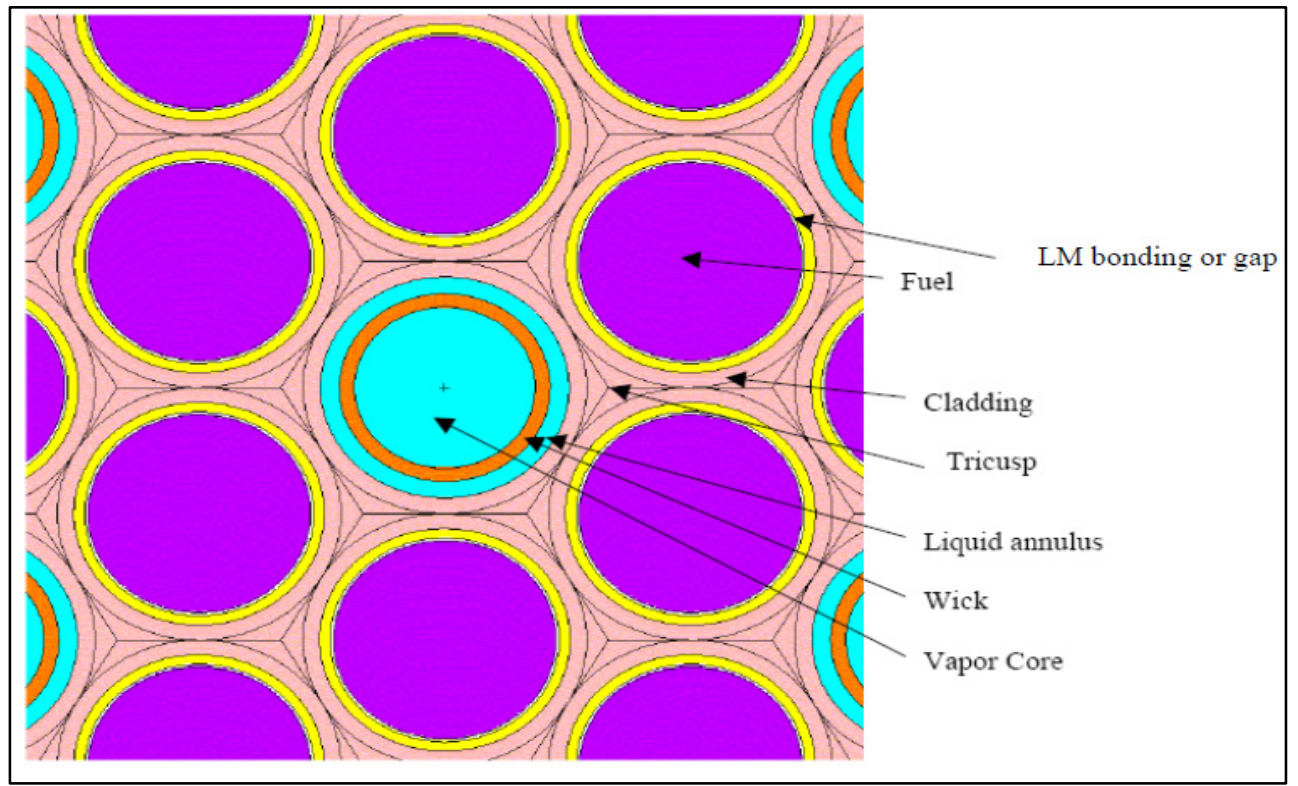

Figure 4.5 Cross Sectional View of Nuclear Core [36] 


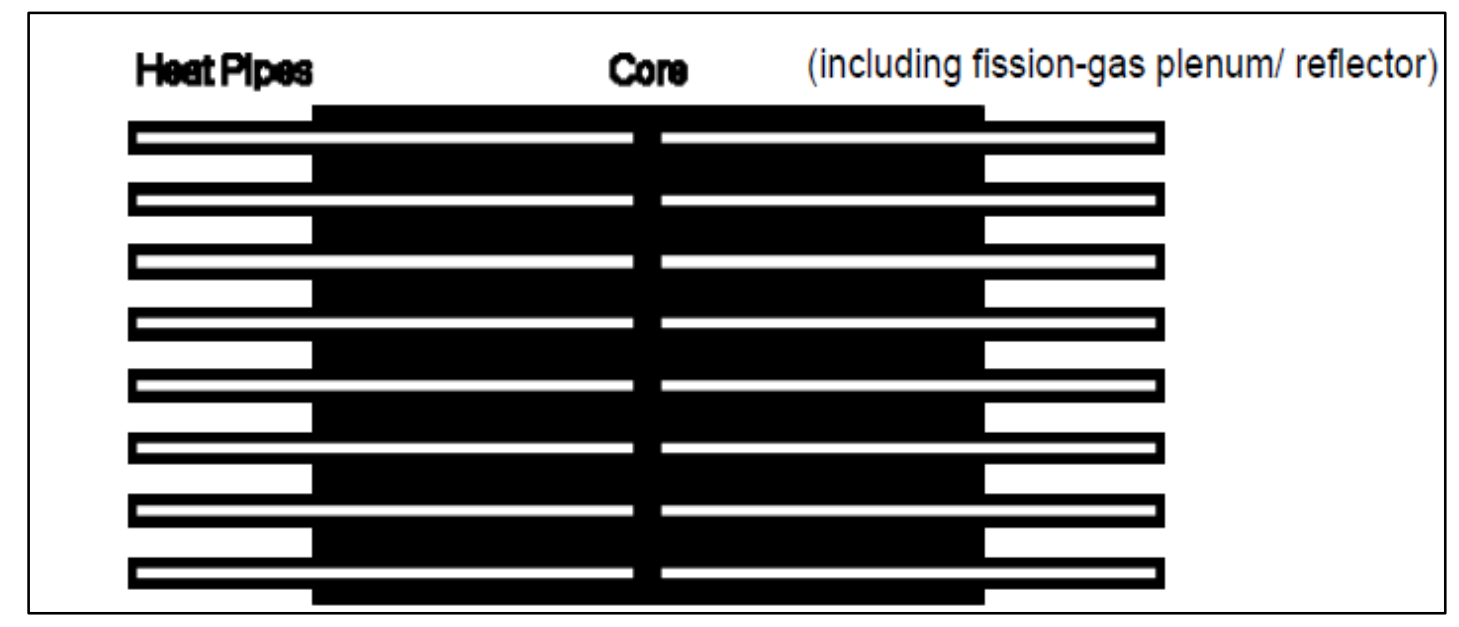

Figure 4.6 Axial Cut of Nuclear Core [36]

- Heat Pipe Embedded Drill: Drilling is one of the most complex machining operation and the continuous contact between the tool and the chip results in the production of excessive heat. The drill tip under continuous high temperature and pressure results in failure due to softening and development of thermal stresses. Coolant are needed to keep this temperature within the safety limit but it is necessary that the coolant should flow continuously, other than that its drainage and environmental issues are a topic of concern. So in order to remove the quickly generated at the tip, a model with heat pipe embedded at its center was created and was tested. The results were viable and opened the doors for the other machining operation to opt the heat pipe embedded technology. The model can be seen in Figure 4.7. [37] [38] [39] [40]

Some other applications of high temperature heat pipes are in:

- Rocket Nozzle

- Isothermal furnace liner

- High-tech electronics

- Annealing

- Crystal growth for materials 


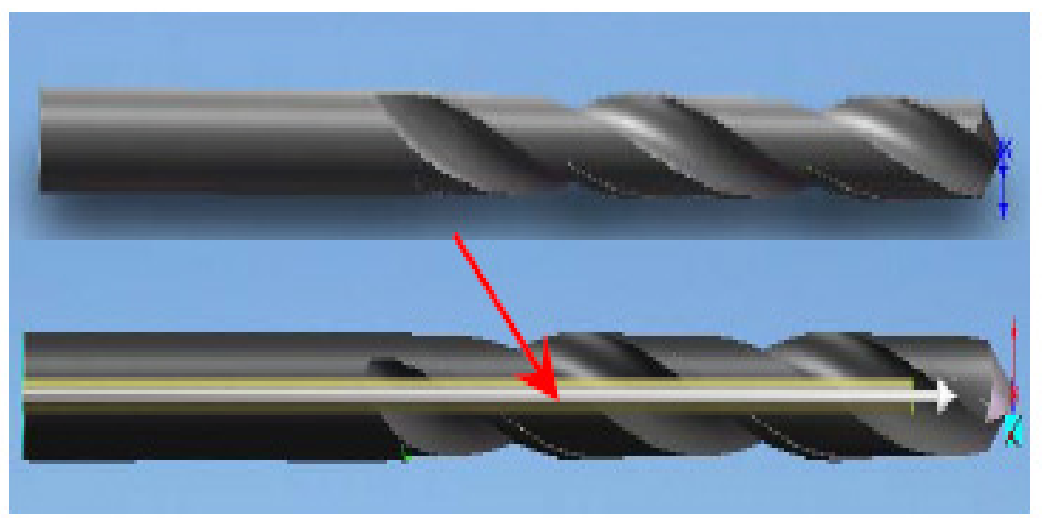

Figure 4.7 A Model Showing Drill with and without Heat Pipe [37]

\subsection{Problems}

Some of the concerns of a liquid metal heat pipe are:

\subsubsection{Start-Up}

The working fluid inside the alkali metal heat pipe under ambient conditions will be at the frozen state because of the high melting point. To startup the operation of the heat pipe it is necessary for the fluid to melt and thereby evaporate and fill up the pipe wholly as continuum flow. In practical it is a tough situation to handle because when the fluid at the evaporator end is heated initially it is in rarefied regime while as the fluid melts and its gets converted to vapor the state of continuum is attained. This process can be said to coexist at a particular time from the evaporator zone to the condenser zone until the entire heat pipe starts to operate at a steady state. [41] 
The startup time of the heat pipe is the time it takes form the supply of heat to the evaporator until the steady continuum state is obtained. This time interval is the submission of many time spans and various processes, and is calibrated using Knudsen criterion. Heat supplied to the evaporator can increase its temperature to a certain value, thereafter the state of constant temperature is obtained unless the axial temperature gradient to the condenser vanishes. Depending upon the amount of heat supply the process following this is predicted. [42]

It can be seen in Figure 4.8 that below a certain amount of heat startup process will not kick-off, and after it is triggered the combination of the time in three stage determines the total time needed to start up the heat pipe. First stage is the heat supply to the evaporator till the fluid melts and sonic vapor velocity is attained inside evaporator. Second is the time it takes from the evaporator front to condenser end cross-section to be in continuum state. Third stage is the time for the steady temperature throughout the entire heat pipe. This entire process of start-up can take up to several hours, some non-condensable inert gas is charged partially inside the heat pipe. [42] [43] 


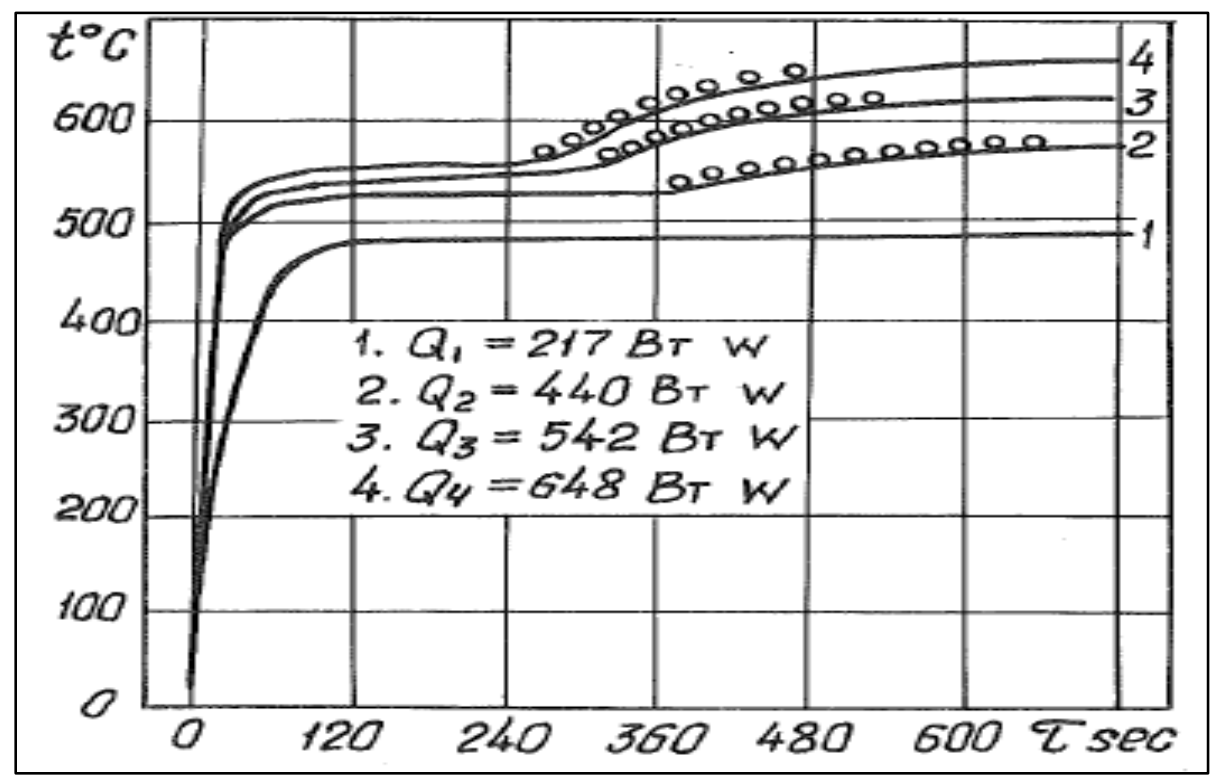

Figure 4.8 Sodium Heat Pipe Various Heat Input

It can be concluded that the heat pipe needs to be superheated by certain degrees to kick start the process but this superheating shouldn't be so high that the dry-out phenomena starts to occur in it. If the dry-out inside the heat pipe is triggered during start-up, then the operation will fail. It is necessary to supply adequate heat i.e. neither too much nor too less to carry out the operation successfully. The other methods are the modifications that can be made on account of heat pipe components like using screen wick with grooves and without grooves makes difference in start-up time. This is shown in the Figure 4.9. 


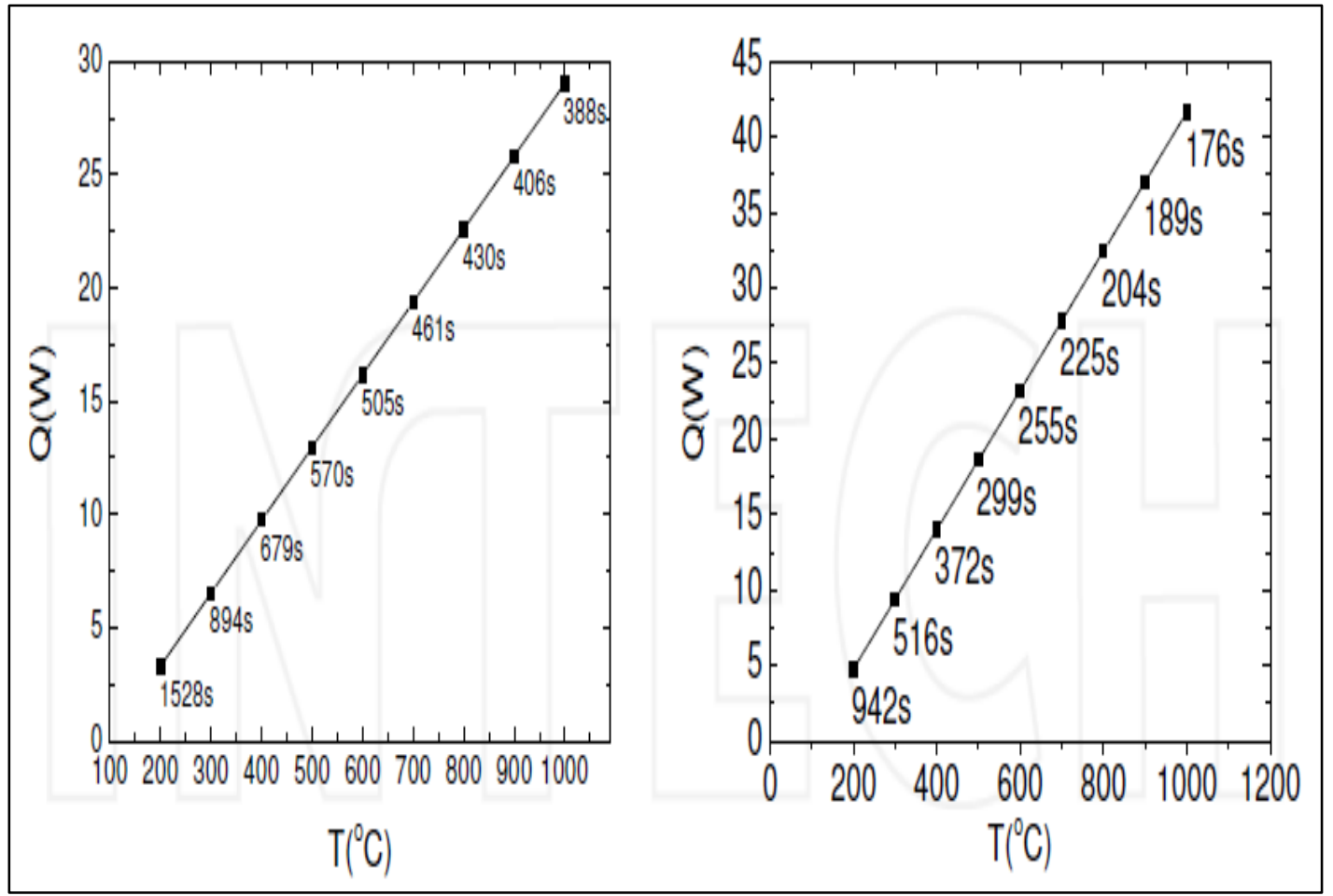

Figure 4.9 Comparison of Sodium Heat Pipe Startup Time with Different Wick Structures [19]

\subsubsection{Boiling Limit}

The boiling limit in the high temperature heat pipe can be observed since to start-up the heat pipe superheating is needed. Above a certain temperature or say applied heat, hot spots tend to grow in the device which results in the failure in the operation of the heat pipe. Hot spot or dry out process is not necessary dependent on the temperature rather it is dependent over the working fluid, the liquid-vapor interface radius and the radius of the wick. When the critical value of applied heat is reached the process of evaporation at the liquid-vapor interface is supplemented by the boiling phenomena due to the high temperature at the wall of the pipe. [44] 
Resultantly, fluctuations in temperature and pressure are seen in the heat pipe. This is because of the formation of vapor bubble tends to generate and destroy successful operation. Due to the vapor bubble formation the condensate gets restricted to flow back and the dry out inside the wick is observed. The temperature variation along the radial direction in a sodium heat pipe is shown in Figure 4.10

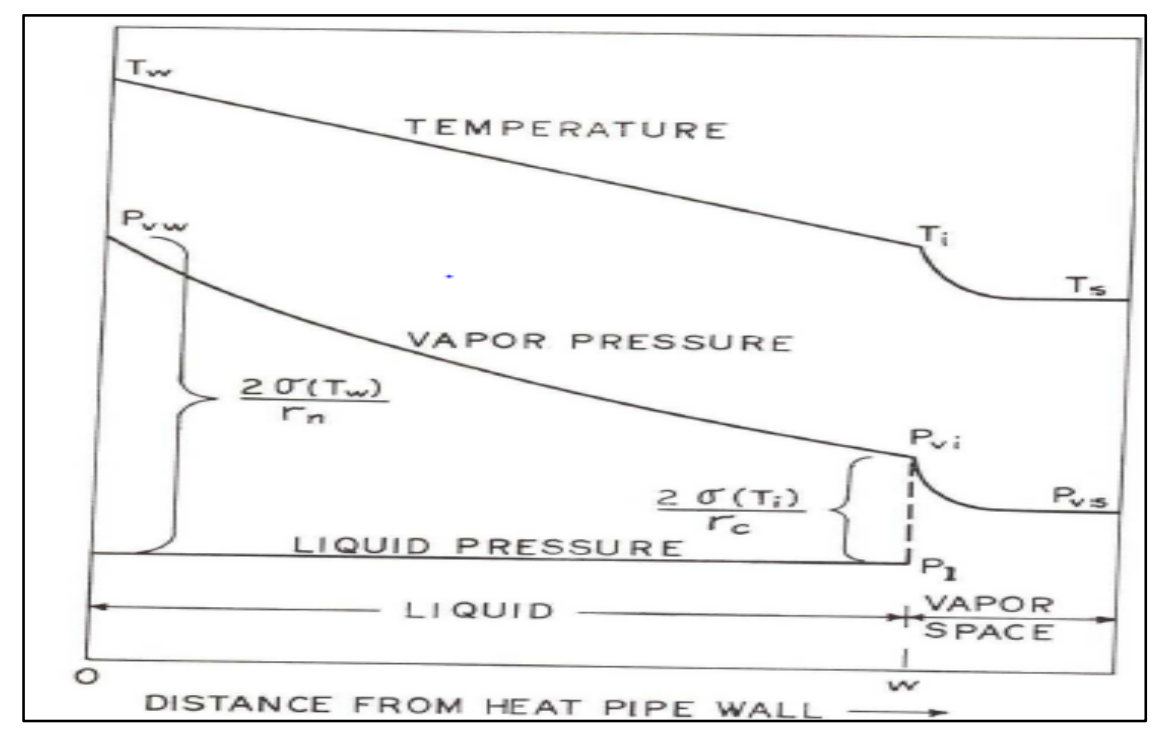

Figure 4.10 Temperature and Pressure Variation in Radial Direction [44]

Experiments have been performed on various alkali metal heat pipes revealing how much heat flux can be transferred before the boiling limit is triggered. According to an experiment, the boiling limit in potassium will not be reached unless the temperature is $1370^{\circ} \mathrm{F}$, while other experiment reveal that this limit come into view when the temperature 
ranges between $760^{\circ} \mathrm{C}-945^{\circ} \mathrm{C}$. Figure 4.11 reveals the result of the previous experiment. [25] [44] [45]

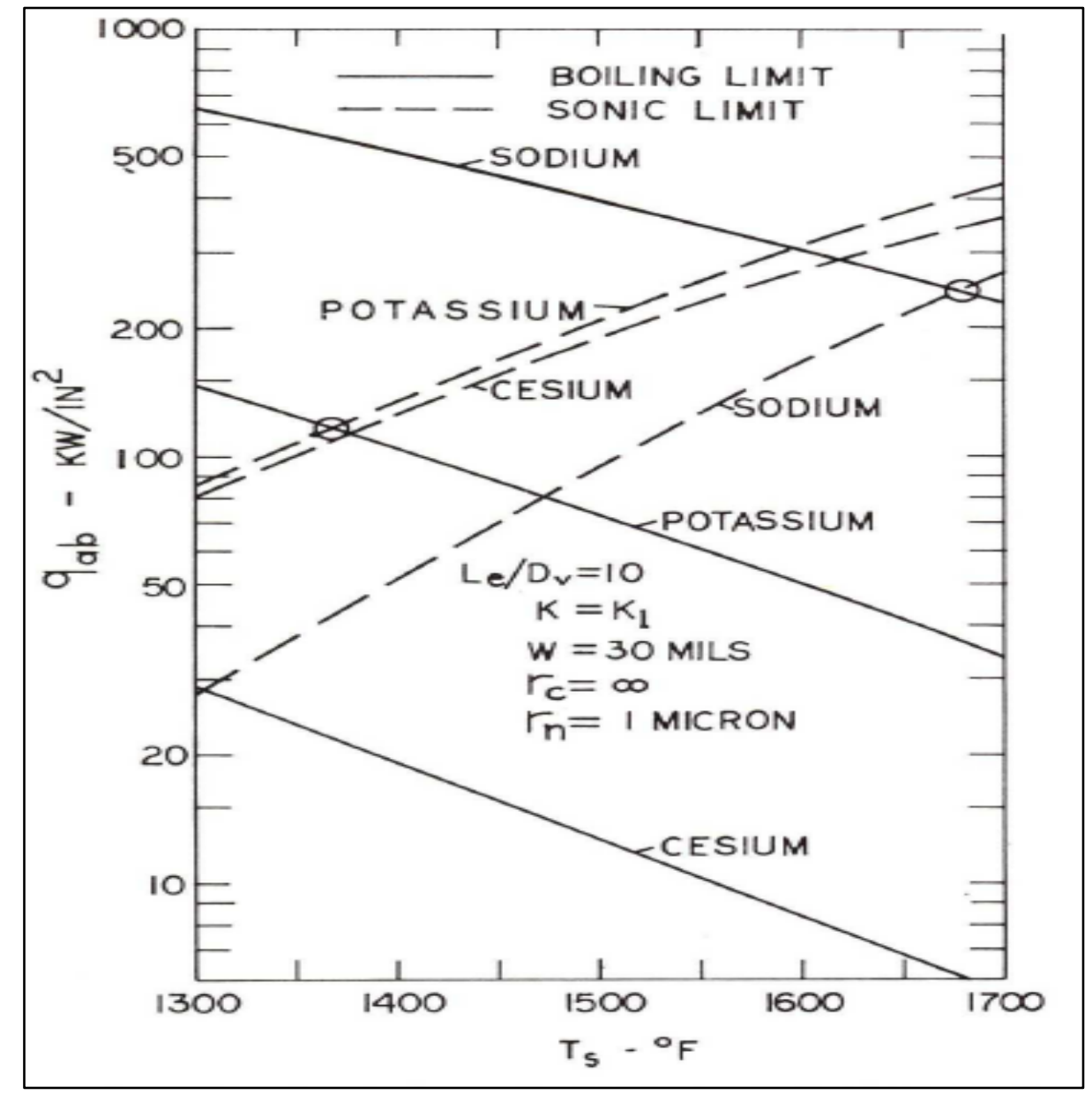

Figure 4.11 Incipient of Boiling Corresponding to Sonic Limit [44]

\subsubsection{Corrosion}

Since liquid metal heat pipes operate at high temperature the chances for the corrosion increases drastically and it may result in the reduced life of the heat pipe or in severe case result in the complete seizure 
of the operation. It has been found that environment plays a important role in determining the corrosion effect on the heat pipe. Among all the factors, presence of oxygen plays the most dominant role in this effect when the heat pipes were tested for sodium, potassium and lithium as working fluid for certain refractory materials.

The presence of the fluid in single phase is not as impactful as the presence of two phases. Condenser are more prone to solution attack, being solute free, which may lead to major depletion in the condenser section. The dissolved solute will tend to clog the wick and it may lead to the stoppage of operation. Other factor that needs to be given due concentration is the purity level of the liquid metal. The presence of impurity tends to accelerate the phenomena of corrosion. Complex oxides have been found to form at the reactive grain boundaries, which melts and penetrate deep into the material. [19] [46]

A point to be noted is that Indium, Lead and Thallium are not considered as good working fluids, though these are also liquid metals. The experiments performed over these fluids revealed that the corrosive attack is dominant and at such high temperature even 1000 hours of operation is not possible. Calcium is much better option for being considered as the working fluid in the heat pipes.

Same point can be made to the outer surface of the wall. If the wall is exposed to oxide formation, the corrosion will occur but till certain limit. Thereafter, the oxide layer will act as the anti-corrosive layer as can be seen in the case of aluminum. One process that has been seen to have 
remarkable effect is the micro-cell erosion. This erosion occurs if the material used is impure, and an electro chemical effect comes into view. The impurities have higher electrical potential that make them act as cathode while the pure metal act as anode. A combination of several such cathode and anode at micro level tend to cause severe corrosion. Figure 4.12 shows the electrochemistry involved in micro cell erosion.

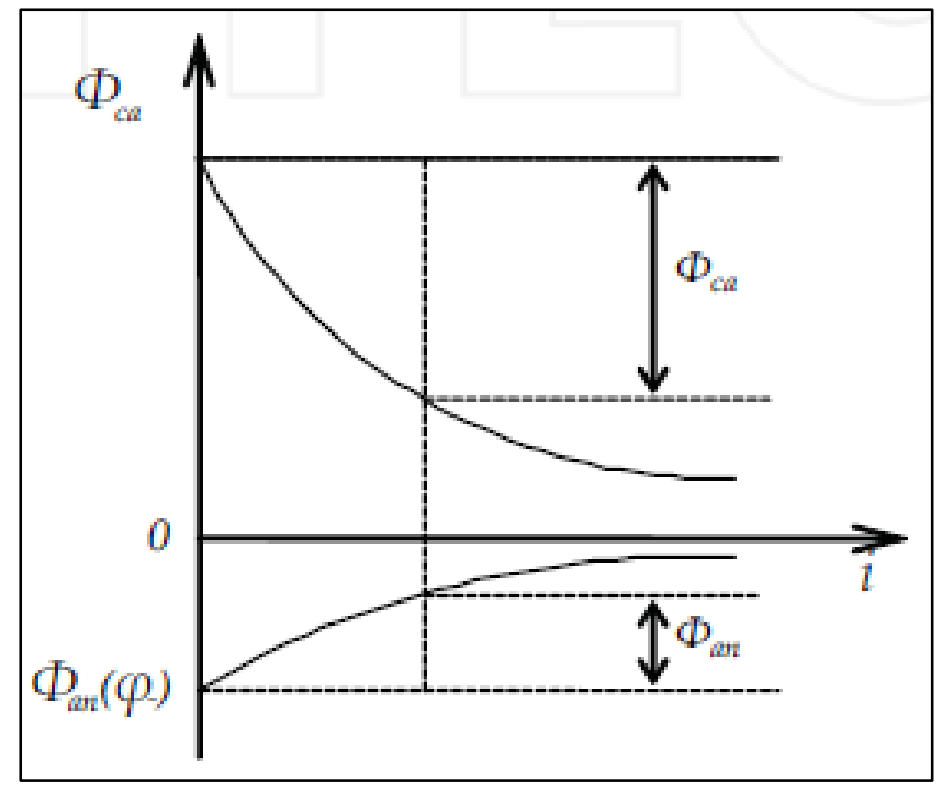

Figure 4.12 Electrochemistry of Micro Cell Erosion [19]

Other problems of the high temperature heat pipe are the sonic and viscous limitations, which have already been discussed. It is important to point out that sonic limitations are seen in liquid metal heat pipe and are rare phenomena in medium or low temperature heat pipes. At low operating temperature for alkali metal heat pipes viscous limit has been noticed to be dominant but it soon disappears as the temperature rises. 


\section{Chapter 5. Magnetohydrodynamic Effect}

The major equation involved in magnetohydrodynamics is NavierStoke's i.e. momentum equation, which has an extra term associated with it that was represented by the function $f$. This extra term in our analysis is of the Lorentz force, which always tends to drop the pressure and results in the performance degradation of the heat pipe. The work and progress have been done to reduce this damaging effect by developing and modifying the wick structure or by aligning the magnetic field parallel to the flow of liquid metal.

It has already been discussed that high temperature heat pipe has a important application for nuclear power fusion reactor i.e. to cool the blanket covering the fusion plasma. The plasma at the center is confined to its state using strong magnetic field. It can be seen in Figure 5.1 that liquid lithium is used as the coolant for the blanket, which is heated due to the neutron transfer of hot plasma through vacuum chamber. In order to provide uniform cooling process and accelerate it, liquid lithium is replaced by liquid lithium heat pipe, which is shown in Figure 5.2.

This chapter will deal with the MHD (Magnetohydrodynamic) effect on the flow of liquid metal inside the alkali metal heat pipes. It is evident that when the conducting fluid interacts with the magnetic field, the electricity is generated and electromagnetic force comes into existence that tends to change the velocity, pressure and other profile of the flow. This chapter is all about the physics involved in these processes. All these phenomena will be discussed and their effect will be presented. 


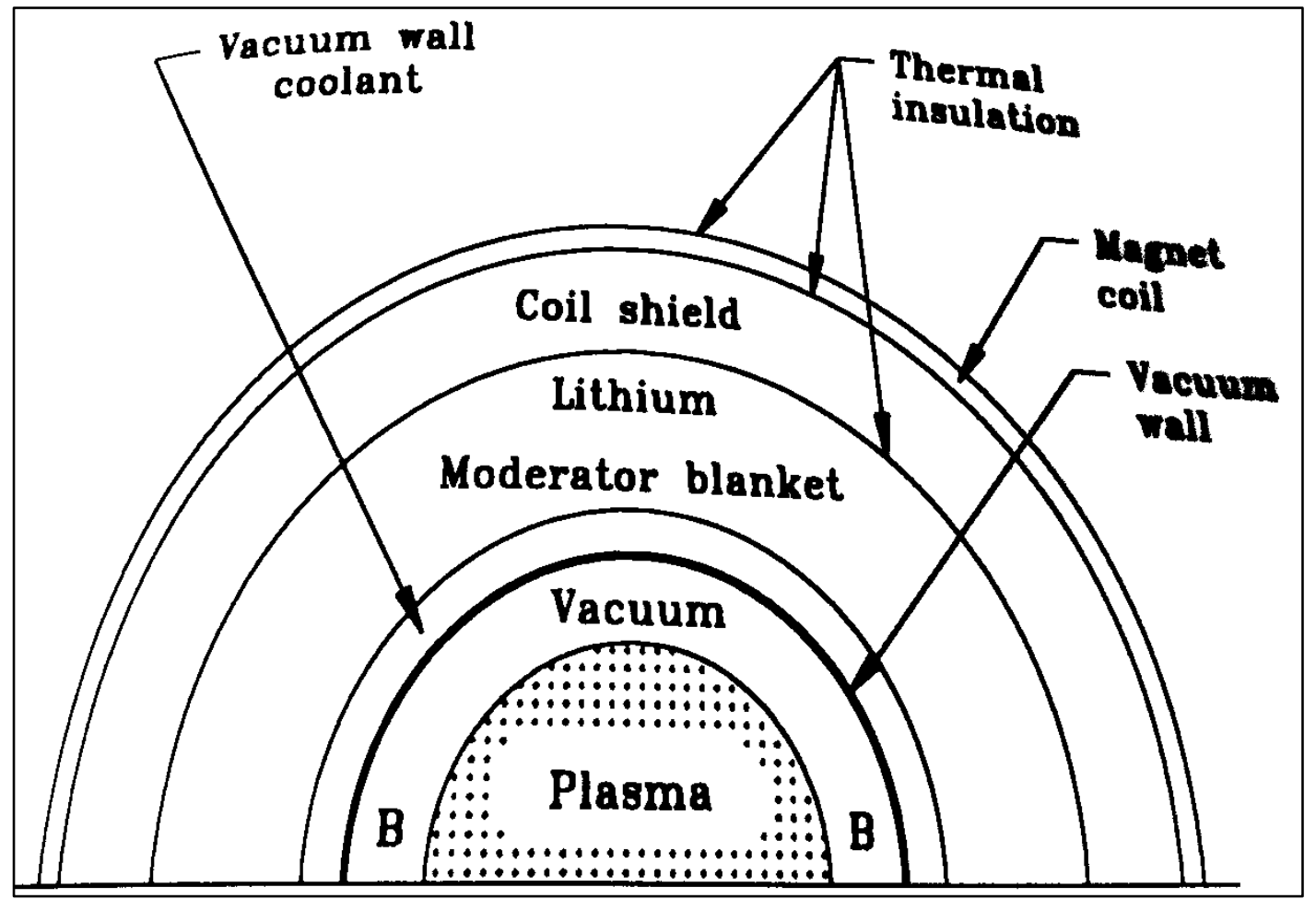

Figure 5.1 Schematic of a Nuclear Fusion Reactor [1]

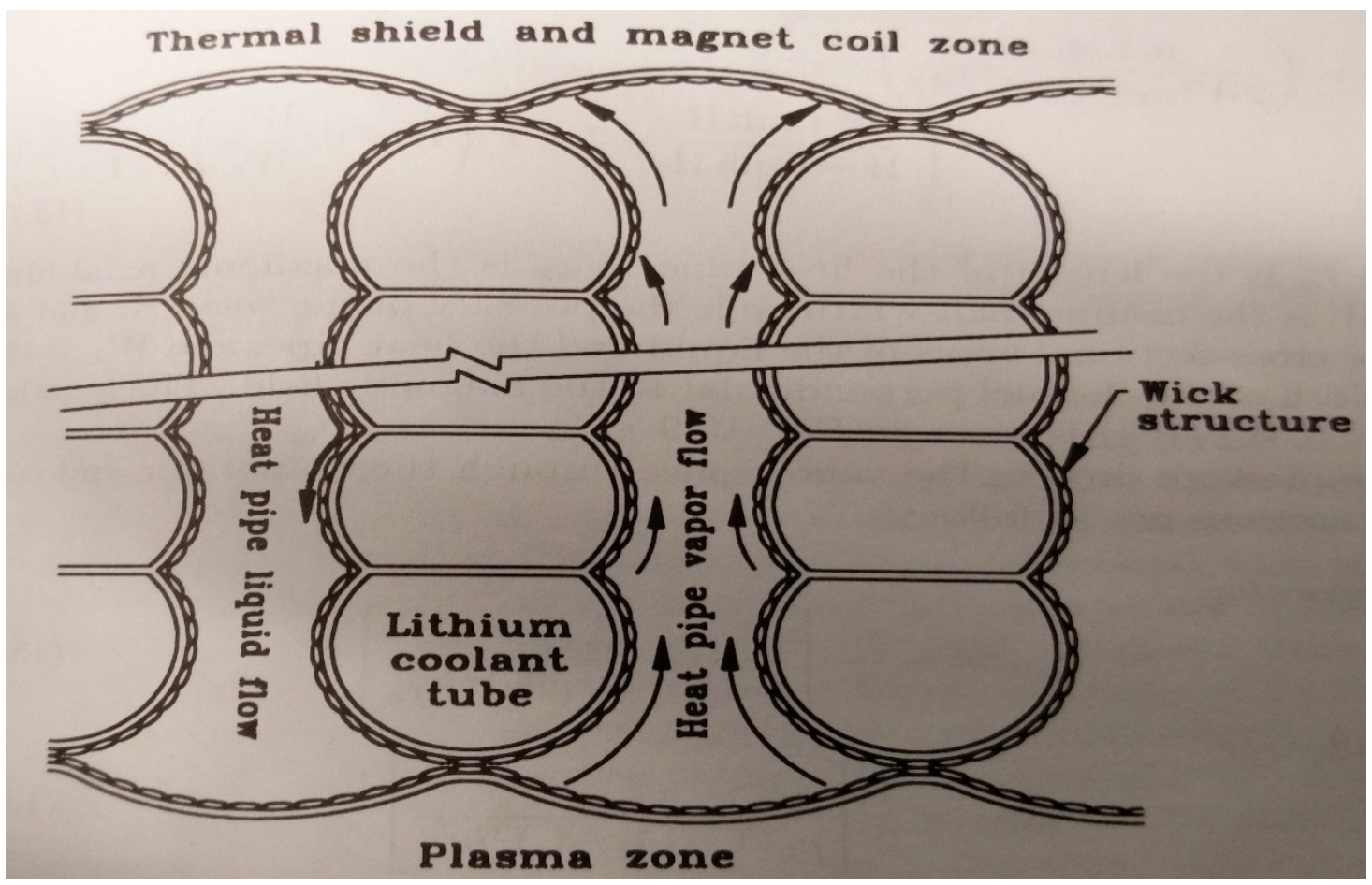


Figure 5.2 Liquid Metal Heat Pipe in Nuclear Reactor [1]

A number of experiments have been done to show the impact of the magnetic field in terms of pressure drop. One such experiment in the presence of uniform magnetic field was presented by Carlson and Hoffman in which they showed how the use of different wick results in the reducing the adverse effect of the magnetic field. Experiments have shown the difference in the maximum heat transfer ability in the presence and the absence of magnetic field. It was concluded that wall conductance and aspect ratio plays an important role in determining the pressure drop. [47] [48] [49] [50]. Maximum heat transfer capability as a function of aspect ratio in the presence and absence of magnetic field is shown in Figure $\mathbf{5 . 3}$

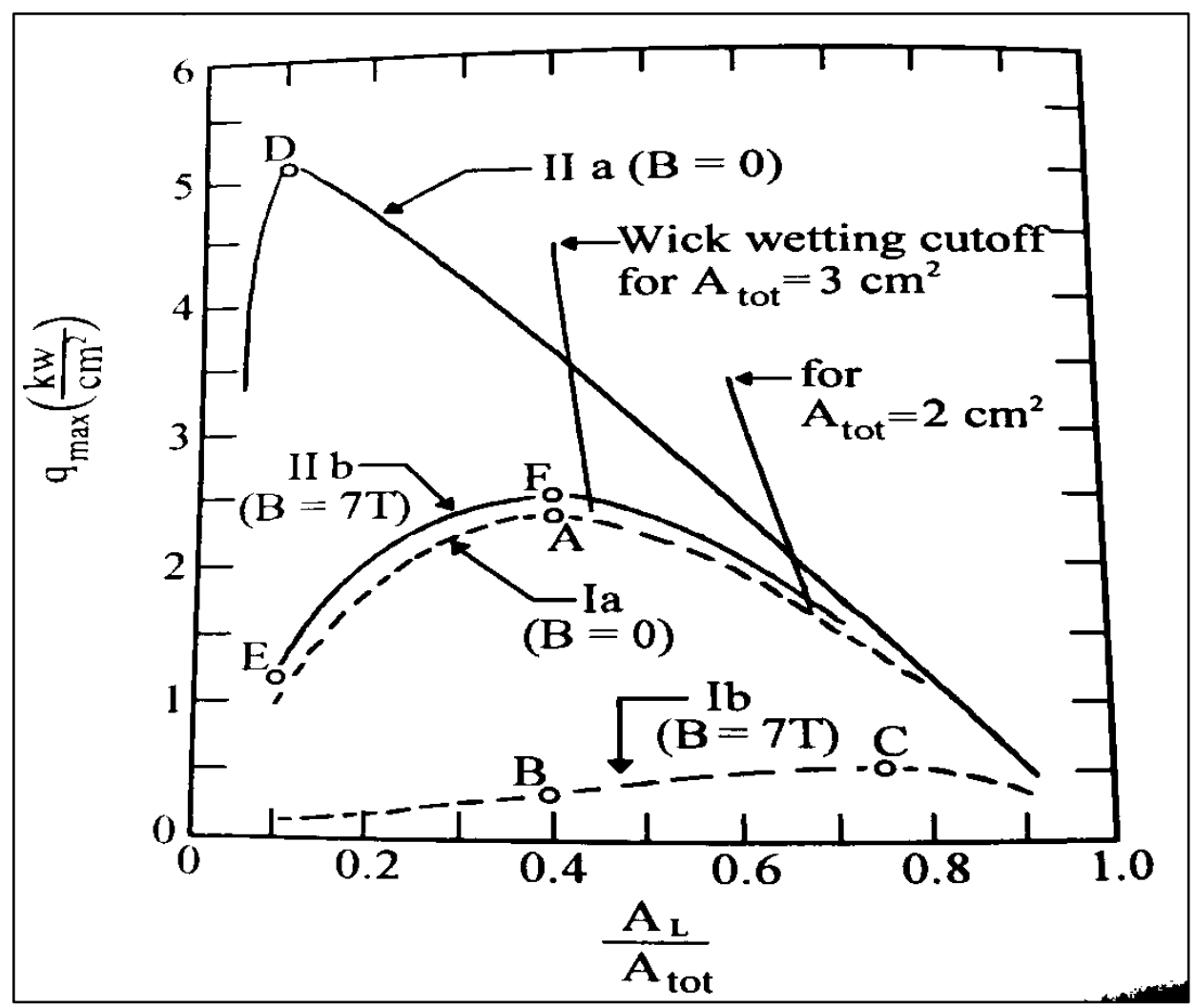


Figure 5.3 Effect of Magnetic Field on Heat Transfer Ability [1]

\subsection{What is MHD}

Magnetohydrodynamics is comprised of three technical words. Magneto, means relating to magnetic field, hydro means dealing with the fluid and dynamics means dealing with the force and its related laws. It can be summarized that MHD is the study of interaction between the electromagnetics and the electrically active fluids. In other words, the concept of MHD looks into the perspective of fluid motion as well as the electromagnetic effect involving Maxwell equations. MHD can be said to serve as the boundary line for hydrodynamics and electromagnetics but at the macroscopic level. It has nothing to do with the kinetic theory of gases nor does it involve electron theory. The microscopic study in this field is known as plasma physics. [51] [47]

\subsection{History}

Magnetohydrodynamic in itself seems to be a comparatively new field of study but its roots were planted as early as 1899 when sun was quoted as a giant magnet by Bigelow because of the resemblance of coronal plumes during solar eclipse. Hale in the year 1908 proved that sunspots are the source for powerful magnetic field as high as several thousand gausses. Though the study of MHD involves the use of Maxwell's equation but the actual effects has been in provision prior to that. The study of celestial body is the main cause for the interest in MHD 
during its early period but the experimental evaluation in the laboratory was never possible for such analysis.

A number of experimental results were produced during 1920's and 1930's, however, the revolutionary idea was put forward by Alfvén. He said that for a high electrically conducting medium the magnetic field freezes into the fluid. Nowadays this topic is of particular interest because of the use of liquid metal in the nuclear reactor fusion blanket as coolant. The presence of magnetic field on the liquid metal tends to bring out the magnetohydrodynamic changes and the same topic has been discussed in further sections. [47] [48]

Work has been done over the MHD study at the cosmic level and the study regarding the development of plasma flowing in the magnetic field. Nevertheless, the modern technology is more viable and interested in its effect over the liquid metal due to its increased usage either as coolant or as a working fluid inside the heat pipes.

\subsection{Physics of MHD Phenomena}

As stated earlier MHD involves the combination of Maxwell's equation, heat transfer equations and hydrodynamic (conservation of mass, momentum and energy) equations for the flowing fluid. The terms associated with all the equations tends to change and modify the entire phenomena. Any change either in electromagnetic parameters or in the thermal characteristic will be reflected as a deviation from the initial state. The major equations corresponding to electromagnetic part are majorly defined by modified Maxwell's equation since in this case the medium is 
moving so the stationary equations are not viable. Rather the modified combination of Maxwell equation \& Ohm's law comes into picture. Certain assumptions are made while solving the MHD equations:

- All the changes that occur at macroscopic level are considered, no kinetic theory or electron theory is accompanied

- Mainly the permeability of vacuum is used, because there is hardly any variation in relative permeability for liquid metals

- Extraneous emf is so small that it is not accounted for.

So out of the two halves, the electromagnetic equations are shown in (40), (41), (42), (43), (44) \& (45) which are basically the Ampere's law, Gauss law and Faraday's law. [52]

$$
\begin{gathered}
\operatorname{Curl} B=R e_{m} j \\
\operatorname{Curl} E=-\frac{\partial B}{\partial t}=-\mu_{o} \frac{\partial H}{\partial t} \\
\operatorname{div} j=0 \\
\operatorname{div} H=0
\end{gathered}
$$




$$
j=\sigma\left(E+\mu_{o}[V X H]\right)
$$

$$
\frac{\partial B}{\partial t}=\operatorname{Curl}(V X B)
$$

$\mathrm{J}=$ Current density, $\mathrm{H}=$ Magnetic field intensity, $\mathrm{B}=$ Magnetic field, $\mathrm{E}=$ Electrical field, $\mathrm{V}=$ Velocity of conducting fluid, $\mathrm{Re}_{\mathrm{m}}=$ magnetic Reynold's number and $\mu_{\mathrm{o}}$ is magnetic permeability.

$\mathrm{R}_{\mathrm{m}}$ is the magnetic Reynold's number which gives the relative effect of advection of the magnetic field in the conducting medium to the magnetic permeability.

The above-mentioned equations belongs to the electromagnetic half, the other half part will involve fluid mechanics. The principle equations to be used in hydrodynamic are the continuity and momentum equation.

The hydrodynamic equations are shown in equations (46), (47), (48) $\&(49)$

$$
\frac{\partial \rho}{\partial t}+\operatorname{div}(\rho V)=0
$$

For steady state flow, considering the fluid incompressible, the equation takes the following form

$$
\operatorname{div} V=0
$$




$$
\rho\left(\frac{\partial V}{\partial t}+(V \nabla) V\right)=-\nabla P+\eta \Delta V+F_{m}
$$

It should be noted that $F$ represents any external force that act on the fluid, it may be due to the compressibility of the fluid or the gravitation. In magnetohydrodynamics, this force includes the Lorentz body force.

$$
\rho C_{p} \frac{\partial T}{\partial t}=-\rho C_{p} V \nabla T+\operatorname{div}(X \operatorname{grad} T)+\frac{J^{2}}{I \sigma}+\frac{W_{f r}}{I}
$$

$\eta \Delta V$ represents inertial frictional force, $\mathrm{J}^{2} / \sigma=$ power expended as joule heat, $\mathrm{W}_{\mathrm{fr}}=$ frictional work and $\mathrm{I}$ is the mechanical equivalent of heat.

It can be concluded that choosing the wick structure with low electrical conductance and manipulating the aspect ratio i.e. crosssectional area of heat pipe and liquid can reduce the pressure drop.

The next chapter will have the mathematical model that will include the principles discussed in this chapter and the representation to mitigate this pressure drop will be put into picture. 


\section{Chapter 6. Mathematical Model}

In the previous chapters, we have seen how a heat pipe operates, what are its limitations and advantages. Several advancements in its technology lead to the development of high temperature heat pipe which have now become an important commodity for space applications, nuclear reactor etc.

The heat transfer ability of the heat pipe depends on the magnetic field strength and performance is reduced due to the interaction with the magnetic field. Experiments have been performed to reduce the pressure drop due to magnetic field lines, some of them are:

- Modification in the wick structure

- Varying the conductance of the wall

- Suppressing the magnetic field parallel to the flow of the fluid

- Varying the aspect ratio

None of the above method has ever been able to eradicate this problem. Compiling all the aspects discussed up-till now, we tried to develop the mathematical model, which will help in understanding the effect of magnetic field on operation.

\subsection{0ur Approach}

Firstly, the momentum equation considering the inclusion of magnetic field is found and then it is represented in characteristic form. 
The terms associated with fluid property and magnetic field might yield some parameters that can be varied to obtain the result of our expectation.

The interaction of the magnetic field with the electrically conducting fluid results in electromagnetic force and this force in proportional to the speed of motion of the fluid and the magnetic flux intensity. Corresponding to this an induced force also comes into view, which tends to act opposite to the actual force. A term known as magnetic Reynold's number determines how the flow pattern should be treated, which is the ratio of the induced magnetic field to applied magnetic field. The value of $\mathrm{Re}_{\mathrm{m}}$, is neglected as for most of the liquid metals its values is small $\left(\operatorname{Re}_{\mathrm{m}}<<1\right)$. The model is proposed by combining the Navier-Stoke's equation for the liquid metal with the Lorentz force that tends to drop the pressure. [53] [54] [55] [56]

Using Ohm's law, the current density $\vec{J}$ is defined as (50):

$$
J=\sigma(E+U X B)
$$

And the electromagnetic force due to this current density considering no electric field is given by (51)

$$
J X B=\sigma(U X B) X B=-\sigma(B . B) U+\sigma(U . B) B
$$

Since velocity and magnetic field are perpendicular to each to other, $\mathrm{U} \cdot \mathrm{B}=0$

$$
F_{m}=J X B=-\sigma B^{2} U
$$


Navier-Stoke's equation for the fluid flow is given as (52):

$$
\rho \frac{\partial U}{\partial t}+\rho(U . \nabla) U=-\nabla p+\mu \Delta^{2} U
$$

Magnetic equation corresponding to N-S equation is shown in (53):

$$
\frac{\partial B}{\partial t}+B(\nabla \cdot U)=\frac{1}{\mu \sigma} \nabla^{2} B+\mu(\nabla \cdot B)
$$

Which is used to find the strength of magnetic field to be applied and thereafter gives the value of current density.

Continuity equation for the fluid and magnetic flow are (54) \& (55):

$$
\begin{aligned}
& \nabla . U=0 \\
& \nabla . J=0
\end{aligned}
$$

The electromagnetic force term, which is a body force gets added to the N-S equation which has already been discussed and gives the following equation (56):

$$
\rho \frac{\partial U}{\partial t}+\rho(U . \nabla) U=-\nabla P_{n e t}+\mu \Delta^{2} U+J X B
$$

For steady state and neglecting smaller viscous terms, $\mathrm{k}^{*}=\mathrm{k}^{*} \mathrm{~h}$, $\mathrm{P}_{\text {net }}=P-2 \frac{\sigma_{t}}{r_{\text {pore }}}, \eta=\mathrm{y} / \mathrm{h}, \mathrm{P}^{*}=$ dimensionless pressure $=\mathrm{P} / \mathrm{P}_{\mathrm{o}}$ $\xi=\mathrm{x} / \mathrm{L}, \mathrm{U}^{*}=$ Characteristic velocity $=\mathrm{U} / \mathrm{U}_{\mathrm{avg}}, \sigma_{\mathrm{t}}=$ Surface tension $\mathrm{N} / \mathrm{m}$ 


$$
\begin{gathered}
\mathrm{Ca}=\text { Capillary number }=\frac{\mu U_{a v g}}{\sigma_{t}}, \mathrm{Ha}=\text { Hartmann Number }= \\
B_{\max } h \sqrt{\frac{\sigma}{\mu}} \\
\frac{d P_{\text {net }}}{d x}=\frac{P_{o}}{L} \frac{d P^{*}}{d \xi}-\frac{d k^{*}}{d \xi} \frac{\sigma_{t}}{h \cdot L}
\end{gathered}
$$

The equation will take the following form then,

$$
\frac{h^{2}}{\mu U_{\text {avg }}} \frac{1}{R e} \frac{P_{o}}{L} \frac{d P^{*}}{d \xi}-\frac{h^{2}}{\mu U_{\text {avg }}} \frac{1}{R e} \frac{d k^{*}}{d \xi} \frac{\sigma_{t}}{h . L}=\frac{d^{2} U^{*}}{d \eta^{2}} \frac{1}{R e}-\frac{H a^{2}}{R e} U^{*}
$$

On solving the characteristic equation, the pressure gradient is concluded to be dependent on Hartmann number and Capillary number. The final equation will take the following form (59):

$$
\frac{d P^{*}}{d \xi}-\frac{d k^{*}}{d \xi}=C a \frac{L}{h}\left(\frac{d^{2} U^{*}}{d \eta^{2}}-H a^{2} U^{*}\right)
$$

Hartmann number is a dimensionless number which represents the relative importance of viscous force to the magnetic force. Since the square of Hartmann number appears in the right hand side of the equation, it can be concluded that the combination of Navier-Stoke's and poison's equation will always have a term corresponding to $\mathrm{B}^{2}$. To have better understanding of this equation we need to break it in the form of characteristic equation.

From the above equation, it can be well understood that the pressure will always tend to decrease because of the negative term associated with 
Hartmann number. Since, this term is squared a normal mathematical formulation of the magnetic field will yield a positive value for $\mathrm{Ha}^{2}$.

It should be noted that we are just looking into the magnetic field, there is no electric field, hence, the interaction of magnetic, and electric field in our study is not viable.

\subsection{Magnetic Reynold's number}

$\mathrm{R}_{\mathrm{m}}$ is the magnetic Reynold's number which gives the relative effect of advection of the magnetic field in the conducting medium to the magnetic permeability.

$$
R e_{m}=\mu \sigma U h
$$

Magnetic Reynold's number in our study is considered to be negligible and it is a fair assumption. This is proved below:

For the heat flux transfer ' $\mathrm{q}$ ' of $126 \mathrm{~kW} / \mathrm{cm}^{2}$, the average velocity of flow inside the lithium heat pipe is $.1473 \mathrm{~m} / \mathrm{s}$.

$R e_{m}=\mu \sigma U h$, where $\sigma=2.13^{*} 10^{6} \mathrm{mho} / \mathrm{m}, \mu=4 \pi^{*} 10^{-7} \mathrm{~Wb} / \mathrm{A}-\mathrm{m}, \mathrm{U}=$ $.1473 \mathrm{~m} / \mathrm{s} \& \mathrm{~h}=.005 \mathrm{~m}$.

We get, $R e_{m}=1.976 * 10^{-3}$, which is a small quantity and can be easily neglected. So the limiting condition for Curl B in equation (40) can be rewritten as

$$
\operatorname{Curl} B=R e_{m} j \sim 0
$$


6.3Relationship between Magnetic Field and Magnetic Field Intensity

The relationship between magnetic field and its intensity is generally given by [52] [57] [58]

$$
B=H+4 \pi M
$$

$\mathrm{B}=$ Magnetic field induction, $\mathrm{H}=$ Magnetic field and $\mathrm{M}=$ Magnetization . $M=\chi H$, for liquid lithium at $1000^{\circ} \mathrm{C}, \chi=.75^{*} 10^{-8}$. The equation can be converted corresponding to weak magnetization, which is given by (62)

$$
B=\mu H
$$

\subsection{N-S Equation Analysis}

The characteristic form of MHD Navier-Stoke's equation as the following form. As we see the RHS of this equation, there is negative term associated with the Hartmann number. This negative is the reason for the pressure drop inside LMHP as in equation (59)

$$
\frac{d P^{*}}{d \xi}-\frac{d k^{*}}{d \xi}=C a \frac{L}{h}\left(\frac{d^{2} U^{*}}{d \eta^{2}}-H a^{2} U^{*}\right)
$$

When this term on RHS becomes dominant then a condition is reached when there is no fluid inside the wick because of inadequate capillary pressure to drive the flow. The situation is known as the dry-out, which can be expressed as in (63) 


$$
\frac{d P^{*}}{d \xi}-\frac{d k^{*}}{d \xi}=0
$$

In order for the above condition to occur following velocity profile needs to be satisfied.

$$
u=U_{\max }\left[\frac{e^{-2 H a}}{e^{-2 H a}-1} e^{H a \frac{y}{h}}-\frac{1}{e^{-2 H a}-1} e^{-H a \frac{y}{h}}\right]
$$

Keeping the above equation in mind, we will try to look into the impact on capillary limits for different parameters.

\subsection{Impact on Capillary Limit}

It can be understood from the equation (59) that the pressure drop is dependent upon two dimensionless number, Hartmann and Capillary. The best way to analyze the impact on Capillary limit is to vary the parameters that will bring change in these numbers. So the three parameters that will be covered for analysis are:

- Magnetic field

- Heat flux

- Temperature

\subsubsection{Impact of Magnetic Field}

Hartmann number is defined as $H a=B h \sqrt{\frac{\sigma}{\mu}}$, and in the characteristic equation we can see the pressure drop is dependent upon the square of the magnetic field, so the variation in the pumping ability of the 
heat pipe will vary as the square of the magnetic field. It can be seen in the plot Figure 6.1 that without the magnetic field the scaled value of pressure drop is positive, or we can say that capillary phenomenon is dominant in this domain. As soon as the magnetic field is applied the value scaled value suddenly drops to negative value and with much higher magnitude. It can be said that the second term on the RHS of $\frac{d P^{*}}{d \xi}-\frac{d k^{*}}{d \xi}=C a \frac{L}{h}\left(\frac{d^{2} U^{*}}{d \eta^{2}}-H a^{2} U^{*}\right)$ becomes dominant or in other words, magnetic field effect is dominant over the pumping ability of the heat pipe. As the temperature is increasing though, the impact of reduces considerably. It is better to operate such heat pipes at higher temperature.

There is an indifferent behavior at about $600^{\circ} \mathrm{C}$, which is on account of the transitional change in viscosity at this temperature which can be seen in Figure 6.2.

The parameters for the plots are:

$$
\mathrm{B}=.1 \mathrm{~T}, \mathrm{~L}=1 \mathrm{~m} \text { and } \mathrm{h}=.005 \mathrm{~m}
$$

It is important to note here that the negative value of the scaled pressure gradient doesn't mean that flow will stop, it signifies that the impact of the presence of magnetic field is far more dominant than the pumping ability. We don't have the exact value of the pressure gradient in the heat pipe it is needed to be scaled corresponding to dimensionless terms. 


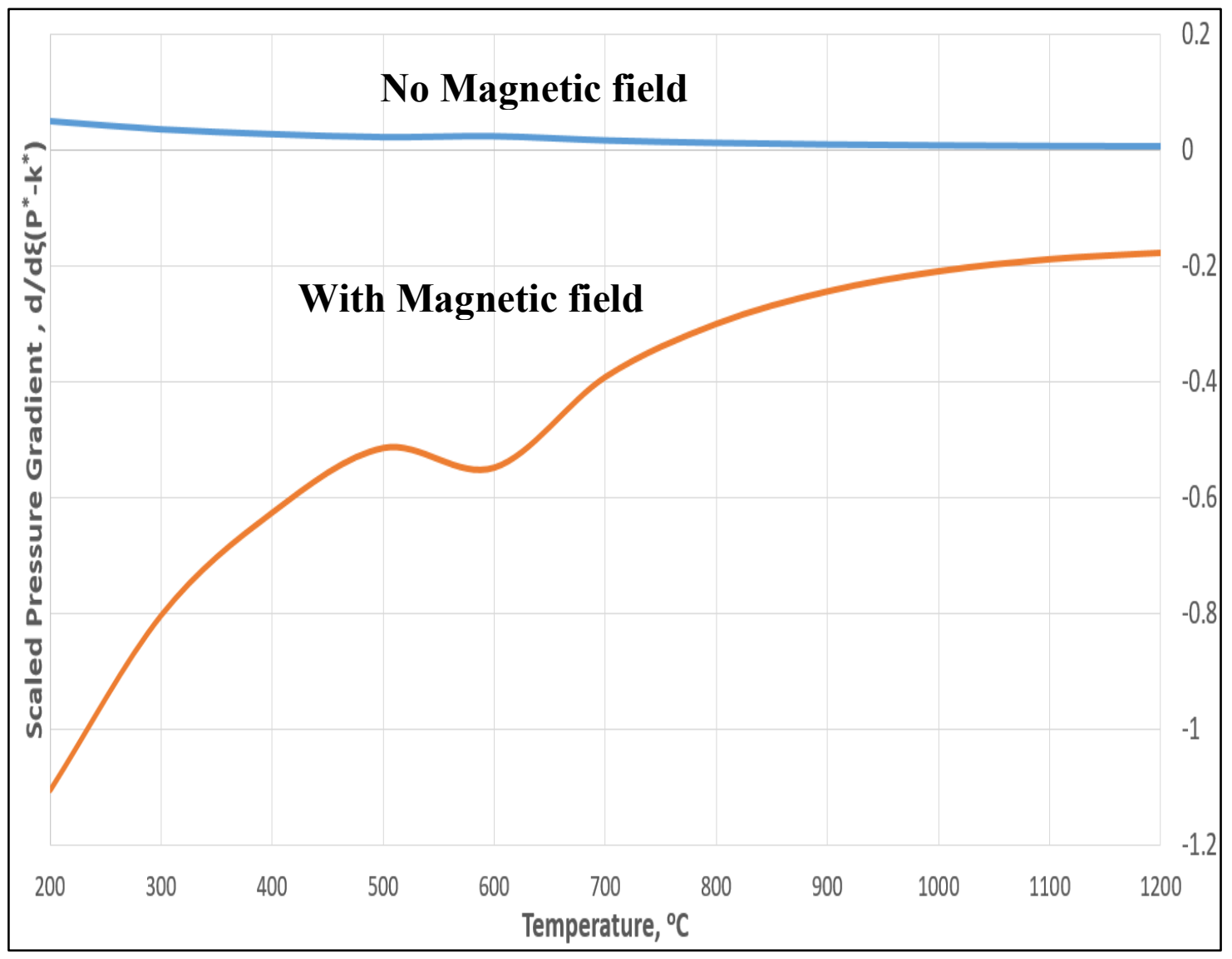

Figure 6.1 Impact of Magnetic Field on Capillary Limit

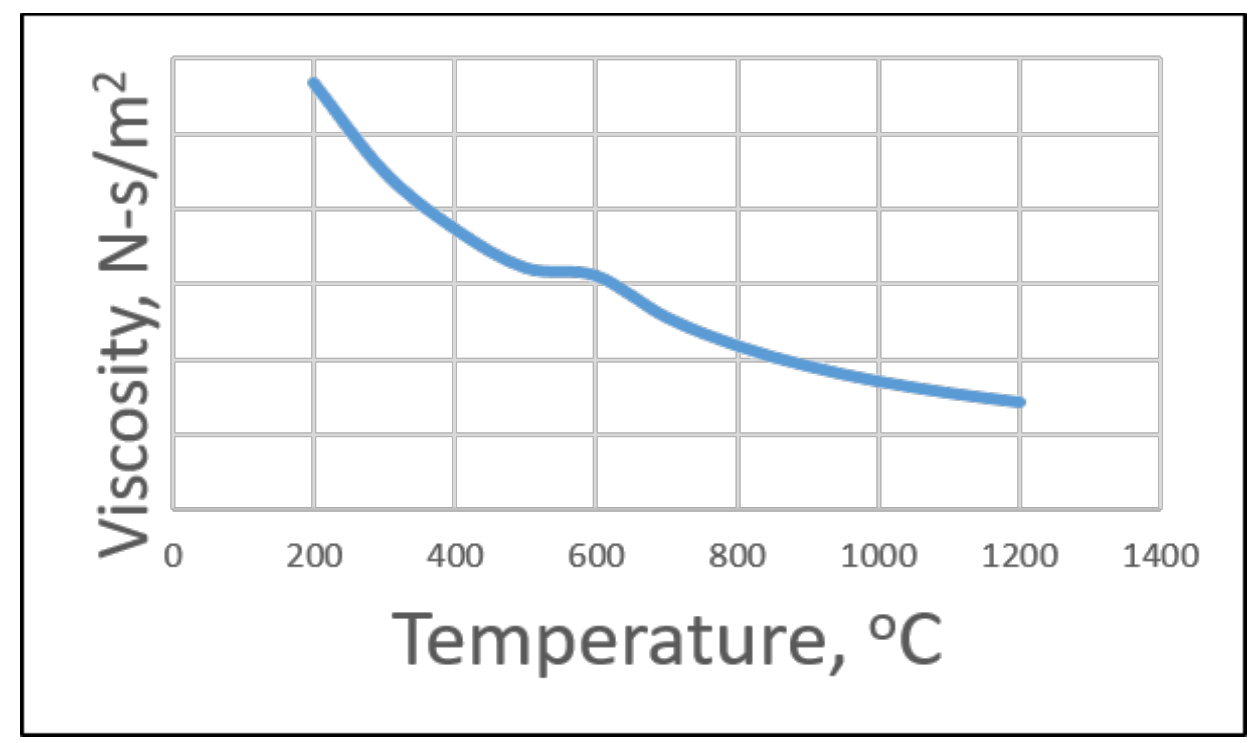

Figure 6.2 Effect of Temperature on Viscosity 
An important conclusion can be made from the above plots that the impact of magnetic field is so high that the first term on RHS of equation (59) can be neglected and the reduced form of equation is (65)

$$
\frac{d\left(P^{*}-k^{*}\right)}{d \xi}=-C a \cdot \frac{L}{h} H a^{2} U^{*}
$$

we will be analyzing the impact of capillary limit in terms of $C a \cdot \frac{L}{h} H a^{2}$

\subsubsection{Impact of Heat Flux}

Heat flux is the amount of heat per unit area being transfer though heat pipe. Since it is a passive device and all the operations involve phase change and there is the involvement of latent heat so the heat transfer ability of the device is high. The fluid inside the heat pipe is in continuous flow and it is the fluid in the form of vapor that carries the heat and the phenomena of heat transfer is advection, which is given by (58)

$$
q=h_{f g} v \rho
$$

Parameter varying with heat flux is velocity and it can be related to Ca. $\frac{L}{h} H a^{2}$ as

$$
\text { Ca. } \frac{L}{h} H a^{2}=\frac{\mu U_{\text {avg }}}{\sigma_{t}} \cdot \frac{L}{h} \cdot B^{2} h^{2} \frac{\sigma}{\mu} \propto U_{\text {avg }}
$$

I.e. this term is directly proportional to velocity and so we expect a linear relation between heat flux and $C a \cdot \frac{L}{h} H a^{2}$ which can be verified from 
the plot shown in Figure 6.3. The plot is shown on the log scale instead of the generalized linear result because the magnitude of the term corresponding to $\mathrm{y}$-axis varies hugely and the term plotted for $\mathrm{B}=.1 \mathrm{~T}$ seems to lies on $\mathrm{x}$-axis.

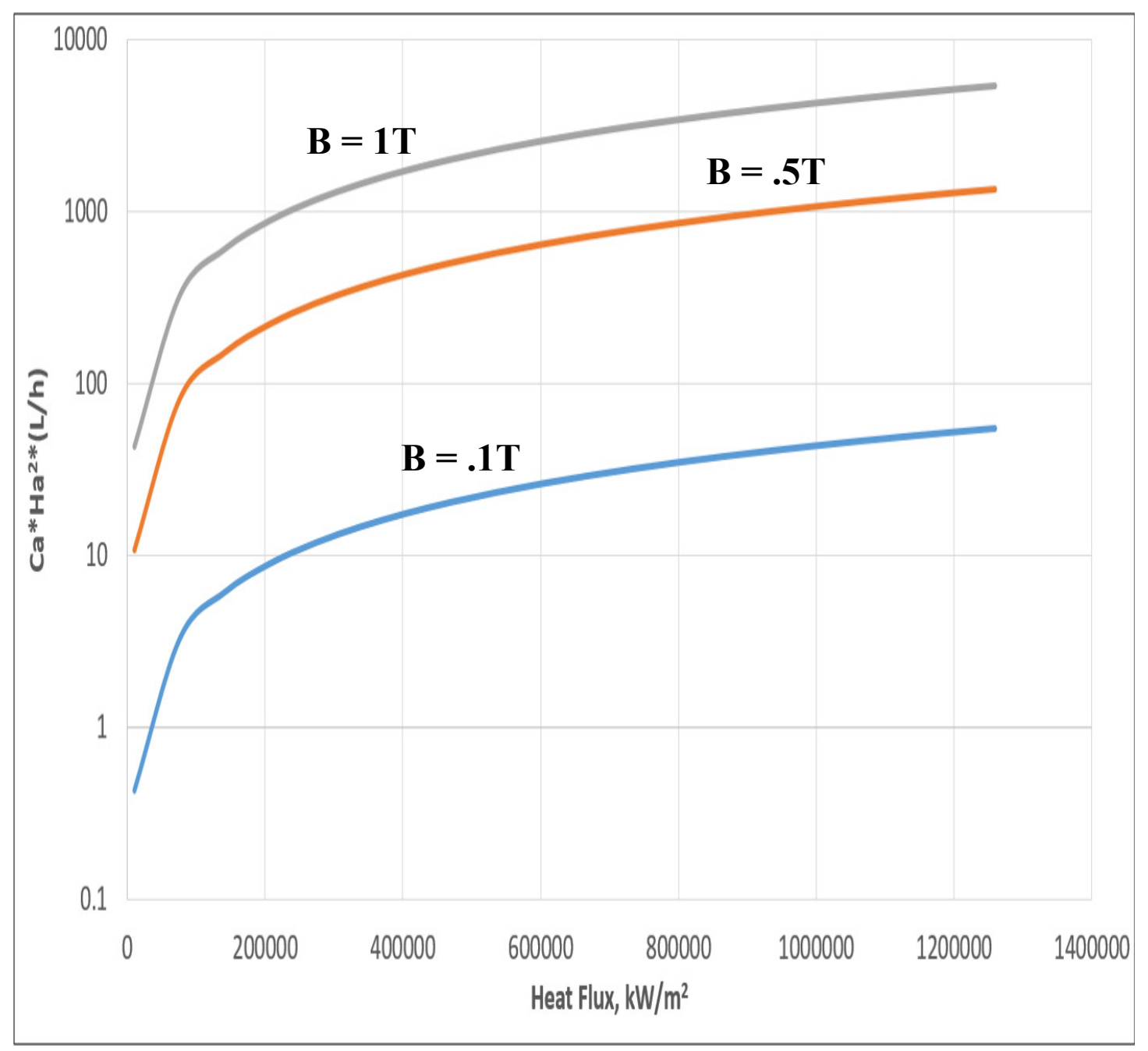

Figure 6.3 Impact of Heat Flux 


\subsubsection{Impact of Temperature}

Parameters that vary with temperature are:

- Viscosity

- Electrical Conductivity

- Surface tension

Viscosity appears in both Capillary number as well as Hartmann number, surface tension will bring the change in Capillary number while Electrical conductivity will result in the variation of Hartmann number. The plot for the impact of temperature is shown in Figure 6.4.



Figure 6.4 Impact of Temperature 
When we look into the plot we see that the impact of the temperature is almost negligible for the combination term of $\mathrm{Ca}, \mathrm{Ha}$ and $\mathrm{L} / \mathrm{h}$. The same result cannot be expected when these terms are plotted independently. A change in temperature from $200^{\circ} \mathrm{C}$ to $1200^{\circ} \mathrm{C}$ brings a variation of less than $10 \%$ for $\mathrm{Ca} \cdot \mathrm{Ha}^{2} . \mathrm{L} / \mathrm{h}$.

It can thereby be concluded that among three parameters (magnetic field, heat flux and temperature), magnetic field has the most considerable effect on the pumping limit of the heat pipe. 


\section{Chapter 7. Spatially Varying Magnetic Field}

We are now interested in seeing if a spatially varying magnetic field can be used to increase the capillary limit compared to that of the uniform magnetic field.

A case for the non-uniform magnetic field is chosen such that the magnetic field is gradually varying and is defined by (67):

$$
B=B_{x} e_{1}+B_{y} e_{2}
$$

Where, $\mathrm{B}_{\mathrm{x}}$ and $\mathrm{B}_{\mathrm{y}}$ both are the function of $\mathrm{x}$ and $\mathrm{y}$ respectively.

The magnetic field needs to satisfy the following boundary conditions at the pole faces of the bar magnet (68) \& (63)

$$
\frac{\partial B_{x}}{\partial x}+\frac{\partial B_{y}}{\partial y}=0
$$

$$
\frac{\partial B_{x}}{\partial y}=\frac{\partial B_{y}}{\partial x}
$$

The asymptotic expansion in terms of odd and even function is carried out by [59] takes the form as (65) \& (66).

$$
B_{y}=B_{y}(X, 0)-\frac{Y^{2}}{2 L^{2}} \frac{\partial^{2} B_{y}}{\partial X^{2}}(X, 0)+O\left(L^{-4}\right)
$$




$$
B_{x}=\frac{Y}{L} \frac{\partial B_{y}}{\partial X}(X, 0)-\frac{Y^{3}}{6 L^{3}} \frac{\partial^{3} B_{y}}{\partial X^{3}}(X, 0)+O\left(L^{-5}\right)
$$

The above solution is obtained after using $\mathrm{X}$ as characteristic length, $\mathrm{X}=\mathrm{x} / \mathrm{L}$. It can be understood looking into the above equation, the term $\mathrm{B}_{\mathrm{x}}$ can be made negative if the $2^{\text {nd }}$ term in the equation is made larger than the first term, which means

$$
\frac{Y}{L} \frac{\partial B_{y}}{\partial X}<\frac{Y^{3}}{6 L^{3}} \frac{\partial^{3} B_{y}}{\partial X^{3}}
$$

This condition was fulfilled with a minor assumption that the magnetic field strength at a distance $\mathrm{X}=\mathrm{R}$ is suddenly zero and the term involving y are considered to be constant.

This means that the variation of the magnetic field is at constant value of $y$, in the direction of $x$, which ultimately means that a point solution is achieved for such negative magnetic field.

Some other solutions were also looked:

1. $B=B_{o}\left(\sin (x) \cos (y) \hat{\imath}+f(y) e^{x} \hat{\jmath}\right)$

For this magnetic field to satisfy the limiting conditions,

$$
\begin{array}{r}
f(y)=e^{-e^{-x} y \cos (x)} \\
\text { 2. } \quad B=\left(e^{x} f(y) \hat{\imath}+M(x) e^{y} \hat{\jmath}\right) B_{o}
\end{array}
$$

After solving this equation we came across the following solution (58) 


$$
B=\left(e^{(x+y)}(-\hat{\imath}+\hat{\jmath})\right) B_{o}
$$

Where $\mathrm{B}_{\mathrm{o}}$ is a constant and is dependent upon the strength of the magnetic field applied. So in this case any random combination of value of $\mathrm{y}$ and $\mathrm{x}$ can be chosen to solve for $\mathrm{B}$.

In our analysis we will be fixing the values of $y$ as .005 since there is no fluid at the center of the heat pipe. The fluid is always present at the periphery of the device. In our previous analysis we saw that Hartmann number is constant at particular temperature but, in this case the Hartmann number will vary spatially and we can call it local Hartmann number $\left(\mathrm{Ha}_{\text {local }}\right)$.

We will now see how this local Hartmann number vary with the position. The magnitude of the magnetic field for (58) can be written as (58)

$$
|B|=\sqrt{2}\left(e^{x+y}\right) B_{o}
$$

Where, $\mathrm{B}_{\mathrm{o}} / \sqrt{2}=.1 \mathrm{~T}, \mathrm{y}=.01 \mathrm{~m}$ and $\mathrm{L}=1 \mathrm{~m}$

The plot shown in Figure 7.1 is for different temperatures and it can be seen that as the temperature increases the local Hartmann number also increases. 


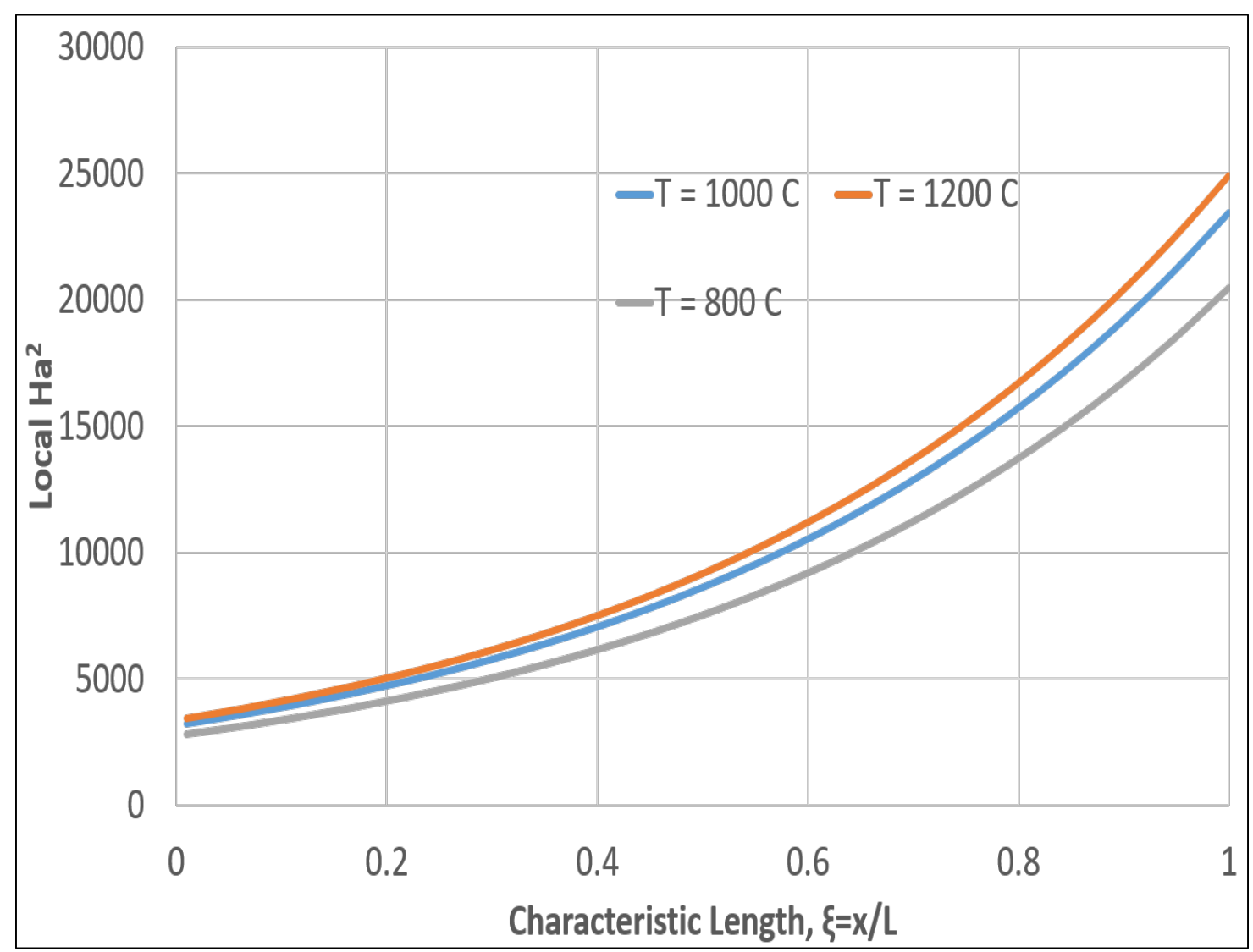

Figure 7.1 Variation of Local Hartmann Number Spatially

It will now be interesting to see how the combination of Ca. $\frac{L}{h} H a^{2}$ behave for this non-uniform field. The graph will be compared with the result obtained for the pressure drop with uniform magnetic field. The plot is shown in Figure 7.2. 


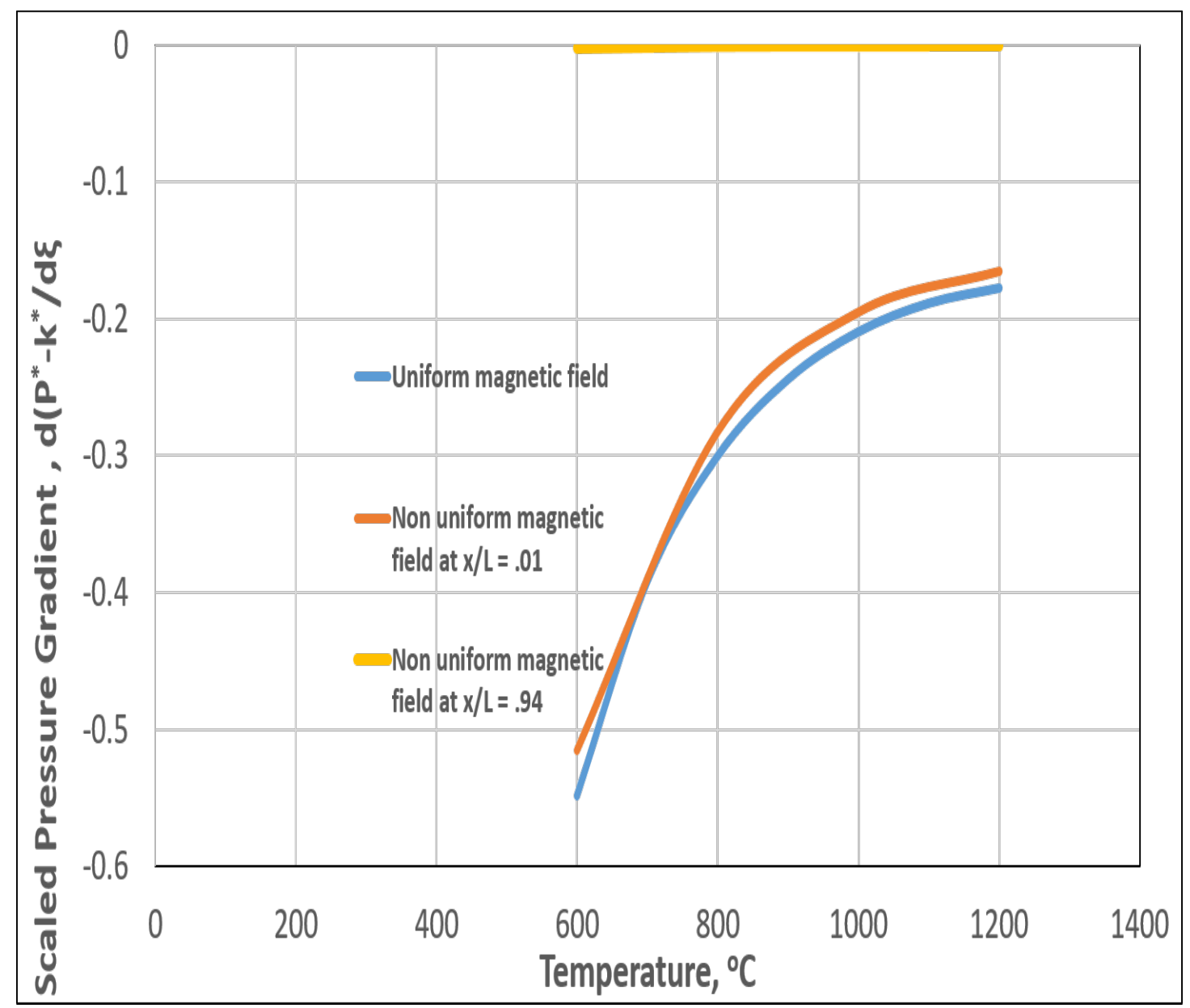

Figure 7.2 Comparison of Uniform and Non-Uniform Magnetic for the Impact on Capillary Limit

It can be clearly seen that at the initial stage the pressure drop for uniform and non-uniform is similar but as the field moves axially the drop starts to decrease and the end of the heat pipe it is almost zero. The reason is the exponential spatially varying magnetic field. It will interesting to see how will the pressure drop behave with different forms of non-uniform field. 


\section{Chapter 8. Results and Discussion}

This thesis started with the study of heat pipe, which was later converged to high temperature heat pipes. Then the study of specific type of heat pipe was carried out i.e. alkali metal heat pipes. This heat pipe uses liquid metal as the working fluid. An important aspect is the impact of magnetic field on the flow of liquid metal inside the heat pipe. This problem was seen because of the usage of LMHP for cooling nuclear reactor core, where the device is exposed to direct magnetic field.

The impact of magnetic field on the flow of liquid metal needed the research about MHD, under which the interaction of magnetic field and conducting fluid is studied at macroscopic level. The concept and all the basic principles involved were presented and thereafter a mathematical model using Navier-Stoke's and Poison's equation was proposed.

The mathematical model looked into the root cause for the pressure drop inside the heat pipe, and it was found that a body force known as Lorentz force tends to create the pressure drop. The impact of magnetic field, heat flux and temperature over the pumping ability of the heat pipe was analyzed. It was found that the magnetic field has the most considerable effect on the performance of the heat pipe, while temperature doesn't seem to make much of the difference.

Thereafter, an analysis was performed to see if the modification of the magnetic field can increase the capillary limit over with the uniform field. So a exponentially spatially varying magnetic field was proposed and 
its impact on the local Hartmann number and pressure drop was projected. It was found that as the temperature increases the local Hartmann number also increases. On the other hand, when the impact of uniform and nonuniform magnetic field were considered, non-uniform magnetic resulted in the better performance of heat pipe and it kept on getting better along the axial direction.

The findings of the study can thereby be concluded as:

- Liquid metal heat pipes are prone to several problems and limitations, but the major area of study for modern technology is the impact of magnetic field on the flow of fluid in the pipe

- The pressure drop inside the LMHP is on account of the Lorentz force which is the result of the combination of ohm's and faraday's law

- Magnetic field presence has the most considerable impact on the capillary limit of the heat pipe

- Capillary limit can be altered by the modification in the magnetic field

- Exponential non-uniform magnetic field tends to improve the performance of heat pipe over the uniform one

- It is not possible to completely eradicate the impact of magnetic field using steady magnetic field

The motive of the work is to analyze the impact of various parameters that could result in the pumping ability degradation of LMHP 
and thereafter, a study to reduce this impact was presented in the form of mathematical equation.

The scope for the future studies of our work:

- The impact of electrical field is not considered; thus a study needs to be done if the inclusion of electric field can defy our findings

- The experiments can be done and the data gathered can be compared to our results

- It will be interesting to see if any magnetic field can be developed that instead of pressure drop, results in flow enhancement

- The impact of time varying magnetic field can be done

The result of the study provides an insight on MHD applied to LMHP. 


\section{REFERENCES}

[1] A. Faghri, Heat Pipe Science and Technology, Washington, DC: Taylor \& Francis, 1995.

[2] D. Reay and P. Kew, Heat Pipes: Theory, Design and Application, 5 ed., Oxford: Butterworth-Heinemann, 2006.

[3] S. W. Chi, Heat Pipe Theory and Practise, USA: Hemisphere Publishing and Corporation, 1976.

[4] G. P. Peterson, An Introduction to Heat Pipes: Modeling, Testing and Applications, New York City, NY: John Wiley \& Sons, Inc, 1994.

[5] A. Faghri, "Heat Pipe: Review, Opportunities and Challanges," Frontiers in Heat Pipe, vol. 5, no. 1, 2014.

[6] M. S. El-Genk and J. M. P. Tournier, "Uses of Liquid-Metal and Water Heat Pipes in Space Reactor Power Systems," Frontiers in Heat Pipe, vol. 2, no. 1, 2011.

[7] C. C. Silverstein, Design and Technology of Heat Pipes for Cooling and Heat Exchange, Abingdon: Taylor \& Francis, 1992.

[8] T. J. Dickinson, Writer, Performance Analysis of Liquid Mteal Heat Pipe for Space Shuttle Experiment. [Performance]. Air Force Institute of Technology, 1996. 
[9] A. W. Adamson and A. P. Gast, Physical Chemistry of Surfaces, New York CIty, NY: John Wiley \& Sons, 1990.

[10] G. M. Grover, J. E. Kemmy and E. S. Keddy, "Advances in Heat Pipe Technology," in Thermionic Electrical Power Generation, Ispra (Italy), 1968.

[11] J. E. Deverall, J. E. Kemme and L. W. Florschuetz, "Sonic Limitation and Startup Problems of Heat Pipe," Los Alamos Scientific Laboratory, Los Alamos, NM, 1970.

[12] C. C. Silverstein, Design and Technology of Heat Pipes for Cooling and Heat Exchange, Washington, DC: Taylor \& Francis, 1992.

[13] D. A. Reay and P. Kew, "Heat Transfer and Fluid Flow Theory," in Heat Pipes: Theory Design and Applications, Oxford, OX, Butterworth-Heinemann, 2006, p. 61.

[14] G. A. A. Asselmen and D. B. Green, "Heat Pipes," Philips Tech Rev, pp. 104-113, 1973.

[15] Y. Cao and A. Faghri, "Closed-Form Analytical Solution of HighTemperature Heat Pipe Startup and Frozen Startup Limitations," Journal of Heat Transfer, vol. 114, no. 4, pp. 1028-1035, 1992.

[16] P. Namec, A. Ceja and M. Malcho, "Mathematical Model for the Heat Transfer Limitation of Heat Pipe," Mathematical and Computer Modelling, vol. 57, no. 1, pp. 126-136, 2013. 
[17] C. Busse and J. Kemme, "Dry-out phenomena in gravity-assist heat pipes with capillary flow," International Journal of Heat and Mass Transfer, vol. 23, no. 5, pp. 643-654, 1980.

[18] Wenwen Zhang; et al, "Preliminary Design and Thermal Analysis of a Liquid Metal Heat Pipe Radiator for TOPAZ-II Power System," Annals of Nuclear Energy, vol. 97, pp. 208-220, 2016.

[19] W. Qu, "Progress Works on High and Super High Temperature Heat Pipes," in Developments in Heat Transfer, Rijeka, Croatia, InTech, 2011, pp. 503-522.

[20] "Lithium Capillary System to Cool Wings on Re-entry," Flight International, vol. 168, no. 4998, p. 26, 2005.

[21] Peter Meisel; et al, "Material Selection, Manufacturing and Performance Testing of Ceramic High-Temperature Heat Pipes Using Liquid Metals as Working Fluids," Advanced Engineering Materials, vol. 16, no. 10, pp. 1243-1251, 2014.

[22] S. M. Geng and J. Zuo, "An Overview of Long Duration Sodium Heat Pipes," American Institute of Physics, Albuquerque, New Mexico, 2004.

[23] Thermacore, "Datasheet High Temperature Heat Pipes," ThermacoreINC, Lancaster, PA, 2008.

[24] Aavid Thermacore, "High-Temperature Thermal Management," Thermacore, 2010 .

[Online]. Available: 
http://www.thermacore.com/applications/high-temperature-heatpipes.aspx. [Accessed 22 Feb 2017].

[25] C. A. Busse and P. Vinz, "Axial Heat Transfer Limit of Sodium Heat Pipe between $25 \mathrm{~W} / \mathrm{cm} 2$ to $15.5 \mathrm{~kW} / \mathrm{cm} 2$," in International Heat Pipe Conference, Stuttgart, 1973.

[26] R. Shaubach, P. Dussinger and J. Bogart, "Boiling in Heat Pipe Evaporator Wick Structure," in 7th International Heat Pipe COnference, Minsk, 1990.

[27] H. Bolt; et al, "Heat Flux Experiments for Plasma-facing Applications," in 18th Symposium on Fusion Technology, Karlsruhe, August, 1994.

[28] M. A. Merrigan, E. S. Keddy and J. T. Sena, "Transient Performance Investigation of a Space Power Systems," in 2nd SP-100 Program Integration Meeting, Denver, Co, 1985.

[29] L. B. Lundberg and H. E. Martinez, "Fabrication of HighTemperature /1400-1700 K/ Molybdenum Heat Pipes," in Fifteenth Intersociety Energy Conversion Engineering Conference, Seattle, WA, 1980.

[30] M. S. El-Genk and J.-M. Tournier, "DynMo-TE: Dynamic Simulation Model of Space Reactor Power System with Thermoelectric Converters," Nuclear Engineering and Design, vol. 236, no. 23, pp. 2501-2529, 2006. 
[31] T. P. Cotter; et al, "Status Report on Theory and Experiments on Heat Pipes at Los Alamos," in European Nuclear Energy Agency and Institute of Electrical Engineers, London, England, 1965.

[32] J. E. Kemme, "Heat Pipe Capability Experiments," Los Alamos Scientific Lab, New Mexico, 1966.

[33] D. Liu and Y. Liu, "Heat Transfer Capability Simulation of High Temperature Heat Pipein Supersonic Vehicle Leading Edge Applications," Advances in Mechanical Engineering, vol. 8, no. 4, pp. 1-10, 2016.

[34] Y. Cao and F. A, "Conjugate Modeling of High Temperature Nosecap and Wing Leading Edge Heat Pipes," Journal of Heat Transfer, vol. 115, no. 3, pp. 819-822, 1993.

[35] J. M. Modlin, Writer, Hypersonic Aerospace Vehicle Leading Edge Cooling Using Heat Pipe, Transpiration and Film Cooling Techniques. [Performance]. Georgia Institute of Technology, June, 1991.

[36] E. Greenspan, "Solid-Core Heat-Pipe Nuclear Battery Type Reactor," University of California, Berkeley, CA, 2008.

[37] Lin Zhu; et at, "Investigation of Heat Pipe Cooling in Drilling Applications Part II: Thermal, Structural Static and Dynamic Analyses," in International Mechanical Engineering Congress and Exposition, Lake Buena Vista, Florida, 2009. 
[38] L. Zhu and e. al, "Experimental Analyses to Investigate the Feasibility and Effectiveness in Using Heat-Pipe Embedded Drills," International Journal of Advanced Manufacturing Technology, vol. 58, no. 9, pp. 861-868, 2012.

[39] T.-C. Jen and R. Jadhav, "Thermal Management of a Heat Pipe DrillA FEM Analyses," in ASME Heat Transfer Conference, Las Vegas, Nevada, 2003.

[40] T.-C. Jen, Q. Liao and Q. Chen, "Thermal Performance of Heat Pipe Drill: A New Simulation Model for Heat Pipe Drill," in $A S M E$ Summer Heat Transfer Conference, San Francisco, CA, 2005.

[41] Y. Cao and A. Faghri, "A Numerical Analysis of High-Temperature Heat Pipe Startup from the Frozen State," Journal of Heat Transfer, vol. 115, no. 1, pp. 247-254, 1993.

[42] J.-M. Tournier and M. S. El-Genk, "Start-up of a Horizontal Lithium -Molybedenum Heat Pipe from Frozen State," International Journal of Heat and Mass Transfer, vol. 46, no. 4, pp. 671-685, 2003.

[43] V. I. Tolubinski, E. N. Shevchuk and V. D. Stambrovsky, "Study of Liquid Metal Heat Pipes Characterisitcs at Start-up and Operation Under Gravitation," in American Institue of Aeronautics and Astronautics, Inc, Palo Alto, CA, 1978. 
[44] C. C. Silverstein, "Boiling Limit in Alkali Liquid Metal Heat Pipes," in American Society of Mechanical Engineers, Winter Annual Meeting, Washington, D.C., 1971.

[45] K. A. Woloshun and e. al, "Radial Heat FLux Limits in Potassium Heat Pipes: An Experiment and Analytical Investigation," in 7th Symposium on Space Nuclear Power Systems, Albuquerque, NM, 1989.

[46] G. D. Johnson, "Corrosion Studies of Liquid Metal Heat Pipe Systems at 1000 to 1800 Deg C," in New York, Plenum Press, Philadelphia, Pennsylvania, 1970.

[47] I. M. Kirko, Magnetohydrodynamics of Liquid Metals, Moscow: Energiya Press, 1964.

[48] V. C. A. Ferraro and C. Plumpton, An Introduction to Magneto-Fluid Mechanics, Belfast: Oxford University Press, 1961.

[49] A. Jeffrey, Magnetohydrodynamics, Edinburgh: Oliver and Boyd Ltd, 1966.

[50] R. J. Hosking and R. L. Dewar, "Magnetohydrodynamics (MHD)," in Fundamental FLuid Mechanics and Magnetohydrodynamics, Singapore, Springer, 2016, pp. 157-201.

[51] D. D. Schnack, "Introduction," in Lectures in Magnetohydrodynamics, Madison, WI, Springer, 2009, pp. 1-4. 
[52] L. D. Landua and E. M. Lifshitz, Electrodynamics of Continous Media, Oxford: Elsevier Butterwirth-Heinemann, 1984.

[53] G. Pulugundla and e. al, "Transition to a Quasi-Fully Developed MHD Flow in an Electrically Conducting Pipe Under a Transverse Non-Uniform Magnetic Field," Fusion Science and Technology, vol. 68, no. 3, pp. 684-689, 2015.

[54] J. C. Petrykowski and J. S. Walker, "Liquid Metal Flow in a Rectangular Duct with a Strong Non-Uniform Magnetic Field," Journal of Fluid Mechanics, vol. 139, pp. 309-324, 1984.

[55] A. Altintas and i. Ozkol, "Magnetohydrodynamic Flow of LiquidMetal in Circular Pipes for Externally Heated and Non-Heated Cases," Journal of Applied Fluid Mechanics, vol. 8, no. 3, pp. 507$514,2015$.

[56] A. Malekzadeh, A. Heydarinasab and M. Jahangiri, "Magnetic Field Effect on Laminar Heat Transfer in a Pipe for Thermal Entry Region," Journal of Mechanical Science and Technology, vol. 25, no. 4, pp. 877-884, 2011.

[57] Lithium Literature Review: Lithium's Properties and Interactions, March 1978.

[58] H. W. Davison, Writer, Compilation of Thermophysical Properties of Liquid Lithium. [Performance]. National Aeronautics and Space Administration (NASA), July 1968. 
[59] A. Ting, Writer, Combined Analytical and Numerical Solutions in Liquid Metal Flows in a Rectangular Duct With Uniform or NonUniform, Strong Magnetic Fields. [Performance]. University of Illinois, 1992.

[60] V. P. Carey, Liquid-Vapor Phase-Change Phenomena, Washington, D.C: Taylor \& Francis, 1992.

[61] F. M. White, Fluid Mechanics, New York City, NY: The McGrawHill Companies, 2009.

[62] B. R. Munson, Fundamentals of Fluid Mechanics, Hoboke, NJ: John Wiley \& Sons, 2009. 


\title{
APPENDIX A
}

\author{
Permissions for reference
}

\section{Permission for Figure 1.3, Figure 1.4, Figure 1.5, Figure 1.6,}

\section{Figure 1.7, Figure 2.3, Figure 2.4, Figure 3.10, Figure 5.1, Figure}

\section{2 and Figure 5.3}

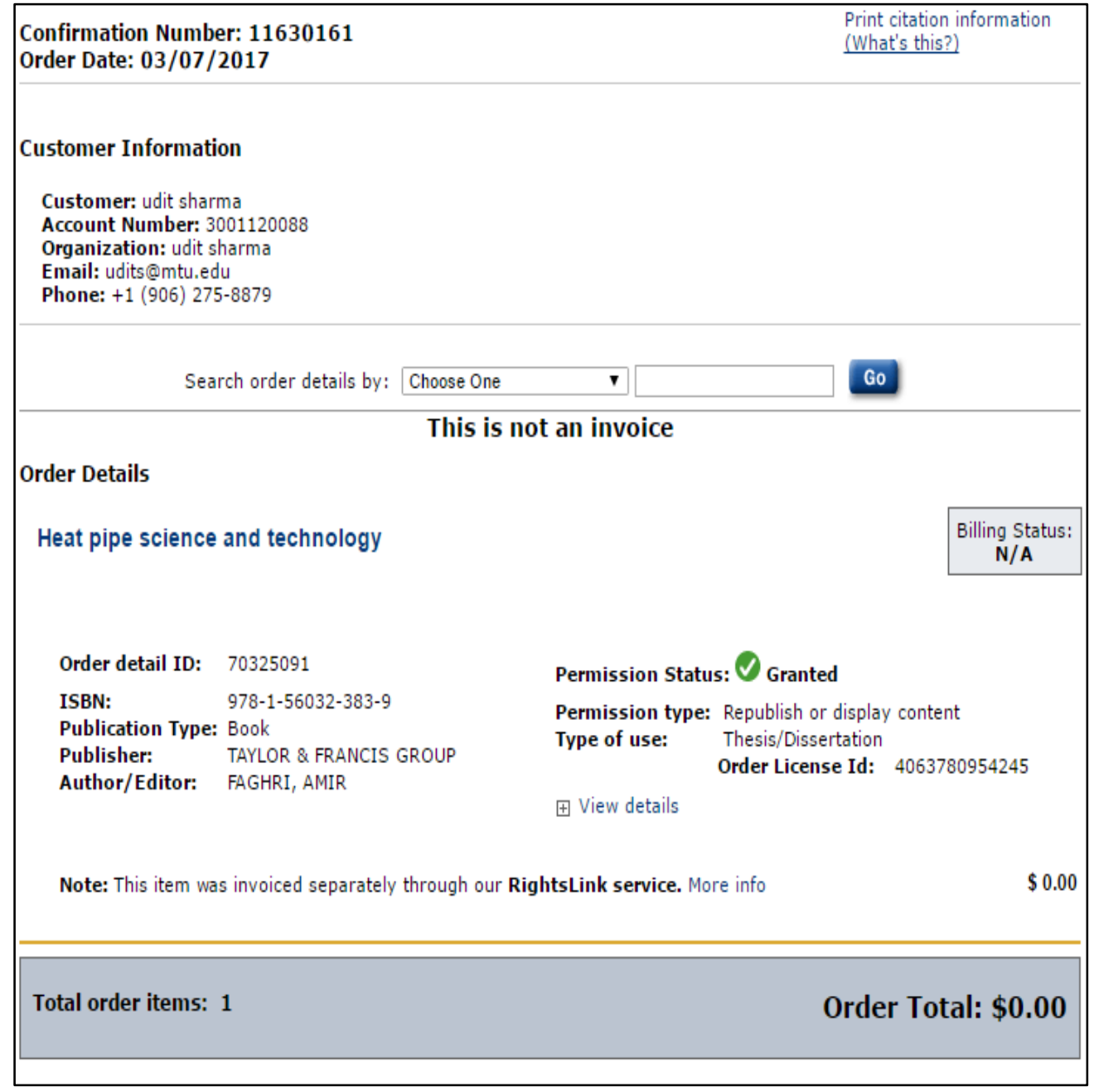




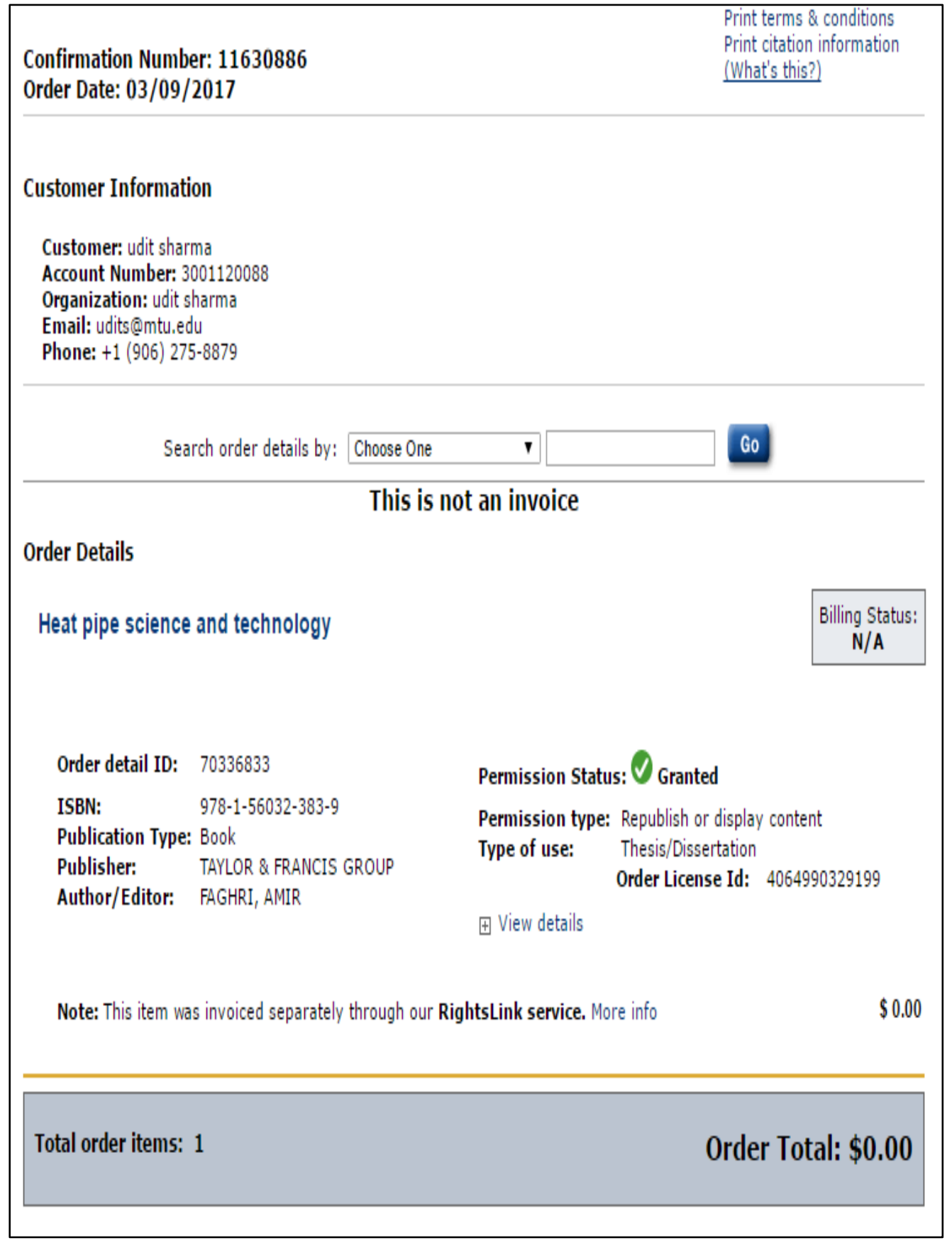




\section{Permission for Figure 1.1, Figure 1.2, Figure 3.3, Figure 3.4, Figure 3.5, Figure 3.6 and Figure 3.8}

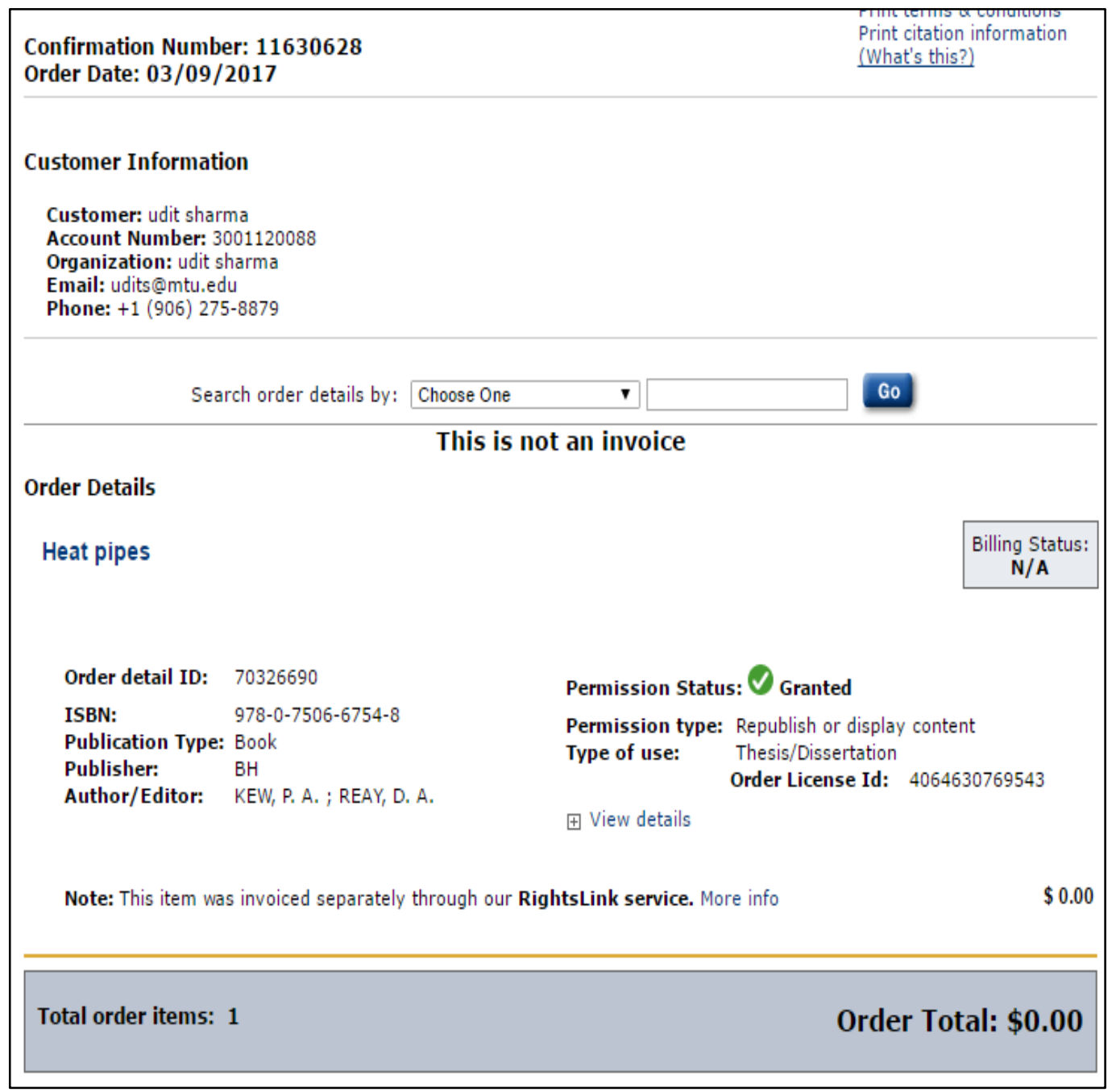




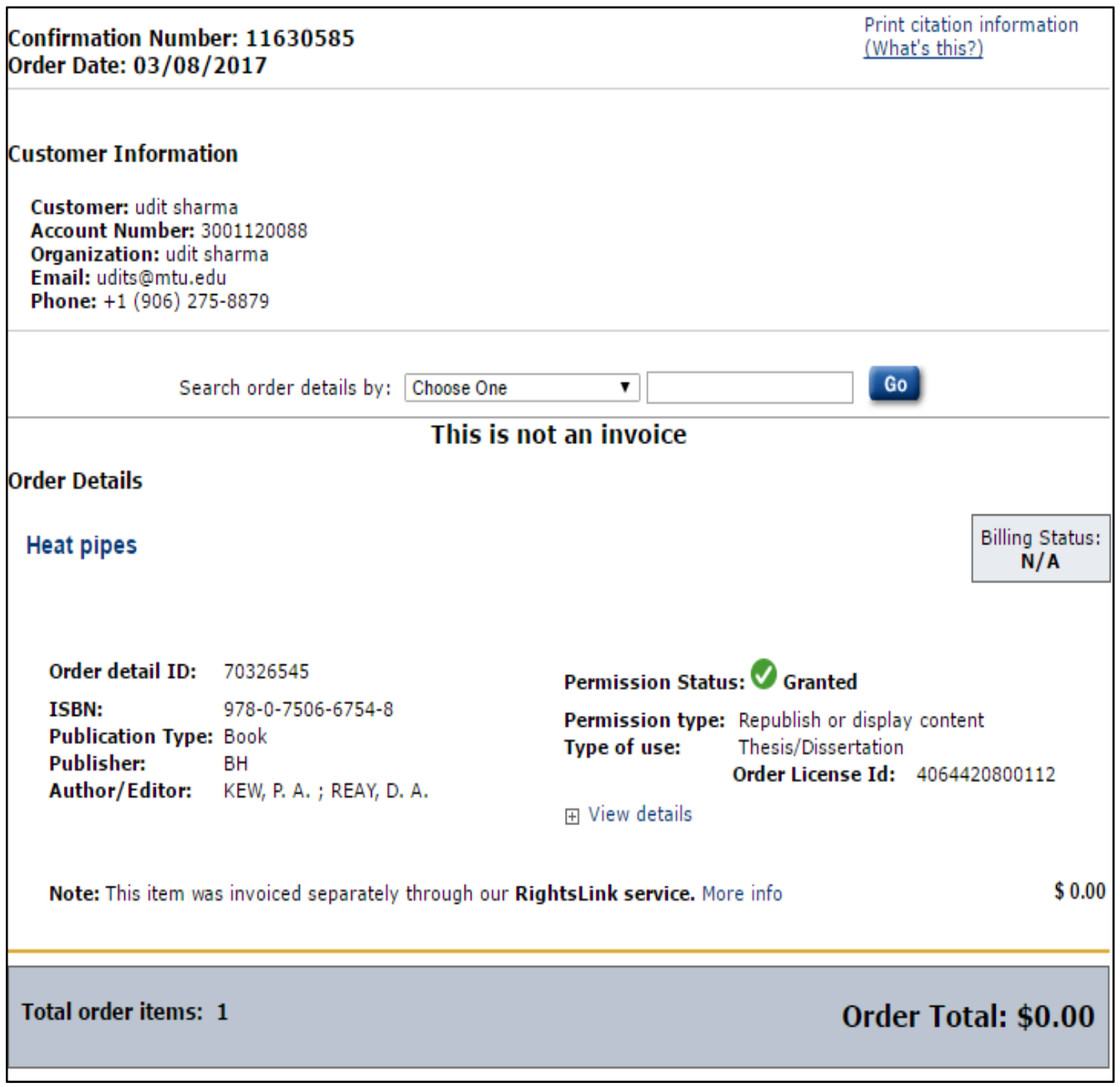




\section{Permission for Figure 3.1 and Figure 3.2}

\section{Wiley Global Permissions}

7:16 AM (6 hours ago)

to me $\sqrt{ }$

Dear Udit Sharma,

Please see your permission grant below for reuse of the figures requested in your thesis:

Permission is granted for you to use the material requested for your thesis/dissertation subject to the usual acknowledgements (author, title of material, title of book/journal, ourselves as publisher) and on the understanding that you will reapply for permission if you wish to distribute or publish your thesis/dissertation commercially. You must also duplicate the copyright notice that appears in the Wiley publication in your use of the Material; this can be found on the copyright page if the material is a book or within the article if it is a journal.

Permission is granted solely for use in conjunction with the thesis, and the material may not be posted online separately.

Any third party material is expressly excluded from this permission. If any of the material you wish to use appears within our work with credit to another source, authorisation from that source must be obtained.

Kind regards

Aimee Masheter

Permissions Coordinator

John Wiley \& Sons Ltd 


\section{Permission for Figure 2.2 and Figure 3.7}

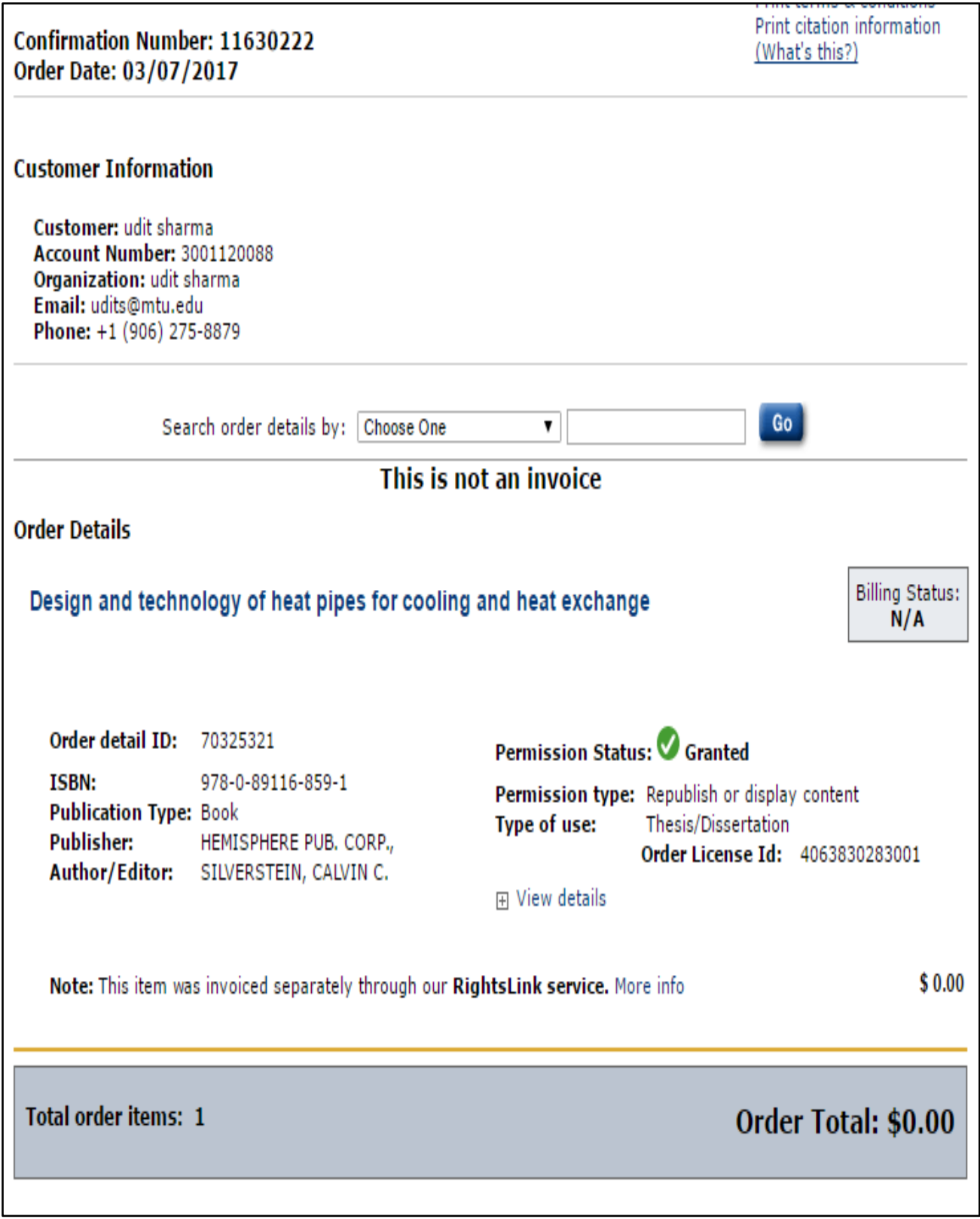




\section{Permission for Figure 4.1}

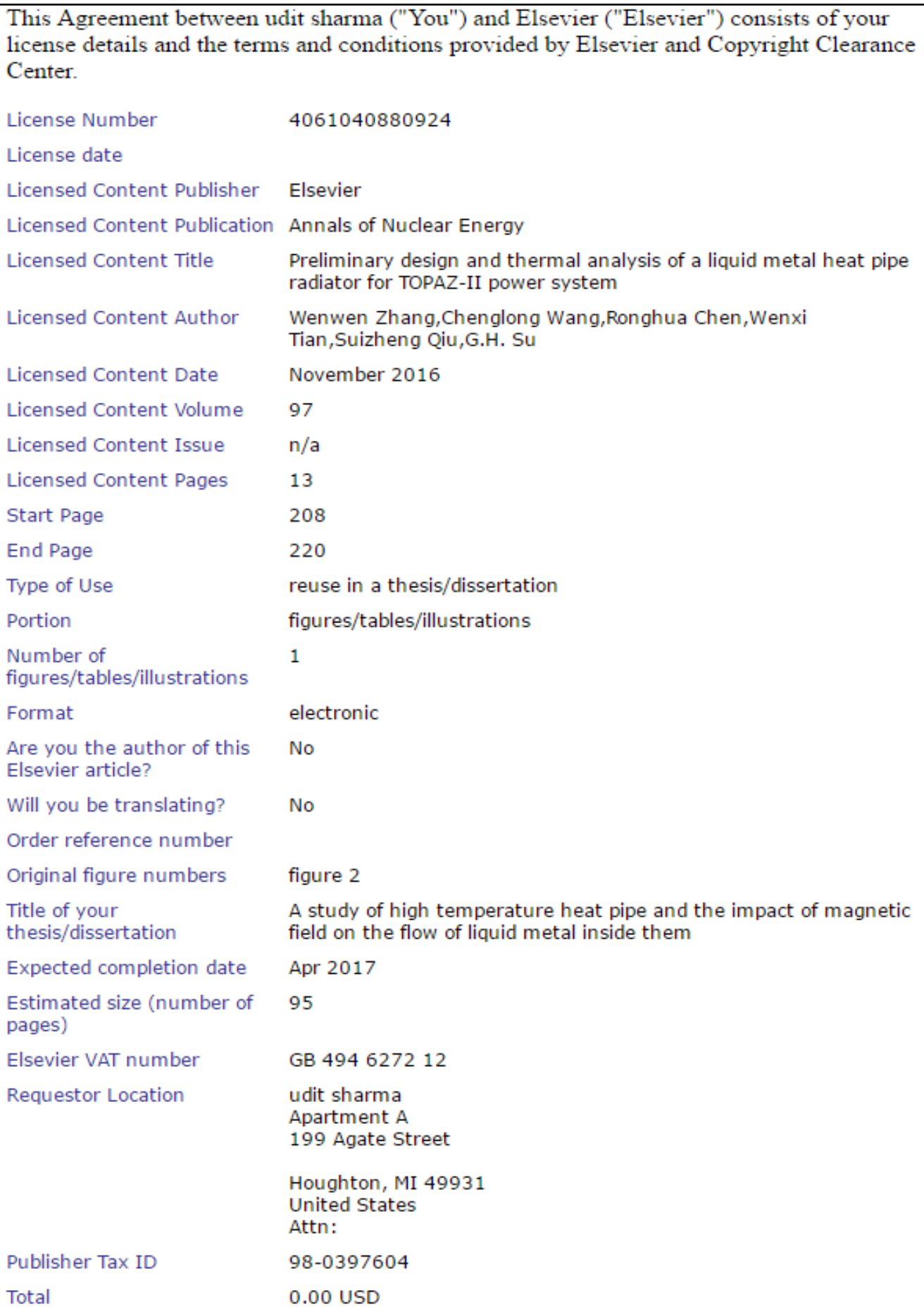

\section{Permission for Figure 4.2}




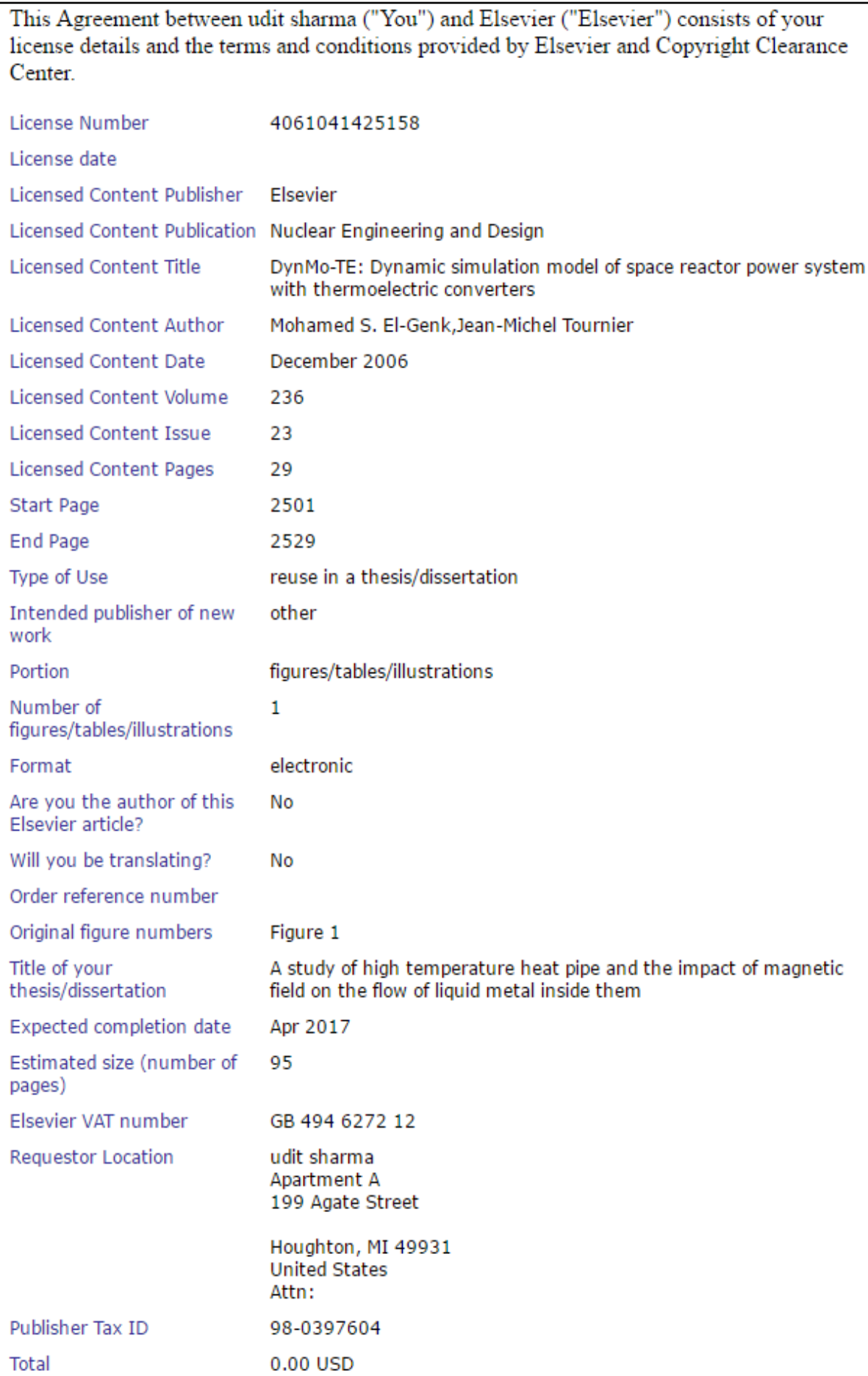

\section{Permission for Figure 4.5 and Figure 4.6}


$\therefore$ Foust, Susie

Mar 14 (5 days ago)

to me, mb-reports

Dear Udit Sharma,

Thank you for the report. We do not have this report in our collection, therefore, I suggest you contact Mr. Greenspan direct to receive permission. Mr. Greenspan's phone number and email address is below. Thank you, Susie Foust, OSTI, 865-576-8401

Ehud Greenspan

(510) 643-9983

gehud@nuc.berkeley.edu

From: Udit Sharma [mailto:udits@mtu.edu]

Sent: Tuesday, March 14, 2017 1:25 PM

To: Foust, Susie<FoustS@osti.gov>

Subject: Re: FW: Permission to use document data

Ehud GREENSPAN <gehud@berkeley.edu>

Mar 3

to Massimiliano, me $\nabla$

Udit -- you have my permission.

$\cdots$

Ehud

On Thu, Mar 2, 2017 at 9:04 PM, Udit Sharma <udits@mtu.edu> wrote:

Hello

I am a master's student in mechanical engineering department from Michigan Technological University. I am working over my thesis over liquid metal heat pipes, so I wanted to use 2 figures from the summary report published by the title ' Solid

Core Heat Pipe Nuclear Type Battery Reactor'.

I need to use 2 figures, Figure 1 and figure 2 to show the location of heat pipe inside the core of the reactor.

Kindly grant me the permission.

Thanks \& Regards

Udit Sharma

MS Michigan Technological University

Department of Mechanical Engineering

$+1(906) .275 .8879$ 


\section{Permission for Figure 4.7}

Beth Darchi <DarchiB@asme.org>
to me
Dear Mr, Sharma:
It is our pleasure to grant you permission to use the ASME Figure 6 from "Investigation of Heat Pipe Cooling in Drilling Applications: Part 2
-Thermal, Structural Static, and Dynamic Analyses," by Lin Zhu, Tien-Chien Jen, Chen-Long Yin, Yi-Hsin Yen, Mei Zhu and Jianhua Zhang,
Paper No. IMECE2009-10314, cited in your letter for inclusion in a thesis over liquid metal heat pipe to be published by Michigan
Technological University.
As is customary, we request that you ensure full acknowledgment of this material, the author(s), source and
ASME as original publisher. Acknowledgment must be retained on all pages printed and distributed.
Manny thanks for your interest in ASME publications.
Sincerely,
Beth Darchi
Publishing Administrator
ASME
2 Park Avenue
New York, NY 10016-5990
Tel 1.212.591.7700
darchib@asme.org




\section{Permission for Figure 4.10 and Figure 4.11}

Beth Darchi
to me -
Dear Mr. Sharma:
It is our pleasure to grant you permission to use the ASME Figure 1 from "Boiling Limit in alkali metal heat pipe," by C.C. Silverstein, ASME
winter annual meeting 1971, Paper Number 71-WA/HT-10, cited in your letter for inclusion in a Master's Thesis to be published by
Michigan Technological University.
As is customary, we request that you ensure full acknowledgment of this material, the author/s), source and
ASME as original publisher. Acknowledgment must be retained on all pages printed and distributed.
Many thanks for your interest in ASME publications.
Sincerely,
Beth Darchi
Publishing Administrator
ASME
2 Park Avenue
New York, NY 10016-5990
Tel 1.212.591.7700
darchib@asme.0rg

Note: Permission corresponding to references [14], [19] and [33] is not needed as these are under the license agreement of open source and the work can be reproduced without further permissions. The figures from these sources are Figure 4.3, Figure 4.4 and Figure 4.12 